\title{
Re-imagining Suburban Living in Residual Urban Space
}

\author{
Emma Cunningham
}





\title{
Re-imagining Suburban Living in Residual Urban Space
}

\author{
By Emma Cunningham
}

\author{
A research portfolio submitted in fulfilment of the requirements for the degree of \\ Master of Architecture \\ (Professional) \\ at \\ Victoria University of Wellington \\ School of Architecture
}





\section{Acknowledgements}

To my supervisor Morten Gjerde, thank you for your valued knowledge, guidance and support throughout the year.

To my family, thank you for your endless love, support and encouragement that has enabled me to see this through and achieve my dream.

To my friends, I am so thankful for your constant support, help and advice throughout this journey.

Thank you for all the great times both inside and outside of the studio and for making the university experience so rewarding. I have so many great memories that I will treasure forever. 


\section{Abstract}

The attraction of the suburban lifestyle for many, is the comforting uniformity and lack of density, the desire to own your own little patch of land to use however you please. However, the lack of diversity this lifestyle offers is also a key reason as to why certain demographics are choosing to relocate back to urban centres. A significant number of young adults are rethinking where they want to live, work and play, and they are choosing the city. They are revitalising entire neighbourhoods, making urban living fun and safe for all ages. In choosing the city, they have begun to dream something different to the lifestyle defined as the traditional "Suburban Dream" (Breen \& Rigby, 2004).

As the population continues to increase, available land for development decreases, resulting in suburban sprawl. The consequences of this pattern of suburban sprawl include social issues such as a lack of human contact and a declining sense of community. As people are having to spend longer travelling to and from work in the city, they therefore tend to stay in their homes once they return at the end of a long day. Other key consequences include increased traffic congestion and the resultant environmental problems such as increased petrol consumption, reduced air quality and farmland destruction (Breen \& Rigby, 2004). In contrast, the urban neighbourhood has a sense of community about it, many features are within walking distance and the footpaths and walkways promote a friendly, social environment, which may be lacking or hard to access in the sprawling suburbs.
This research portfolio aims to develop and present an alternative approach to living in inner city New Zealand. A new strategy that will bridge the gap between the typology of the spacious suburban home and over developed, inner city apartment blocks by adapting unused or underutilised sites already existing within the urban fabric. Often people are reluctant to downsize from the commodious suburban homes that they have grown accustomed to. Therefore, this proposed housing must take the fundamentals of suburban housing and condense it into a compact model suitable for the urban environment while also meeting the needs and expectations of the intended occupants.

The objective is to create compact homes that will beautify and give new purpose to unused spaces in the urban environment. As a way of reducing urban sprawl by adapting vacant spaces which already exist within the urban fabric. Learning from, and developing upon successful infill strategies already employed throughout the world dealing with the issue of underutilised urban space. These homes should not detract, but rather add to the appearance of the present streetscape for current residents. Repurposing vacant sites and spaces into condensed, compact, comfortable housing solutions to encourage those looking to relocate from suburban to urban therefore reducing the suburban sprawl. 


\section{Contents}

Acknowledgements $\quad$ V

Abstract VII

01 I N T R O D U C T I O N 8

$\begin{array}{ll}\text { The Problem } & 10\end{array}$

$\begin{array}{ll}\text { The Approach } & 10\end{array}$

Introduction $\quad 11$

$\begin{array}{ll}\text { The Client } & 13\end{array}$

Aims and Objectives $\quad 14$

$\begin{array}{ll}\text { Methodology } & 16\end{array}$

02 LiteratuRE REVIEW \& CASE STUDIES 18

$\begin{array}{lr}\text { Literature Review } & \mathbf{2 0}\end{array}$

The Suburban Dream $\quad 22$

Suburban Qualities $\quad 23$

Residual Space $\quad 26$

$\begin{array}{ll}\text { Inner City Living for Families } & 28\end{array}$

Design Guidelines $\quad 29$

Case Studies

Polygreen $\quad 33$

A's House Project 34

Small House $\quad 35$

The Cul-De-Sac House $\quad 36$ 
03 S ITES 38

$\begin{array}{ll}\text { Site Identification } & 40\end{array}$

Residual Urban Space Definition $\quad 41$

Site Requirements $\quad 42$

Site Typologies $\quad 45$

$\begin{array}{ll}\text { Site Locality Map } & 48\end{array}$

Catalyst Site $01 \quad 49$

$\begin{array}{ll}\text { Catalyst Site } 02 & 51\end{array}$

Catalyst Site 03

Catalyst Site $04 \quad 55$

$\begin{array}{ll}\text { Catalyst Site } 05 & 57\end{array}$

$\begin{array}{ll}\text { Catalyst Site } 06 & 59\end{array}$

Justification of Site $\quad 62$

04 I N I T I A L D E S I G N S

$\begin{array}{ll}\text { Form Studies } & 66\end{array}$

$\begin{array}{lr}\text { Most Successful Outcomes } & 69\end{array}$

05 D EVELOPED DESIGNS

Key Areas of Focus $\quad 73$

$\begin{array}{ll}\text { Spatial Planning } & 76\end{array}$

Flexible Living $\quad 82$

$\begin{array}{ll}\text { Lighting and Privacy } & 88\end{array}$

$\begin{array}{ll}\text { Outdoor Connection } & 94\end{array}$

$\begin{array}{ll}\text { Methods for Accommodating a Car } & 98\end{array}$ 
06 FINAL DESIG N S 104

$\begin{array}{ll}\text { Catalyst Site } 01 & 105\end{array}$

$\begin{array}{ll}\text { Catalyst Site } 02 & 109\end{array}$

$\begin{array}{ll}\text { Catalyst Site } 03 & 113\end{array}$

$\begin{array}{ll}\text { Catalyst Site } 04 & 117\end{array}$

$\begin{array}{ll}\text { Catalyst Site } 05 & 121\end{array}$

$\begin{array}{ll}\text { Catalyst Site } 06 & 125\end{array}$

$\begin{array}{ll}\text { Design Summary } & 130\end{array}$

07 S TRATEGIES 132

Strategies for Spatial Planning 134

Strategies for Flexible Living 136

$\begin{array}{ll}\text { Strategies for Lighting and Privacy } & 138\end{array}$

$\begin{array}{ll}\text { Strategies for Outdoor Connection } & 140\end{array}$

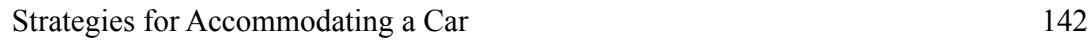

08 C O N C L U S I O N S 144

$\begin{array}{ll}\text { Conclusion } & 146\end{array}$

$\begin{array}{ll}\text { Research Limitations } & 147\end{array}$

$\begin{array}{ll}\text { Future Opportunities } & 148\end{array}$

09 B I B L I O GRAPHY \& L IS T O F F I G U R S

$\begin{array}{ll}\text { Bibliography } & 151\end{array}$

List of Figures $\quad 155$ 



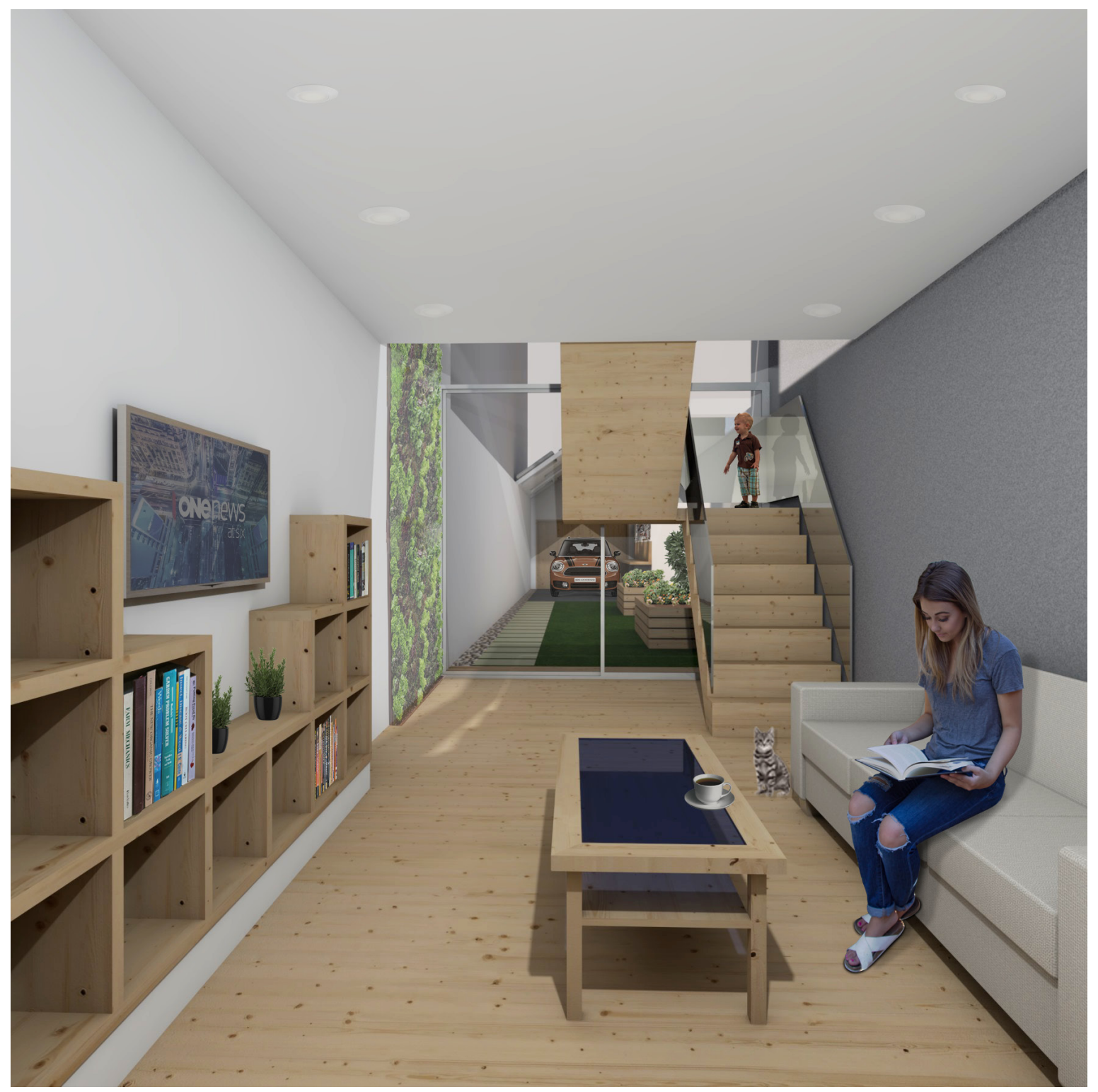


How can residual urban space support a new housing typology based on the key qualities and amenities of Suburban living? 
01

INTRODUCTION 



\section{The Problem}

Over the years, people have been buying and building increasingly larger homes throughout the world.

We need to ask ourselves, how much space do we actually need as we enter into a more resource limited future.

As the population continues to increase, available land for development decreases, resulting in Suburban sprawl.

The consequences of this pattern of suburban sprawl include: Social issues, traffic congestion, environmental problems.

\section{The Approach}

This research portfolio aims to develop and present an alternative approach to living in inner city New Zealand.

To investigate ways in which the Suburban lifestyle can be reimagined as compact urban housing; utilising gaps or residual space which already exists within the urban fabric as a way of reducing both urban and suburban sprawl.

Developing a new strategy that will bridge the gap between the typology of the spacious suburban home and over developed, inner city apartment blocks. 


\section{Introduction}

The suburban dream is an outdated concept that, in New Zealand, dates back to the 1950 s, when the government begun to promote the 'ideal' housing model of a detached, single family dwelling on a quarter acre section. These days, the suburban dream remains the aspiration of many New Zealanders. However, it is no longer a viable or practical lifestyle for many people. Growing populations are causing large-scale suburban sprawl, with housing becoming increasingly further away from urban centres. The result of this, is that people are forced to live further away from their place of work and must face the consequence of a longer commute and the resulting social and environmental issues this entails, as the suburban home aspires to be outside of the city while still relying entirely upon it. 
The suburban ideal doesn't necessarily need to be confined to the suburbs. New, adaptable and innovative homes with outdoor space to live, play, garden, entertain or relax may be created in the inner city. This notion that we must choose between amenity and outdoor space, between small city apartments poorly designed for families and huge houses far-removed from central cities needs to be challenged (Harrison, 2013).

Living in the inner city is a relatively new phenomenon in most New Zealand cities (Witten \& Carroll, 2011). "The traditional and still ubiquitous form of residential development is low-density suburbanisation; dormitory residential zones accessed by motorways and arterial roads that radiate out from the central business district" (Witten \& Carroll, 2011, p.79). By living and working in the central business district, two of suburbia's least liveable attributes - traffic congestion and poor public transport networks - can be avoided (Witten \& Carroll, 2011). The growth of inner city living is likely to continue as an increasing amount of people are choosing to relocate to urban centres to be closer to their places of work. This means cities will be faced with increasing pressure, which will likely result in urban sprawl and increased development of residential tower blocks, a typology that is often linked to over development, with perceived negative consequences such as reduced sunlight (Broadbent, 2011). This means now it is more important than ever to consider alternative ways of accommodating and designing for urban living, to create housing that is designed to be functional for family living while also limiting the effects of urban and suburban sprawl.
In order to create new housing in the urban environment without increasing urban sprawl, gaps that already exist within the urban environment should be developed. Within every city, there are pockets of unused space. These pockets of space offer unique opportunities to create innovative housing. These unusual spaces stimulate the imagination, since the tried and true model of housing will not fit, an entirely new method will have to be developed. The restrictions of these types of site can be turned into opportunities through good design, drawing attention to the potential for leftover space to be utilised for housing options in growing cities.

This research portfolio is intended to suggest a new way to inhabit urban gaps and offer a method for rethinking the suburban home in an urban context. Providing homes that relate to and interact with the site and surrounding factors, providing distinctive architecture with an identity unique to the conditions of the site. Encouraging people to reconsider the amount of space they actually need and the type of environment they want to be surrounded by, altering their lifestyle and downsizing to compact suburban housing within the gaps of the urban fabric. The anticipated outcome of the research is to produce a set of strategies that will provide a guide for future residential development on urban residual sites. 


\section{The Client}

The chosen client for this research portfolio is the demographic that could be described as the epitome of the quintessential suburban family. Typically, this family would consist of two adults, two or three children and possibly a pet cat or dog. This client was selected because the suburbs are the archetype for family living; with many people believing city life is impractical and unsafe for families. This is in large part due to the fact that there is, in general, a lack of planning for children in the design of inner city housing. The current, predominately apartment style of inner city housing, is primarily aimed at young adults, couples without children and empty nesters. In designing homes that are better suited to families, drawing upon the qualities that make suburban homes the current ideal, it is hoped that more families will be drawn to the convenience and opportunity inner city living has to offer.

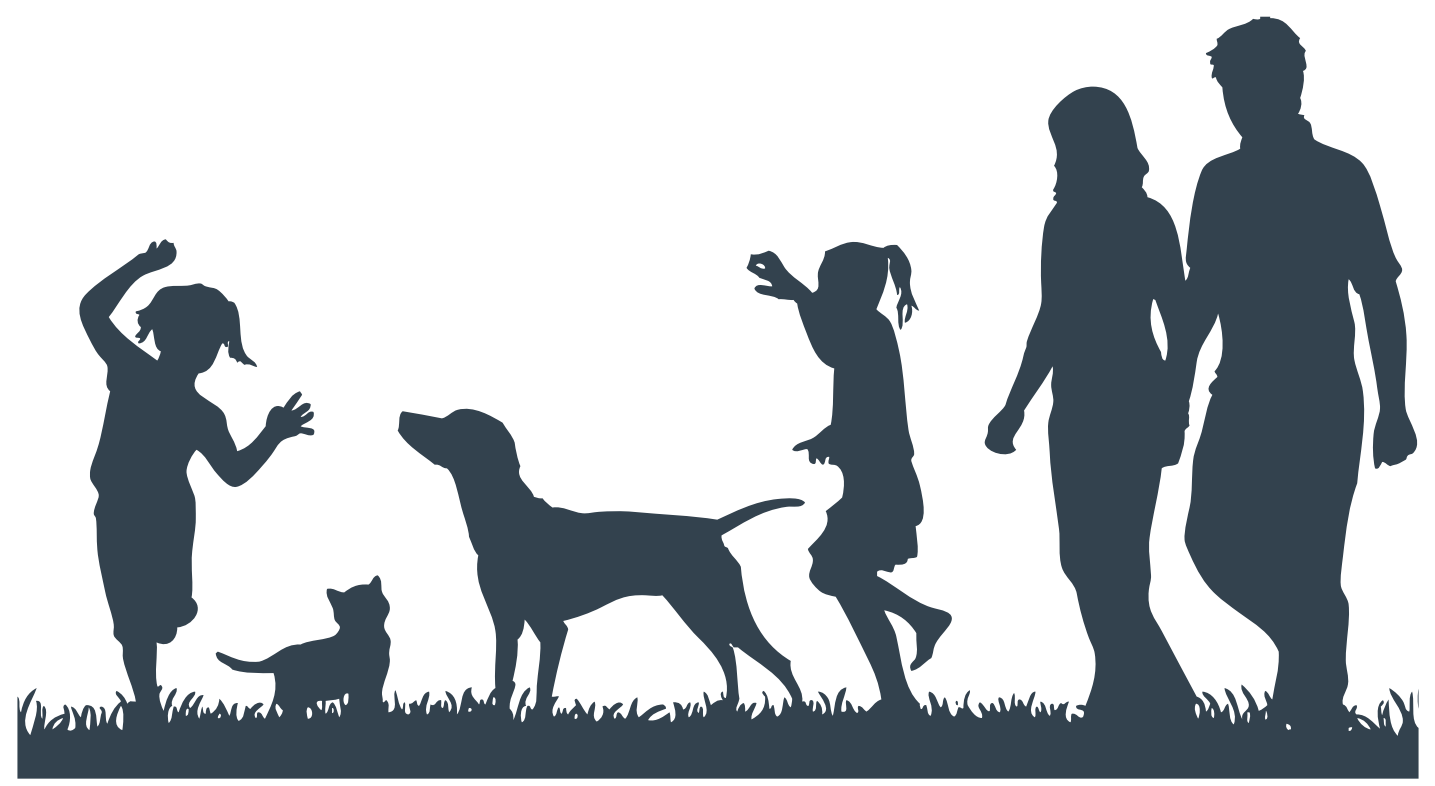




\section{Aims and Objectives}

\section{Aims:}

- To investigate ways in which the suburban lifestyle can be reimagined as compact urban housing; utilising gaps or residual space which already exists within the urban fabric as a way of reducing urban and suburban sprawl.

- To investigate what people want and need from their homes; as well as the key elements of suburban living which make it such an appealing choice, in order to produce a set of design guidelines for urban living based on the key qualities of suburban living.

- To investigate ways in which this housing solution can be achieved without deterring any pre-existing formal or informal public use of the site.

\section{Objectives:}

- The proposed outcome should offer a reasonable, compact alternative to suburban living located within the urban environment.

- The intervention should provide the occupant with a private, safe and comfortable environment while not altogether appropriating the original, formal or informal, usage of the site.

- The intervention should build upon successful infill strategies employed round the world dealing with underutilised urban space. 



\section{Methodology}

This research portfolio follows a design led approach to the research. The design led research methodology allows for an interactive and critical approach to the process. The following list breaks down the process into the key tasks:

- Overview research into relevant and successful past practice, theory and responses to compact housing, reducing suburban sprawl and the key qualities of suburban homes

- Selection of suitable gaps or unutilised sites which meet the predefined site conditions

- Critical site analysis, analysing both analytical and experiential qualities to understand and interpret the sites and related issues

- Literature reviews of key theorists who address the areas of significance set out in the research objectives
- Investigation and research into essential programme based on the needs and requirements of the intended occupant

- A series of design iterations, testing interventions and experimenting within the context of the site analysis and user requirements

- Reflection upon the effectiveness of the iterations and analysis of which aspects may be applied in further design investigation. What does it mean for the discipline?

- Extensive on-going literature review

- Further testing, development and refinement of interventions within the context of site, user requirements and literature to develop a set of strategies for designing homes in residual urban space based on the key qualities of suburban living 

LITERATURE REVIEW 


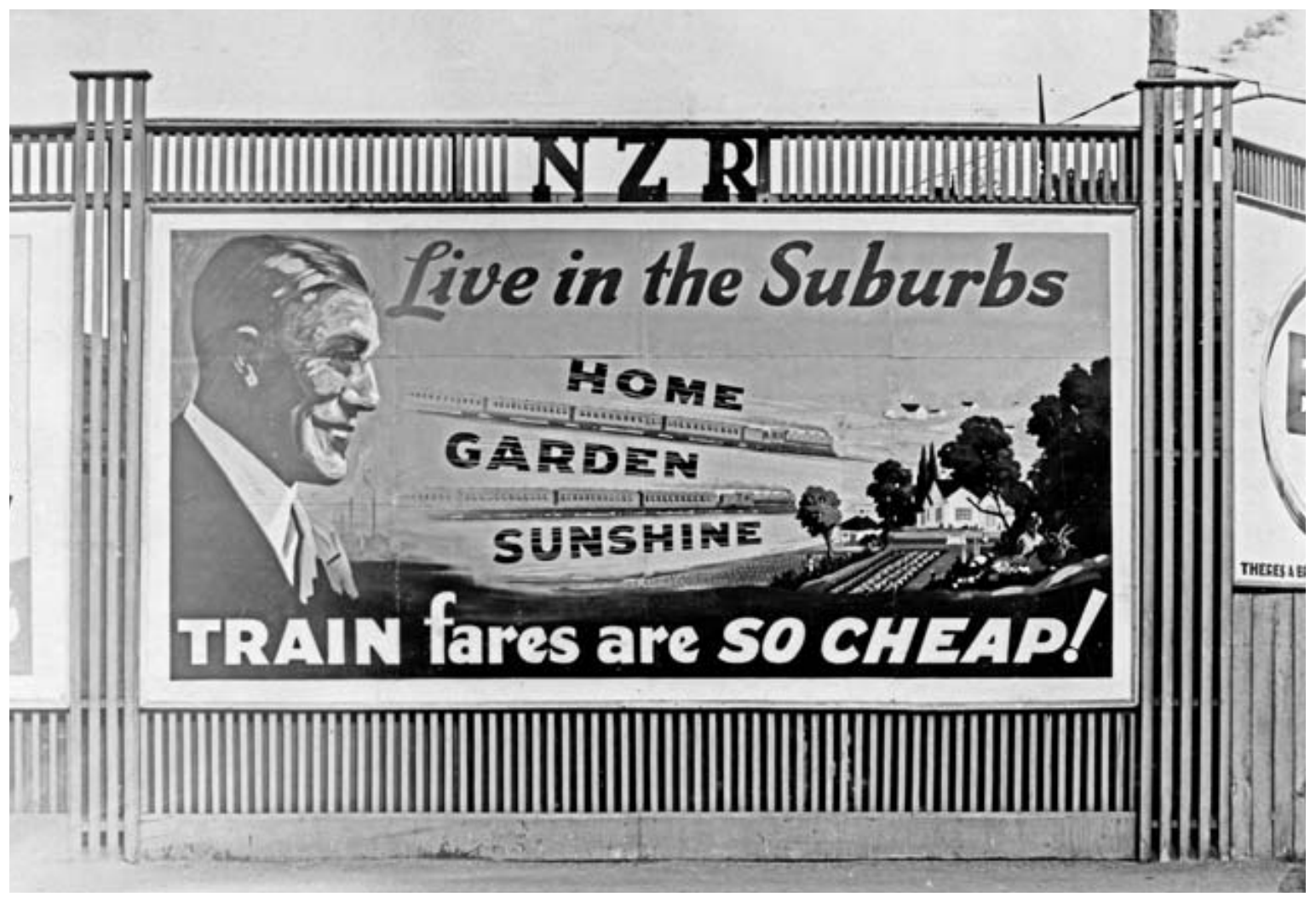




\section{The Suburban Dream}

The suburban dream, also commonly referred to as the quarter acre dream or the New Zealand dream, was the archetype of the detached, single-family dwelling surrounded by private gardens, which contribute to a leafy and attractive neighbourhood setting. This dream ideal was supported by government policies primarily through much of the twentieth century. Government regulated both the form of housing and the form of towns and cities in a way that helped make the suburban home the norm. Government promotion of the suburban home reached a peak in the early 1960s when the State Advances Corporation provided finance for more than half of the houses being built in New Zealand (Ferguson, 1994). The National government emphasised home ownership as the foremost aspiration of all New Zealanders and, "between 1950 and 1970 the symbol of the family home in the suburbs became thoroughly entrenched in the minds of New Zealanders as people took advantage of the state's generous leading programme" (Ferguson, 1994, p.177).

In Building the New Zealand Dream, Ferguson (1994) writes, "The New Zealand dream was always a complex and somewhat vague concept, best understood as a series of strongly held emotions, beliefs and aspirations. The detached family home was the physical symbol of material reward and contentment in return for one's labours" (p.187). According to Ferguson, the reason that the suburban vision triumphed was because those with influence over the distribution of state resources chose to invest them in suburban housing.
These days, the quarter acre section is also associated with a long commute. Due to urban and suburban sprawl, the classic quarter acre section is difficult to obtain and usually located a lot further from the central city than what they were in the past. The Chief Executive of the Real Estate Institute, Helen O'Sullivan says, “Increasingly there are different dreams, peoples versions of home ownership are becoming quite different" (as referenced in Pryor, 2015). In the same report O'Sullivan also forecasts that, "There will be different housing types for different demand and different choices over the next ten to fifteen years." For the majority of New Zealanders, the suburban dream still remains the aspiration, however this is not a viable reality. In the Auckland region alone, the reality is that there are nearly half a million occupied dwellings. If they all covered the ideal land area of one thousand square metres each, they would cover New Zealand's area twice over (Pryor, 2015). Housing ideals and reality have changed significantly since the notion of the suburban dream originated, and people are increasingly prioritising location over the traditional suburban or quarter acre dream. The suburban dream is out dated and the ideal housing aspirations are likely to soon shift as well, meaning housing which is more suited for families is desperately required within urban centres. 


\section{Suburban Qualities}

The market research organisation Ipsos MORI (2012) produced a qualitative research report for the Royal Institute of British Architects, which looked into the needs and expectations people had for their homes. The key findings from the report as to what people need and expect from their homes are as follows:

- Lots of natural light, large windows of some sort that do not detract from privacy and will enhance the sense of wellbeing.

- Spacious feeling main living area for eating, socialising and entertaining.

- Private spaces for relaxation away from social spaces.

- Private space outside, or access to green public space.

- Sufficient long-term and short-term storage for functional items and personal possessions.

- Flexible and adaptable space for socialising, meals, relaxing and working (Ipsos MORI, 2012).

In a survey by building supply company Mitre 10 (2015) it was found, "84 percent of respondents agreed that they liked the idea of the traditional Kiwi quarter-acre paradise - a large plot of land with a standalone house on it, with plenty of room outdoors, and almost all said they would rather live on the traditional quarter-acre section than in high density housing with reduced outdoor living spaces." New Zealanders take pride in their homes; they like to have their own patch of land and private standalone house through which they can express a sense of identity. There is also strong research to suggest that for homeowners DIY is thriving in New Zealand culture, due to the satisfaction associated with creating your own home. Dupuis (2015) states, "There's a strong sense of creativity and joy in DIY; we're living in a DIY culture, we're surrounded by it all the time, as evidenced by the non-stop DIY programmes on TV and the proliferation of home and garden magazines" (as referenced in Mitre 10, 2015). All aspects archetypally associated with the qualities of living that the suburban lifestyle offers.

The key quality of suburbia that draws people away from inner city living is private outdoor space. Based on a study of families living in inner city dwellings, Witten and Carroll (2011) found, "The desire to have a backyard, the family ideal, was the major reason most participants gave for an eventual move from their apartment" (p.85). Traditionally, the suburban section typically consisted of a semi public front garden and a private backyard. The front garden was generally decorative and well maintained as it was considered to be on public display. While the backyard, in comparison, was considered to be far less inhibited. The key components of the backyard typically included a service area for the clothesline, a play area for children, the garage, workshop, toolshed and woodshed. As well as vegetable beds, flower beds and space for poultry and pets (Jamieson, 2015). New Zealanders in particular favourably value private outdoor space. Outdoor living is ingrained in the culture, and therefore it is the major drawing point for suburban living over inner city living. 
The notion of community was another key reason why people were drawn to the qualities of the suburban lifestyle. The Ipsos MORI (2012) report found a strong sense of community was important to participants across the research, "most felt strongly that they preferred to live somewhere with a safe, community feel" (p.5). Across the literature the common assumption people made was that the suburbs offer a stronger community atmosphere. However throughout the literature this belief is often proven mistaken. Consequences due to suburban sprawl include social issues such as a lack of human contact and a declining sense of community (Breen \& Rigby, 2004). As people have to spend longer travelling to and from work in the city, they therefore tend to stay in their homes once they return at the end of a long day rather than socialising with neighbours as they might have done in the past. 

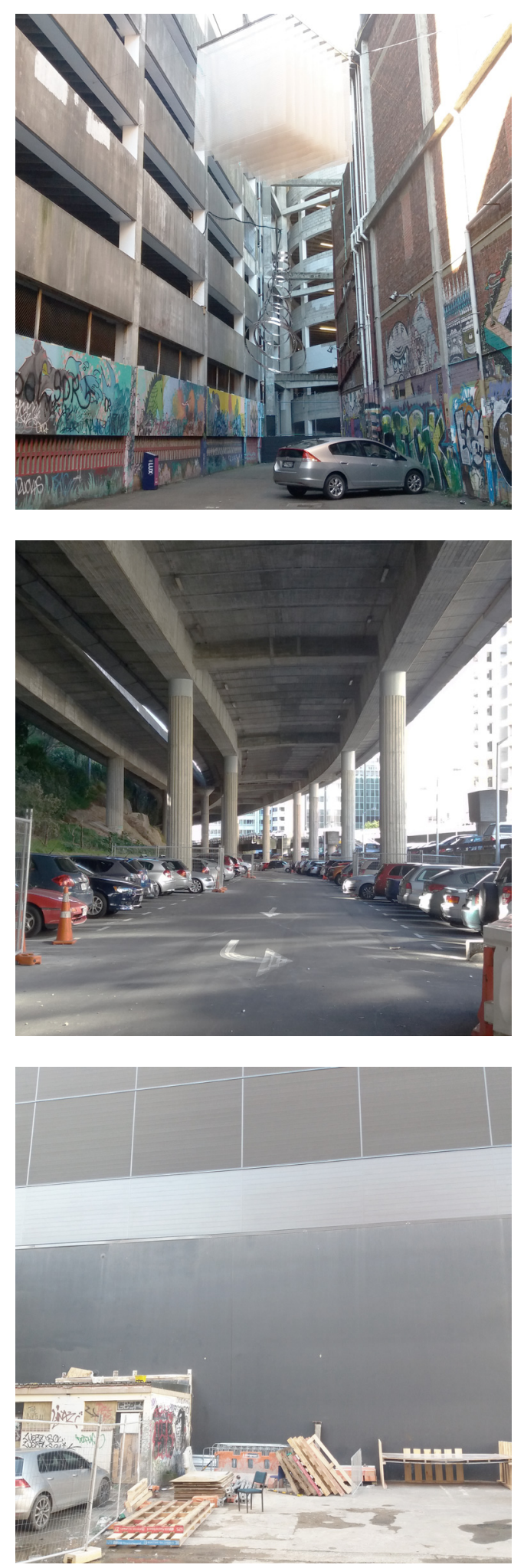


\section{Residual Space}

Residual space, loose space, gaps, voids, vacant space or leftover space; across the literature this notion of space is given many different terms. However, all of these different labels refer to sites with similar qualities. Franck and Stevens define loose space and the many possible informal uses of a vacant site. Loose space is defined in the writing as, "Abandoned and leftover spaces, temporarily free of official planning and commodification and, are appropriated for other uses" (Franck \& Stevens, 2007, p.8). They explore the ways that urban residents appropriate loose space to meet their varying individual needs and desires such as for the purposes of expression, leisure, sociality, trade or political activities. Jonas and Rahmann (2014) have a comparable definition of the void as, "Constituted by different types of vacant spaces and processes of development ranging from small and disjointed leftover spaces, gaps between buildings, to spatial by-products of elevated expressways and train lines" (p.13). Across the literature, the form and location of these spaces is described as unsuitable for conventional development. Hence leaving these places outside of any consideration for formal uses. This therefore opens up these spaces for new, innovative, creative approaches to inspire their activation.

Gilloch writes, "The city is delirious; such defamiliarisation of space promotes loose and playful responses, a rediscovery of spaces' potential. (as referenced in Franck \& Stevens, 2007, p.10)" Franck and Stevens (2007) go on to state, "Whether the physical and representational qualities of a space are a support or a hindrance depends so much on what people want to do" (p.10). This demonstrates that although the qualities of a particular site may not be typically suited to a specific purpose upon first glance, this simply opens the space up to more creative interpretations. Therefore enabling and inspiring a much more imaginative response. Jonas and Rahmann (2014) apply a similar theory to their investigation into Tokyo's voids, discovering the detail, the small and overlooked, the quiet and surprising; looking at Tokyo from the inside, through possibilities in absence presented by urban voids.

Jonas and Rahmann (2014) make reference to the many ways people, planners, designers and local governments around the world have started to embrace voids as valid opportunities for urban regeneration. Discussing residual space in Tokyo they write, "While the average plot size of private dwellings in Tokyo is approximately 150 square metres for a single dwelling, even plots as tiny as thirty square metres are recognised as suitable for dwellings" (p.21). The excitement and creativity these residual spaces inspire, particularly in cities such as Tokyo, highlights the opportunities these spaces may offer in other cities where this approach has yet to be employed.

Residual space supports opportunity and creativity, which is merely starting to be recognised and explored. However, this will likely gain more attention in the coming years as the amount of available land for development in cities inevitably becomes increasingly depleted. 


\section{Inner City Living for Families}

In recent years, an increasing number of families with children have been moving into central cities. "The number of children living in the Auckland CBD increased by 12 percent per annum between the 2001 and 2006 censuses, despite the quality and design of dwellings and neighbourhoods being largely unsuited to the needs of families with children" (Witten \& Carroll, 2011, p.79). Breen and Rigby (2004) discuss the benefits of urban living in contrast to suburban living. Arguing cities can and should be resettled with a substantial number of people from the suburbs, maintaining that it is an essential action to prevent further sprawl. A significant number of young adults are rethinking where they want to live, work and play, and they are choosing the city. In choosing the city, they have begun to dream something different to the lifestyle defined as the traditional 'Suburban Dream' (Breen \& Rigby, 2004). Living in the central city enabled families' easy access to work, schools, study and a range of highly valued public amenities such as city libraries, city parks and a wealth of recreational opportunities available for young people (Witten \& Carroll, 2011). Time and travel costs were also a significant factor in the decision to move to the city for many families. Less time spent commuting meant more time to spend with the family and for other pursuits (Witten \& Carroll, 2011).

In a pilot study, investigating the experiences of families living in inner city dwellings conducted by Witten and Carroll (2011), parents' fears for their children's safety was a main concern. This meant that children were frequently confined inside their apartments unless accompanied outside by a parent. Consequently, home time for children was primarily spent indoors. This was in large part due to limited access to safe outdoor space. Gifford (2007) states, "Children's play is clearly affected, as parents in high rises either keep their children indoors more often, which means close protection or over-protection in an indoor environment, or allow them outside, many floors away, which can result in under-supervision" (p.12). Witten and Carroll found as children were often confined indoors this highlighted other design and amenity issues less than ideal for family living. Some of the identified issues included, a lack of space for children's play, storage and family meal preparation, as well as a lack of natural light and limited privacy, particularly from neighbouring buildings.

Current inner city housing has not been built with children in mind, and is therefore presently far from ideal for comfortable, functional family living. Fincher (2004) states, "Developers' narratives oppose the suburban 'home' to the high rise 'lifestyle', consider central city high rise residences as appropriate only for people without families" (p.325). Families face specific difficulties when integrating family life into the architecture of the city environment. The architecture of the city needs to be adapted to ensure balanced cities, which can better accommodate resident families by catering to their specific requirements. This would result in more family inclusive cities, allowing more children and families to further enjoy the benefits that inner city living has to offer. Therefore helping to make urban living a more desirable option for families, rather than the current second best behind the traditional, quarter acre, suburban lifestyle. 


\section{Design Guidelines}

Based on the literature around residential amenity, suburban qualities and what people want and need from their homes, in particular, a qualitative research report for the Royal Institute of British Architects, which looked into the needs and expectations people have for their homes. The following list of design guidelines has been developed.

The key findings from the report were as follows:

- Lots of natural light, large windows of some sort that do not detract from privacy and will enhance the sense of wellbeing.

- Spacious feeling main living area for eating, socialising and entertaining.

- Private spaces for relaxation away from social spaces.

- Private space outside, or access to green public space.

- Sufficient long-term and short-term storage for functional items and personal possessions.

- Flexible and adaptable space for socialising, meals, relaxing and working (Ipsos MORI, 2012).

These key findings provided the basis for the design guidelines, as well as the findings from the case studies and a reflection on what New Zealanders in particular value the most from their homes. 


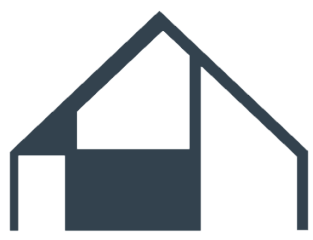

Distinct personality

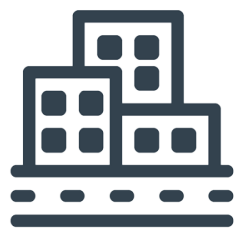

Engagement with the street

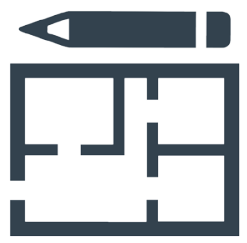

Flexible layout

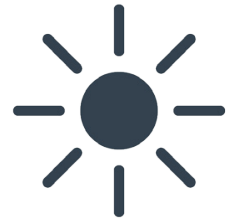

Daylight and sun - am to pm

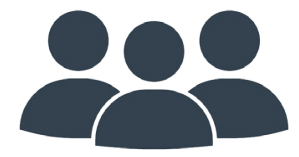

Space for socialising

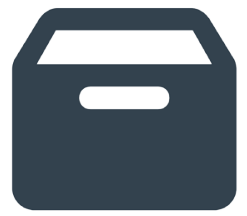

Adequate storage

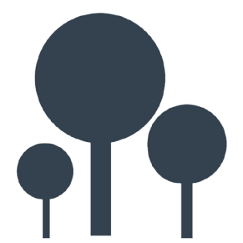

Outdoor connection - privacy included

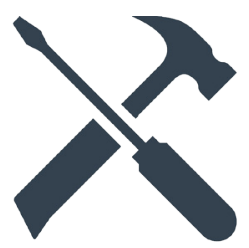

Space for DIY

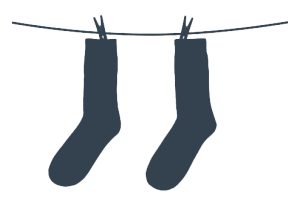

Room for a clothesline 

CASE STUDIES 


\section{Case Study 01}

\author{
Key Design \\ Guidelines
}

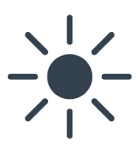

Daylight and sun - am to pm

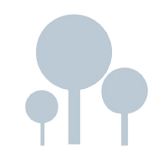

Outdoor connection - privacy included

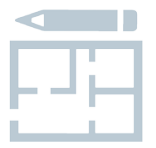

Flexible layout

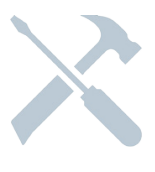

Space for DIY

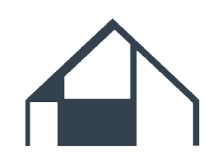

Distinct personality

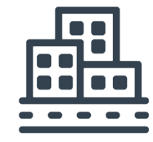

Engagement with the street

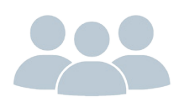

Space for socialising

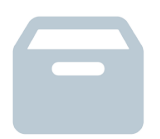

Adequate storage

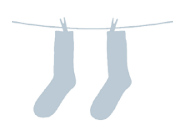

Room for a clothesline

\section{Polygreen}

Bellemo \& Cat Architects - Northcote, Australia - 2007

Polygreen is a compact, eco-friendly home built on an unused car-park site. The design draws inspiration from the industrial, warehouse style of buildings surrounding the site. Therefore engaging with the surrounding site conditions and issues, the printed fibreglass exterior of the home creates a sanctuary for the occupants and a lively public art piece for the existing community. The translucency of the fibreglass exterior also allows natural light to be maximised within the interior while maintaining total privacy for the occupants. 


\section{Case Study 02}

\section{Key Design \\ Guidelines}

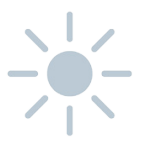

Daylight and sun - am to pm

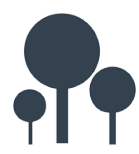

Outdoor connection - privacy included

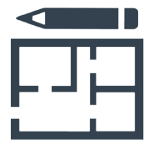

Flexible layout

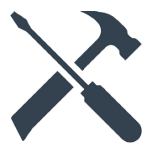

Space for DIY

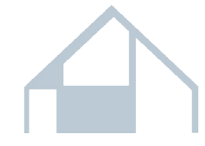

Distinct personality

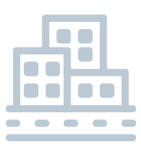

Engagement with the street

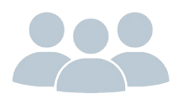

Space for socialising

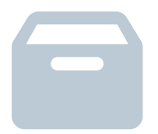

Adequate storage

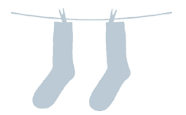

Room for a clothesline

\section{A's House Project}

Global Architects \& Associates - Hanoi, Vietnam - 2016

A compact home hidden away from the noisy city in a small alleyway, the design aims to link living space to natural space while also separating the public and private program. The ground floor comprises of an open plan garage, living, kitchen and dining room to give a feeling of spaciousness and comfort. The second floor consists of private space for the owner and therefore contains the bedroom and bathroom and a private workspace or potential future bedroom. 


\section{Case Study 03}

Key Design

Guidelines

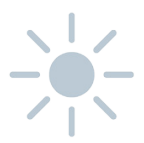

Daylight and sun - am to pm

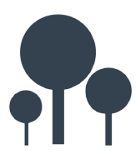

Outdoor connection - privacy included

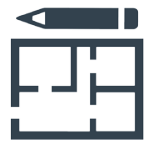

Flexible layout

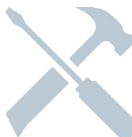

Space for DIY

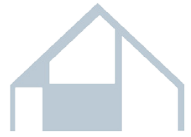

Distinct personality

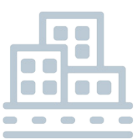

Engagement with the street

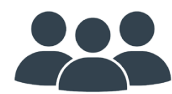

Space for socialising

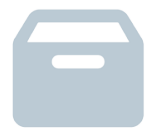

Adequate storage

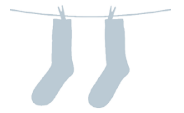

Room for a clothesline

\section{Small House}

Domenic Alvaro - Sydney, Australia - 2011

A vertical apartment style home located on a site measuring only seven by six metres. This home demonstrates a creative use of flexible, adaptable spaces. The living area was intended as undefined and flexible space, with its function to be determined by the changing needs of the occupant (Quinton, 2011). The inverted design of a rooftop garden completes the home by providing a place of contemplation and reflection with its collection of potted plants creating a sense of privacy and seclusion within a busy, urban environment. 


\section{Case Study 04}

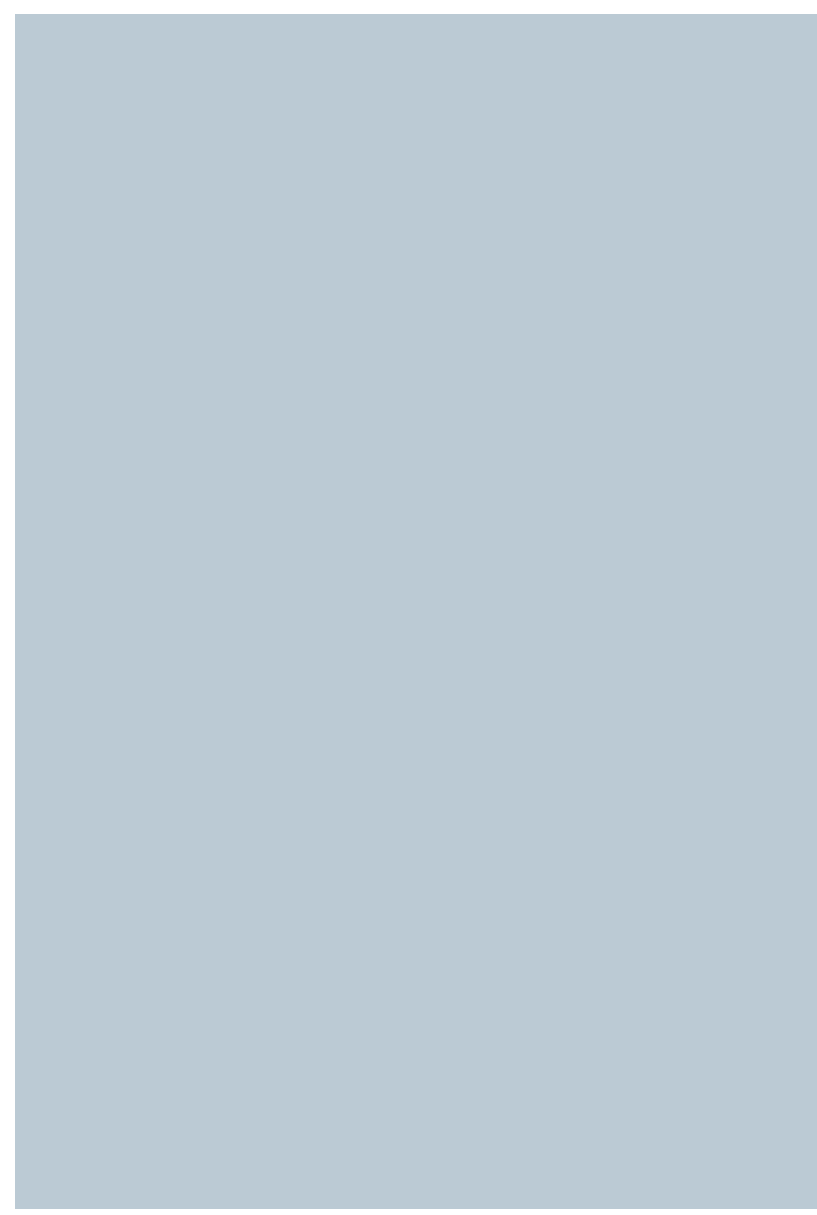

Key Design

Guidelines

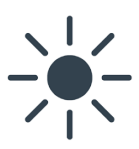

Daylight and sun - am to pm

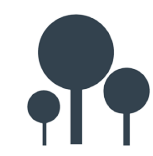

Outdoor connection - privacy included

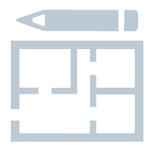

Flexible layout

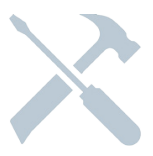

Space for DIY

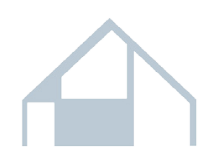

Distinct personality

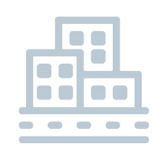

Engagement with the street

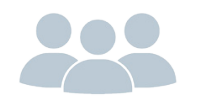

Space for socialising

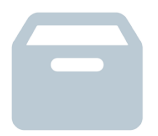

Adequate storage

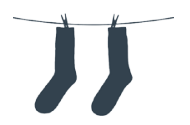

Room for a clothesline

\section{The Cul-De-Sac House}

Nguyen Khac Phuoc Architects - Vinh, Vietnam - 2016

The Cul-de-sac House sits nestled in an urban gap, surrounded by houses on all four sides. It is accessible only from a narrow, twisting alleyway. The ground floor has been treated as an interior courtyard atrium space as there is no garden or empty land surrounding the house.
Skylights and voids are utilised to provide as much natural light and ventilation through the home as possible and the voids also allow for trees to grow up through the interior spaces creating a feeling of indoor/outdoor living within the homes tight boundary constraints. 

SITES 


\section{Site Identification}

A definition for residual urban space was developed specific to this research portfolio and a list of requirements and conditions for site selection was formed based off of the findings from the Residual Space literature review.

The city of Wellington, New Zealand was explored to find spaces which fit with the definition of space and adhered to the site requirements. After analysing the photographs of the spaces found around Wellington, six common site typologies were defined and one site from each typology was selected. The six selected sites will act as catalyst sites, used to explore the design potential for the six site typologies. 


\title{
Residual Urban Space Definition
}

\author{
A gap or an unutilised space which has no assigned function and would be deemed unsuitable to \\ accommodate a standard building type.
}

The portion of space that remains after the quantity for the required buildings has been subtracted or allowed for. 


\section{Site Requirements}

1. The sites should not be suitable to accommodate a conventional building type

2. The selected sites should not take away a space that would otherwise be used for housing (or any other building)

3. The sites should be located in the Wellington CBD

4. The sites shall have access to sufficient direct or ambient daylight

5. Ground condition does not matter

6. The proposed interventions should in some way contribute to or enrich the wider surrounding urban context

7. The selected sites should inspire a radically different design approach

8. The proposed interventions should not disrupt any current formal or informal positive use of the sites 


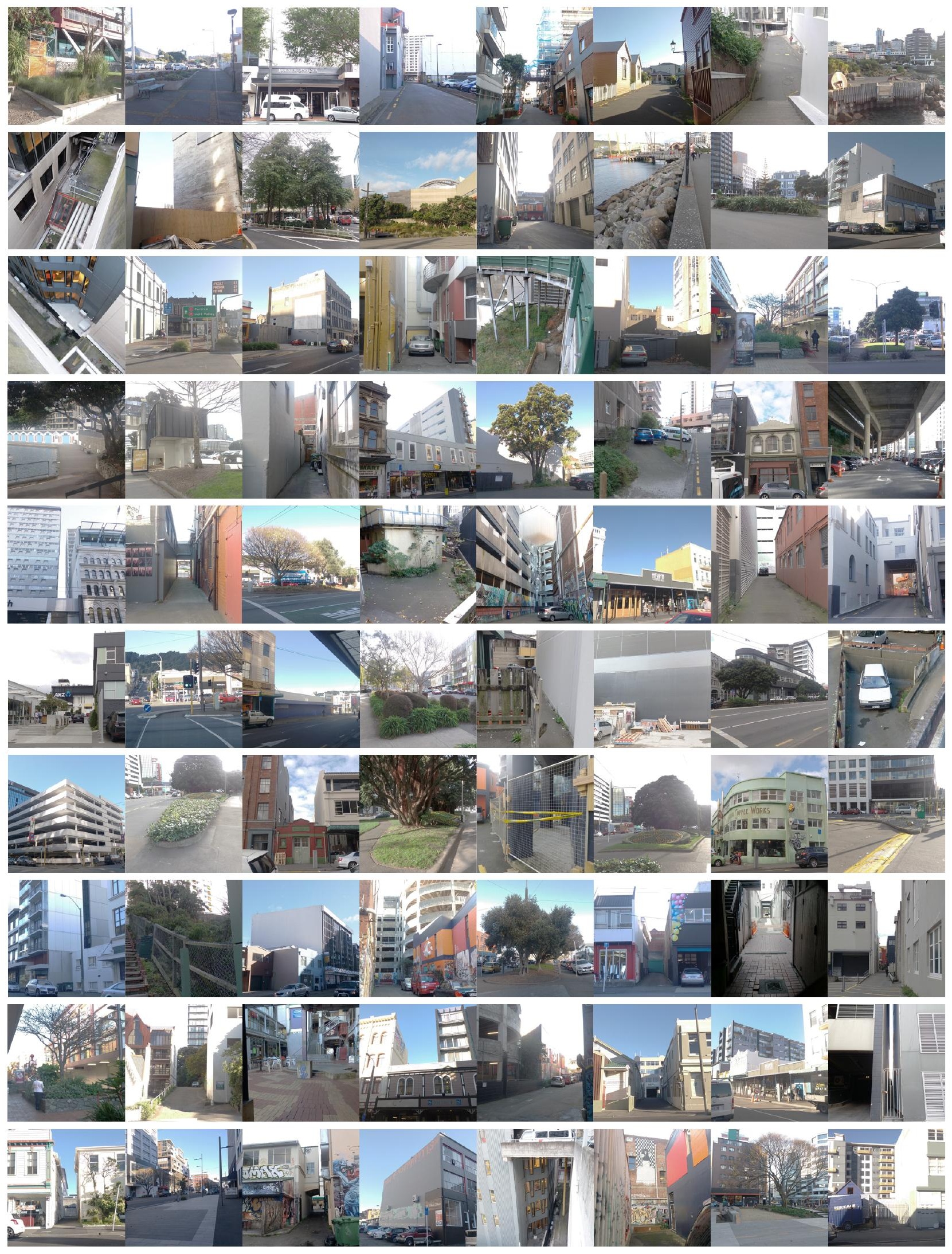




\section{Six Site Typologies}

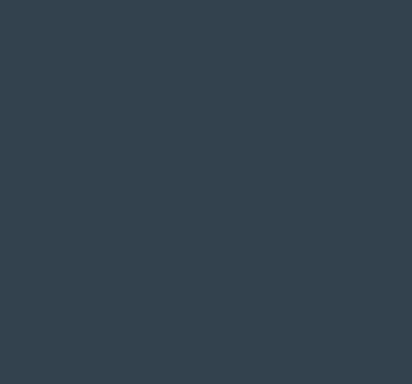

Island

An unused piece of

land surrounded by

development

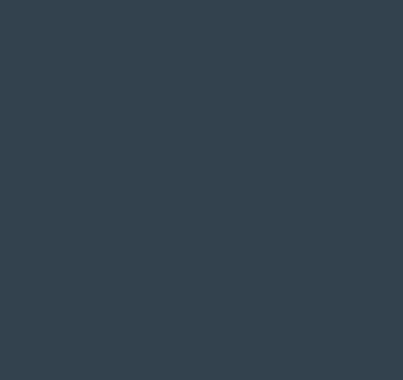

In-Between

A site located between

functional spaces

that could be more

optimally utilised

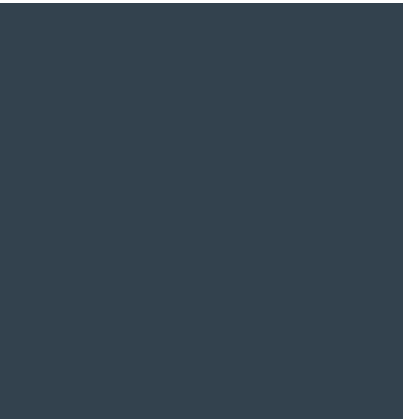

Elevated

A site situated above an existing building or raised above unusable land 


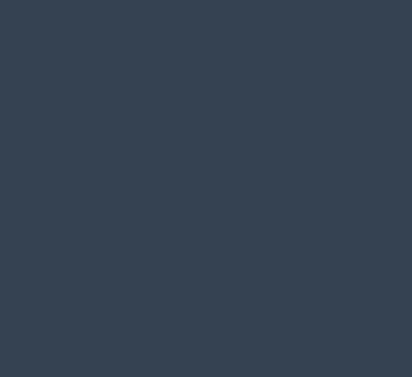

Narrow + Bounded

A narrow site,

enclosed on at least

two sides, most likely

between buildings

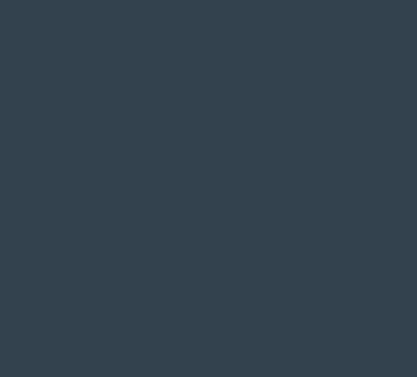

Accessway

A site which functions

as a way to access

something, this

function must be

retained

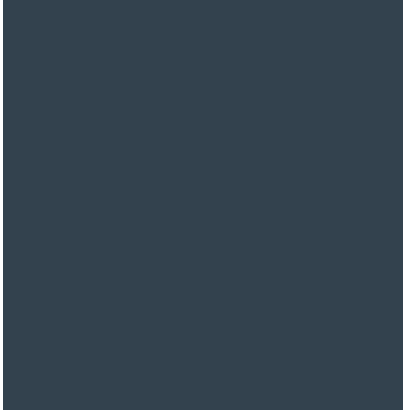

\section{Elevation}

A wall or existing building which allows

a house to be built

against it or hung off it 


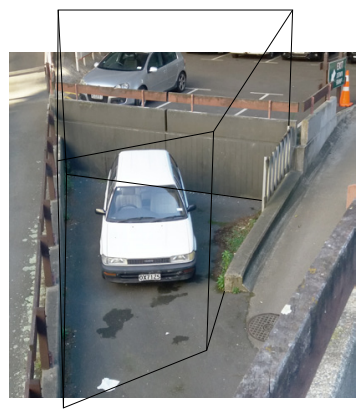

(1)

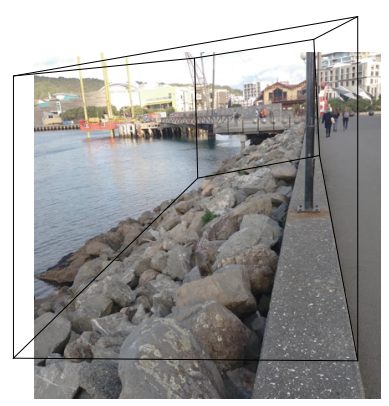

(2)

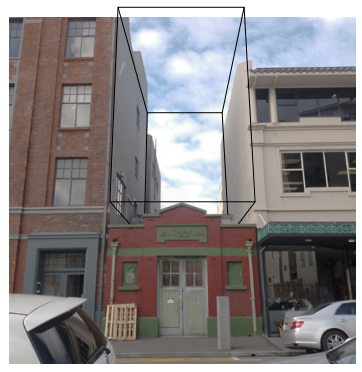

(3)

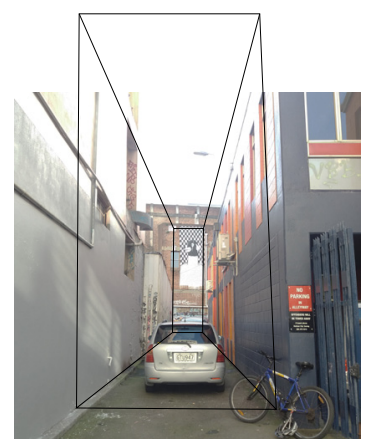

(4)
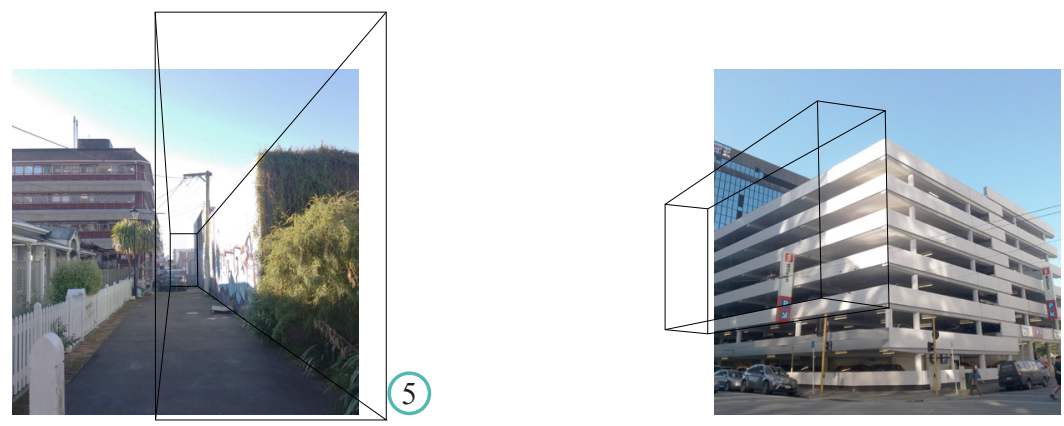

(6) 



\section{Catalyst Site 01}

Clifton Terrace Carpark, underneath the Wellington Urban Motorway

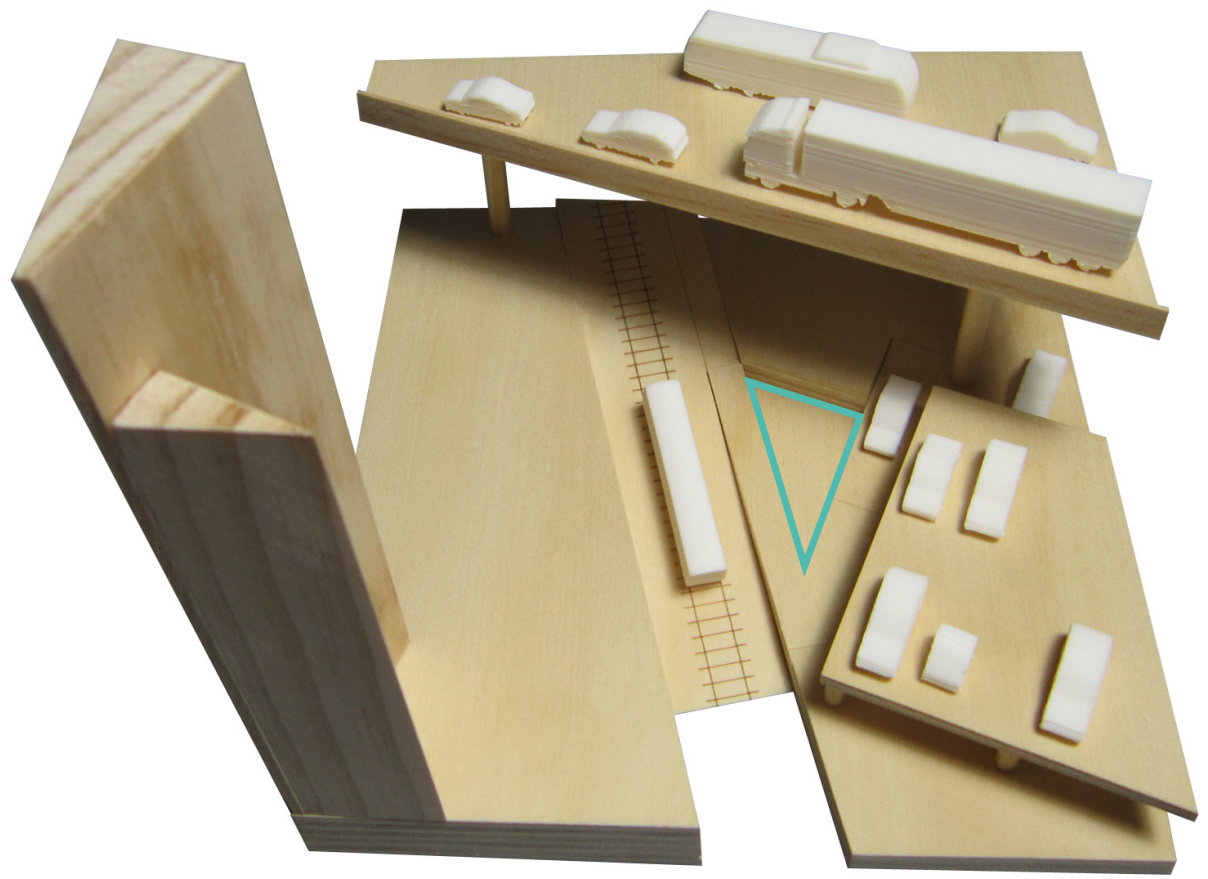

Catalyst site one is an Island typology, located in an unused triangular corner of the Clifton Terrace Carpark, underneath the Wellington Urban Motorway. The site is well connected to the local amenities and is adjacent to the Cable Car (Fig 3.07). Difficulties when designing for this site will include the traffic noise and lack of privacy from the motorway overhead, the Cable Car and footpath

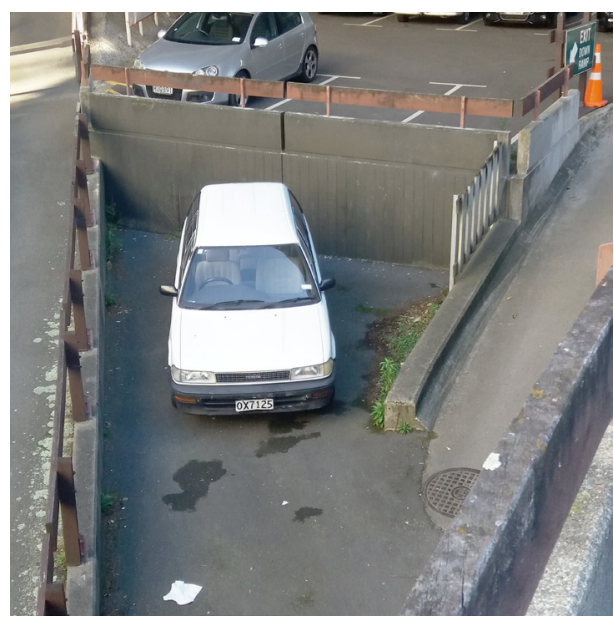

running alongside and the surrounding public carpark. The atmosphere of this site feels cold, due to the fact it is surrounded by hard, concrete surfaces. The small, triangular shaped site outline could prove challenging to develop.

Island

Fig 3.04 (Top) Clifton Terrace Carpark site model showing location of site

Fig 3.05 (Above left) Photograph of the site

Fig 3.06 (Above right) Island site typology 


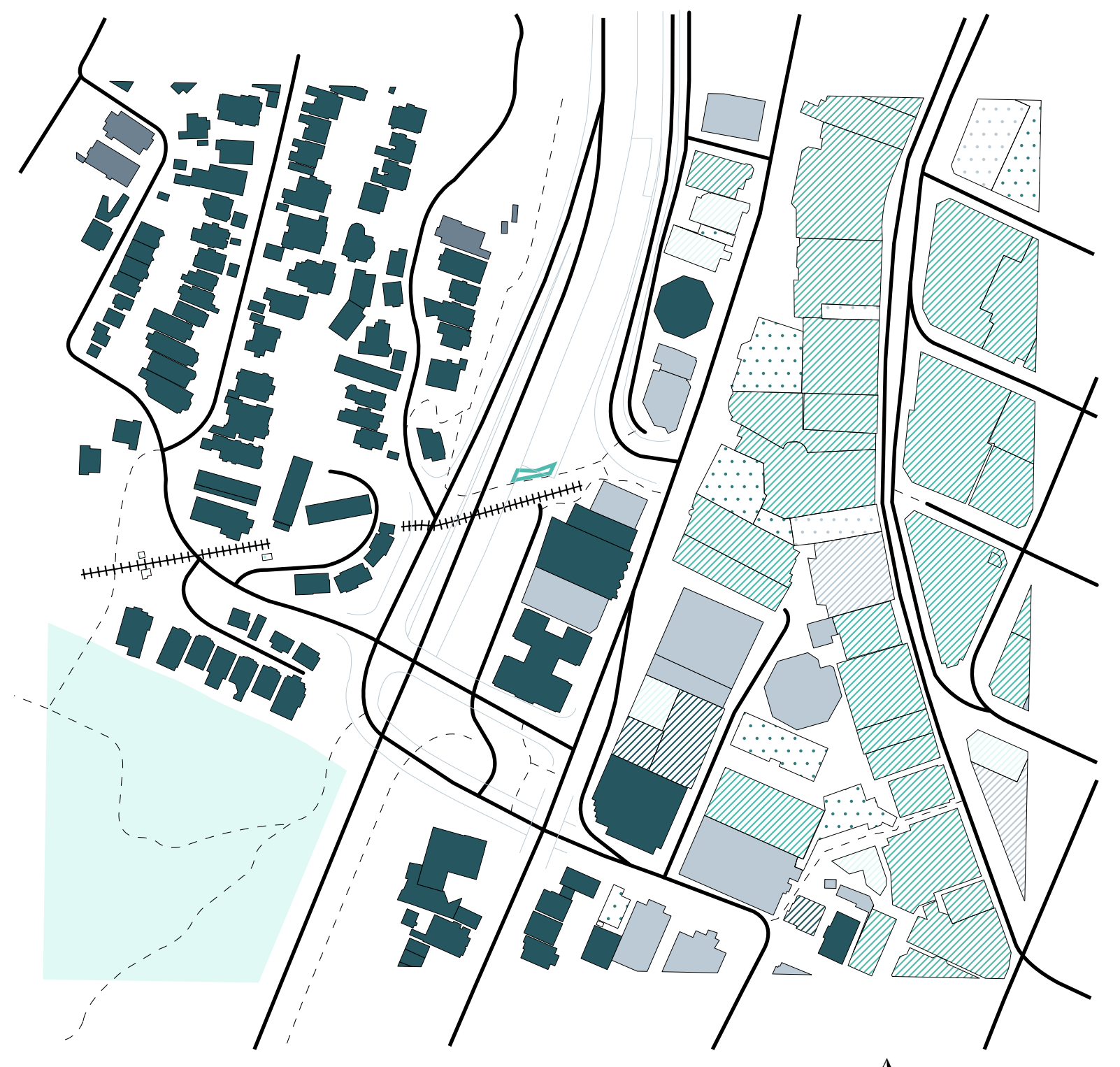

$\widehat{N}_{\mathrm{N}}$ Scale: 1:3000

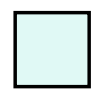

Green Space

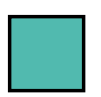

Recreation/Leisure

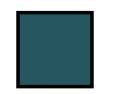

Residential

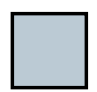

Commercial

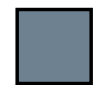

Education

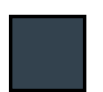

Religious

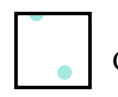

Civic

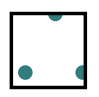

Hospitality

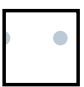

Retail

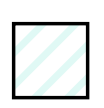

Mixed Use -
Hospitality/Retail + Residential

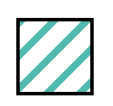

Mixed Use Hospitality/Retail + Commercial

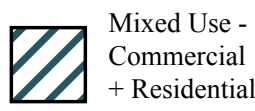




\section{Catalyst Site 02}

Wellington Waterfront, adjacent to Frank Kitts Park

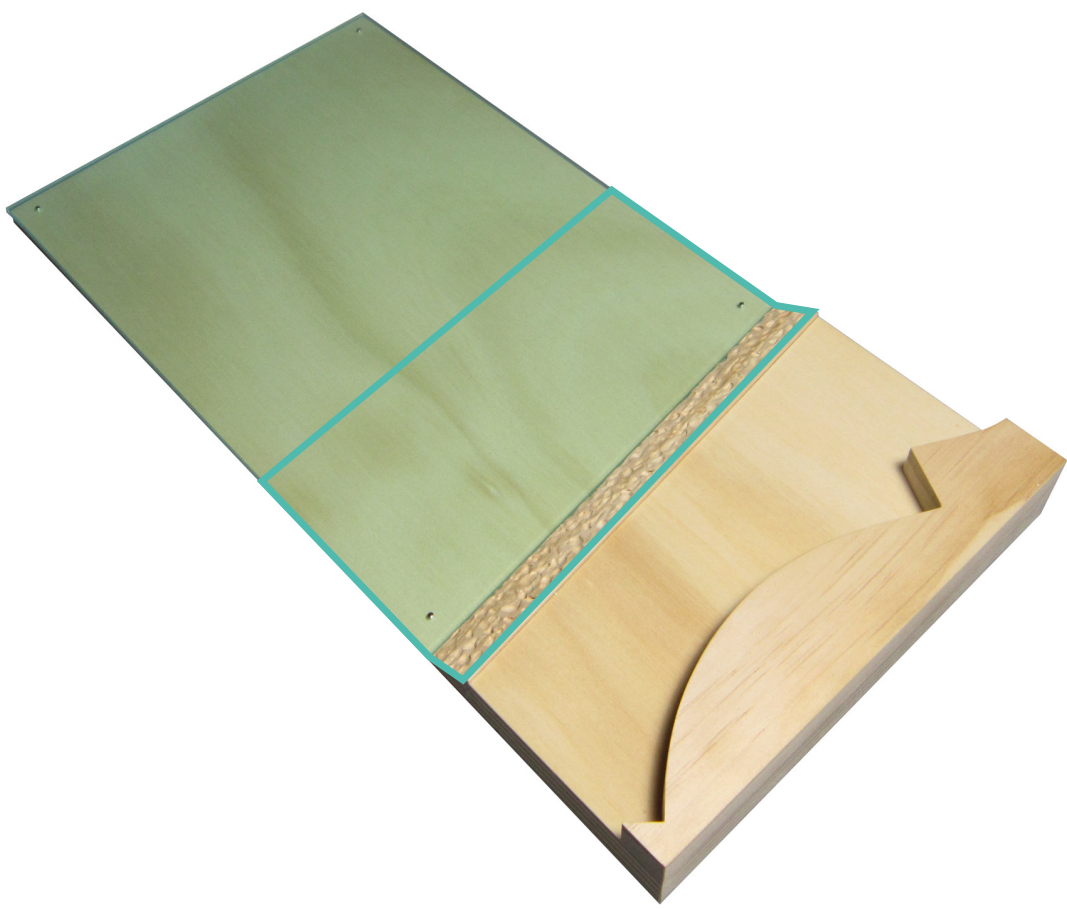

Catalyst site two is an In-between typology, located on the Wellington waterfront adjacent to Frank Kitts Park. The focal residual aspect of this site is the auxiliary rocks between the sea wall and the waters edge. The site is positioned along the route of the Wellington Writer's Walk and is also located alongside the sculptural Len Lye Water Whirler. The site is well situated to take

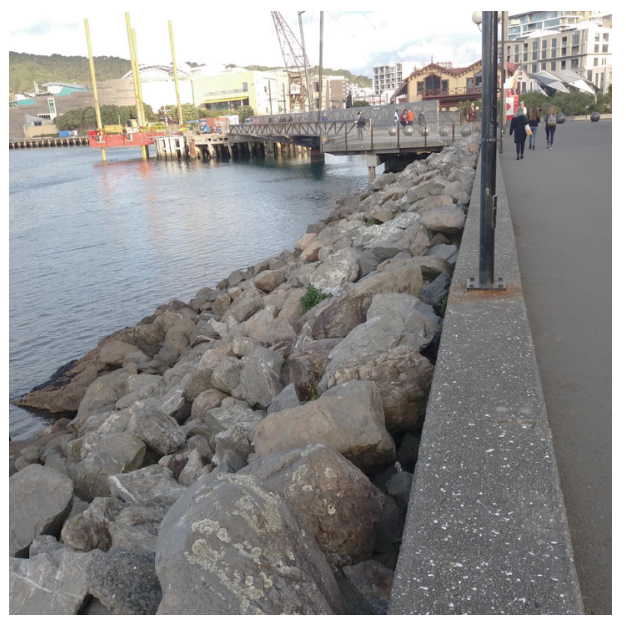

advantage of all of the local amenities (Fig 3.11). Due to the extremely busy public location of this site and high pedestrian traffic, particularly during the summer months, the major difficulty of the site will be achieving adequate privacy. Consideration will also be required to avoid blocking too much of the view or detracting from use of the public space.

\section{In-Between}

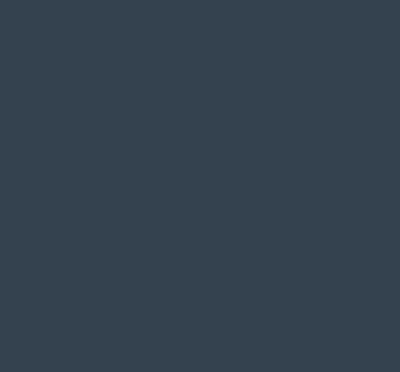

Fig 3.08 (Top) Wellington Waterfront site model showing location of site

Fig 3.09 (Above left) Photograph of the site

Fig 3.10 (Above right) In-Between site typology

$51 \quad$ Fig 3.11 (Opposite) Map of the site and surrounding amenities 


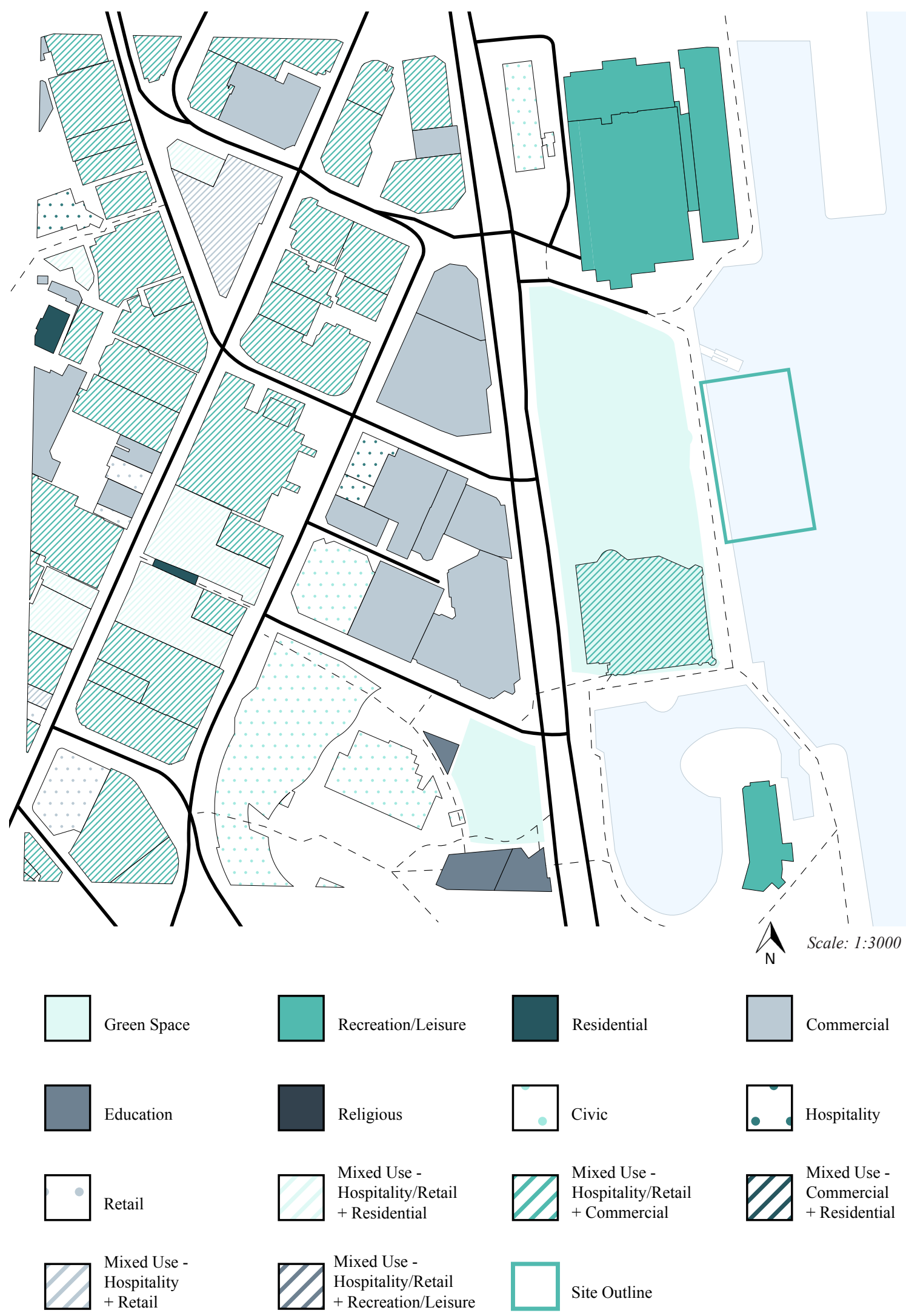




\section{Catalyst Site 03}

\section{Tory Street, above substation}

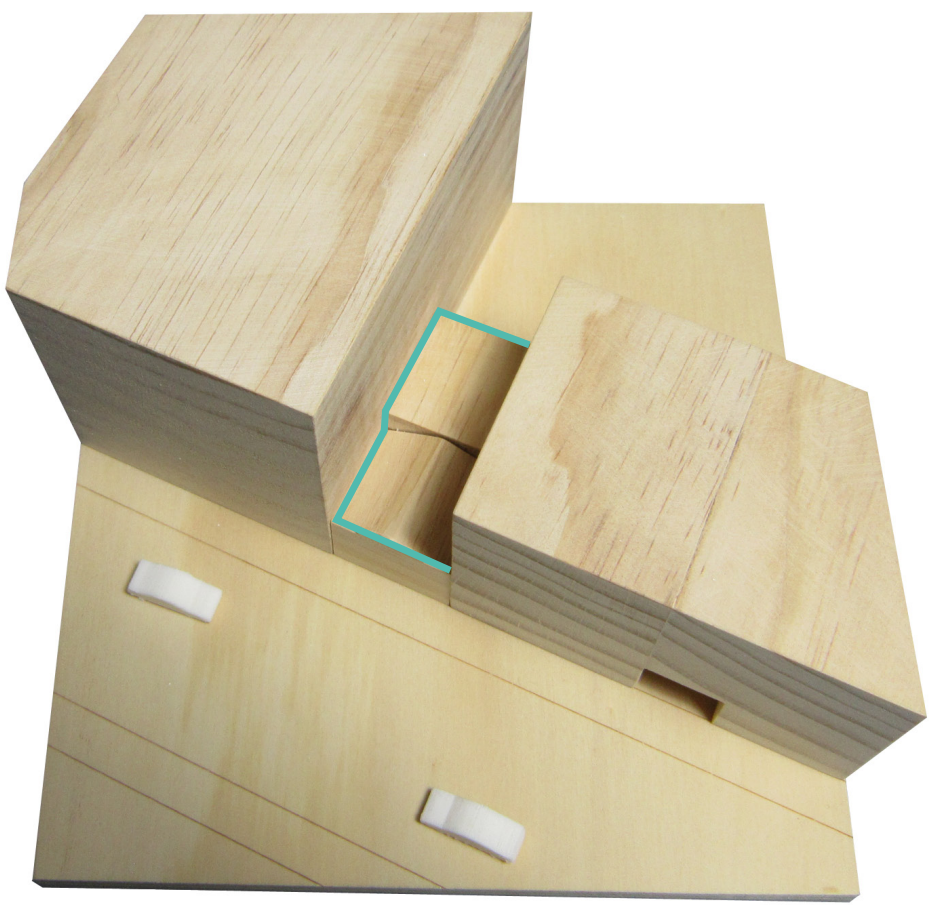

Catalyst site three is an Elevated typology, located at 21 Tory Street in central Wellington. It is a gap between two buildings, elevated above a functioning power distribution substation. This site is also well connected to the local amenities (Fig 3.15). The substation is the primary challenge for this site. As per the site requirement, which states, the proposed intervention should not disrupt any

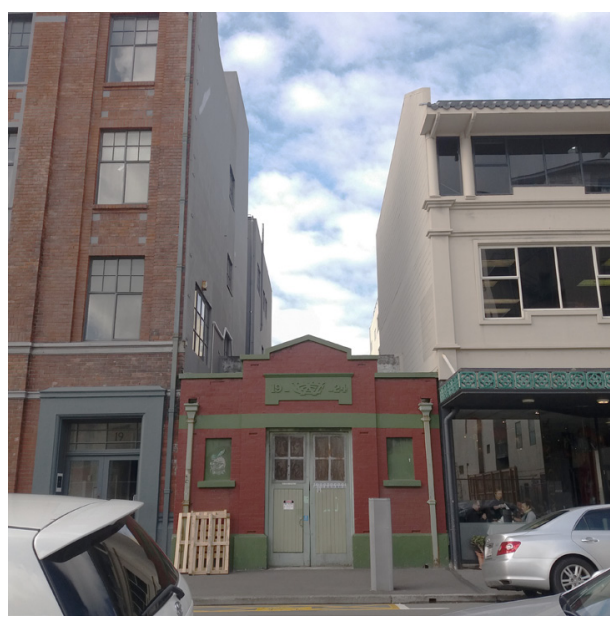

Fig 3.12 (Top) Tory Street site model showing location of site Fig 3.13 (Above left) Photograph of the site Fig 3.14 (Above right) Elevated site typology current formal use of the site, the substation should not be interfered with. Therefore, any building will have to be self sufficient and constructed independently from it. Privacy will also be a concern for this site, particularly from the potential development of the currently undeveloped carpark site across the street.

\section{Elevated}

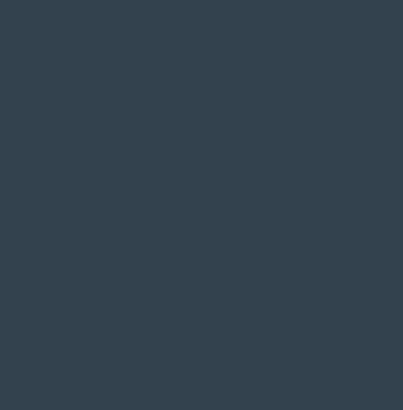




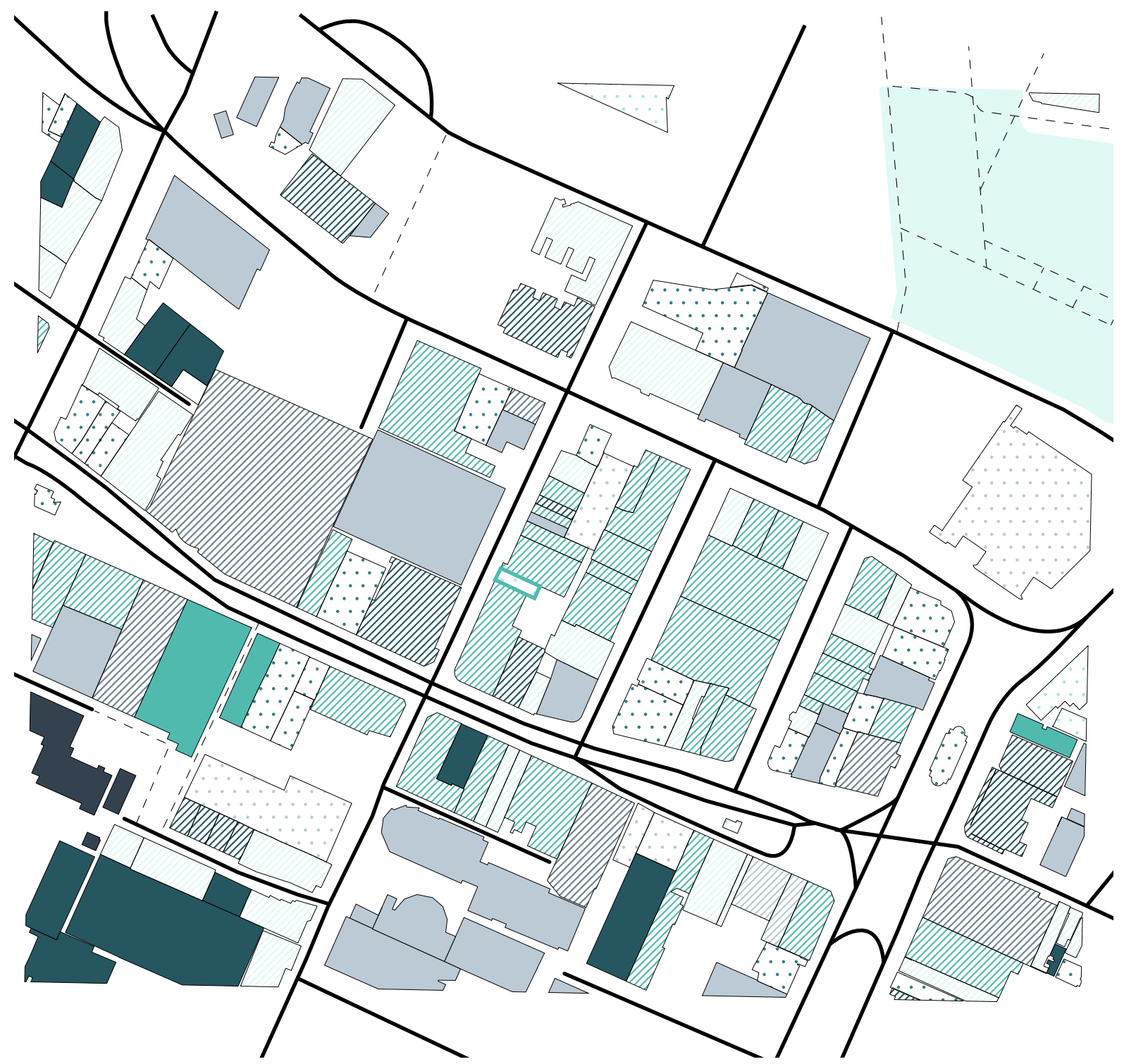

$\widehat{N}_{\mathrm{N}}$ Scale: 1:3000

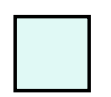

Green Space

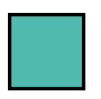

Recreation/Leisure

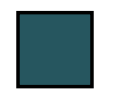

Residential

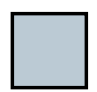

Commercial

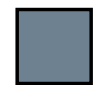

Education

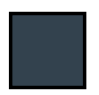

Religious
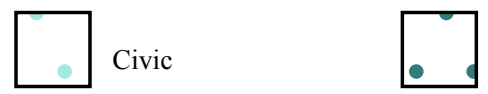

Hospitality

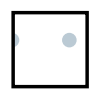

Retail

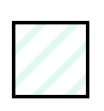

Mixed Use -
Hospitality/Retail + Residential

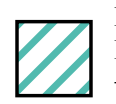

Mixed Use Hospitality/Retail + Commercial 


\section{Catalyst Site 04}

\section{Lukes Lane, alleyway between buildings}

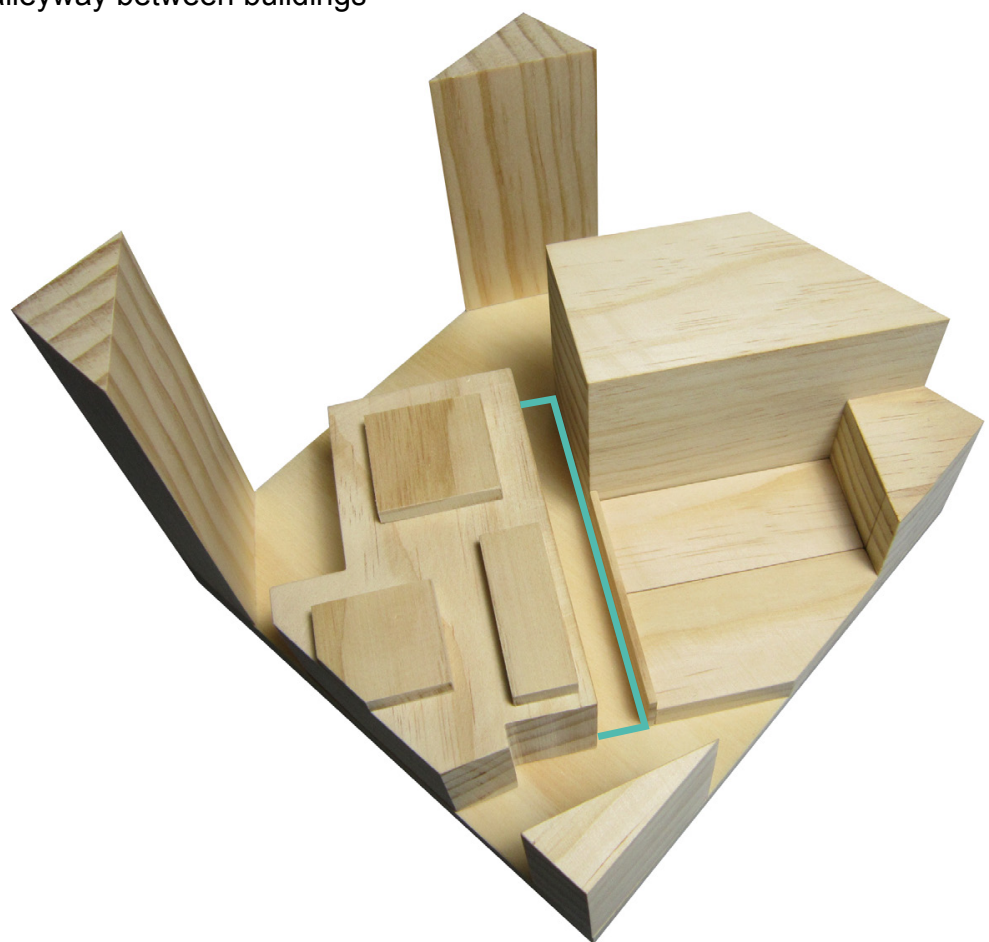

Catalyst site four is a Narrow and Bounded typology, located in a dead-end residual alley which comes off of Lukes Lane. Occasionally used for parking, it is enclosed by buildings on the two long sides and fenced off at one end. This site is relatively private, as it is tucked away down a quiet lane, but is still well located to take advantage of all of the local amenities (Fig 3.19). The

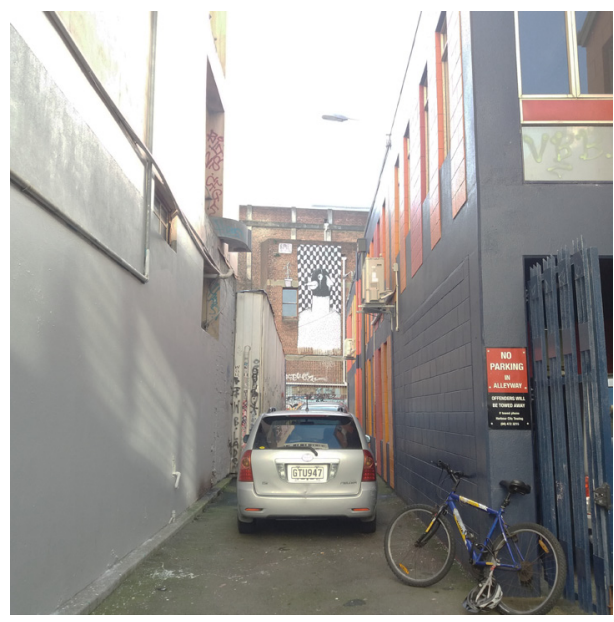

Fig 3.16 (Top) Lukes Lane site model showing location of site Fig 3.17 (Above left) Photograph of the site

Fig 3.18 (Above right) Narrow + Bounded site typology narrowness of the site could prove difficult to design for and adequate lighting could be challenging to achieve due to the buildings either side of the site blocking a degree of sunlight.

\section{Narrow + Bounded}

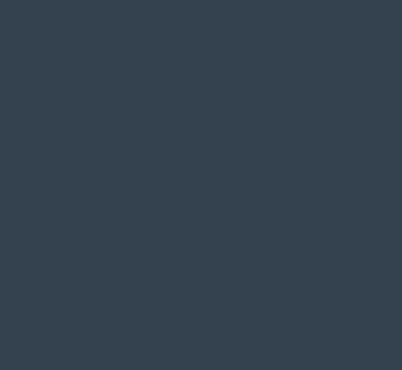




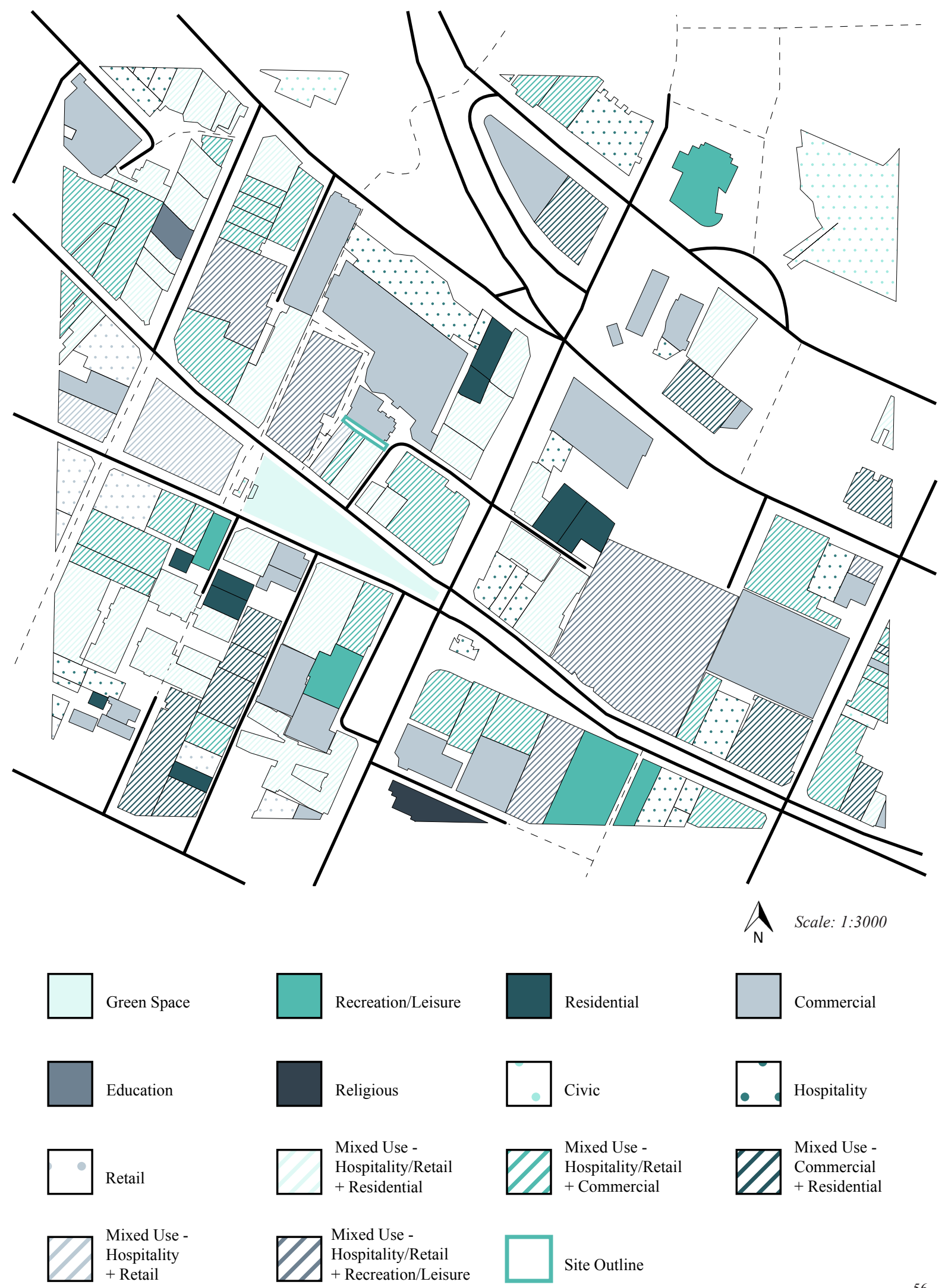




\section{Catalyst Site 05}

\section{Footscray Ave}

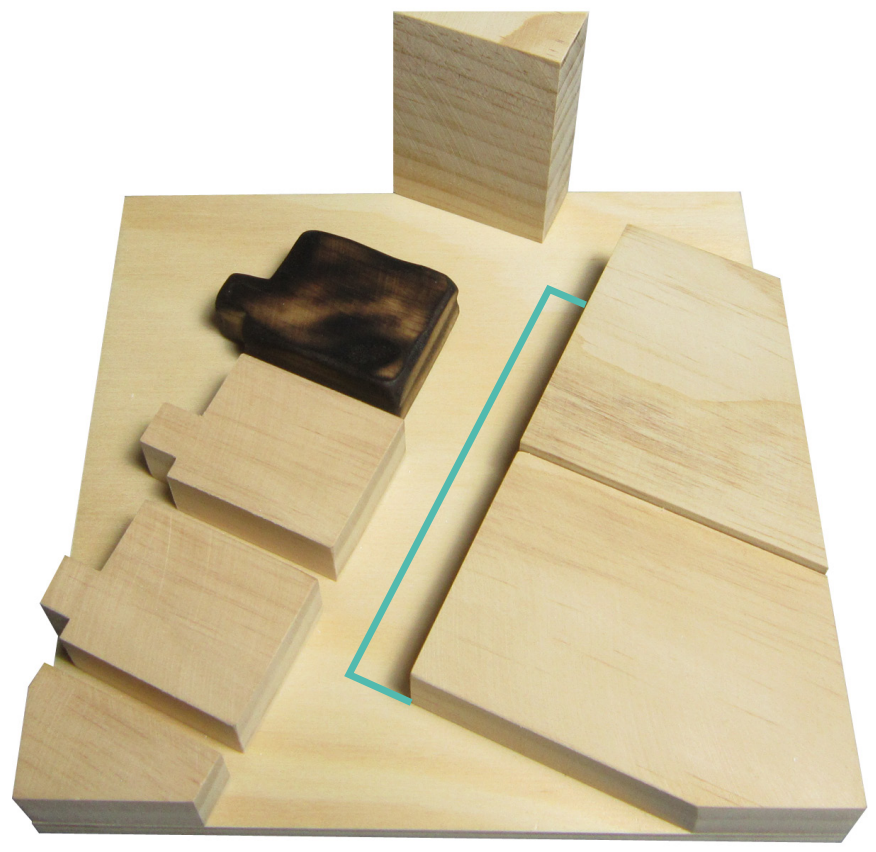

Catalyst site five is an Accessway typology, located on Footscray Avenue and currently functions as an expansive pedestrian walkway and access to the existing homes. The pedestrian access to the existing homes along Footscray Avenue must be retained, limiting the available width of the site. The resulting narrowness of this site may prove challenging to design for. Privacy is also a concern as the entranceways for each of the existing homes on Footscray Avenue overlook the site. This site is located near the edge of the central city in a slightly more residential area, however the site is still well positioned for all of the local amenities (Fig 3.23).

\section{Accessway}
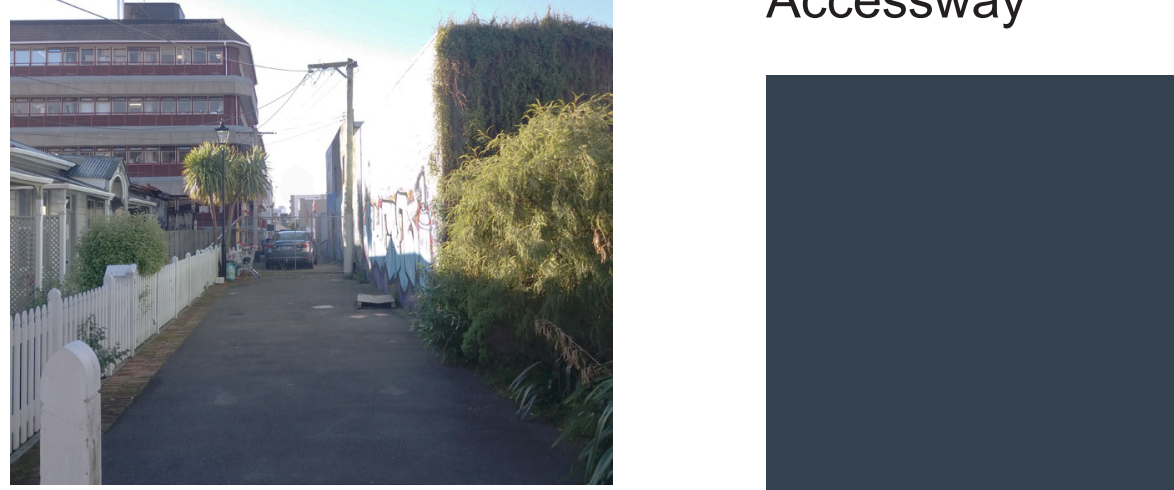

Fig 3.20 (Top) Footscray Avenue site model showing location of site

Fig 3.21 (Above left) Photograph of the site

Fig 3.22 (Above right) Accessway site typology 


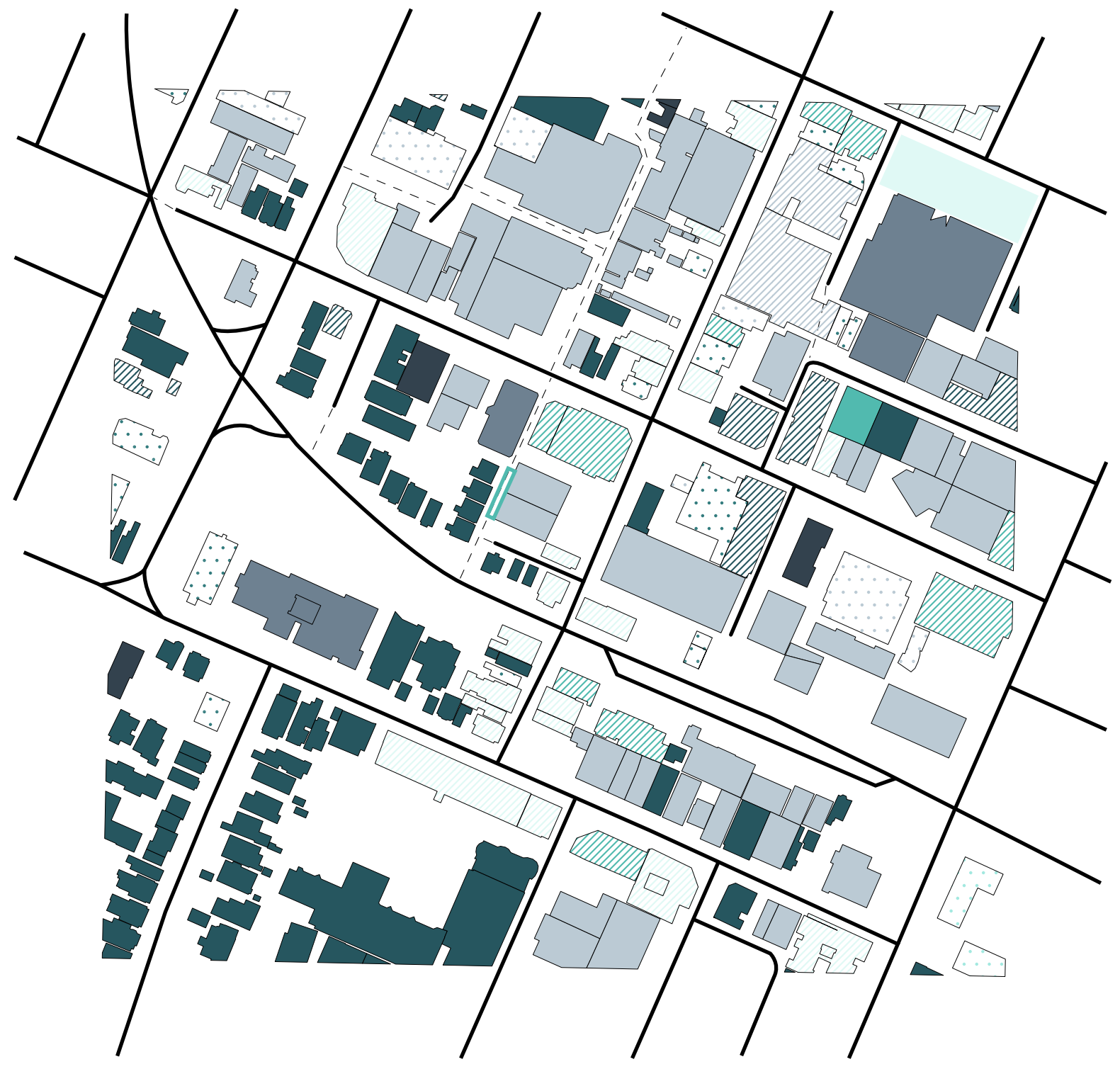

$\widehat{N}_{\mathrm{N}}$ Scale: 1:3000

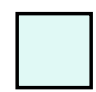

Green Space

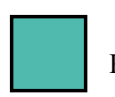

Recreation/Leisure

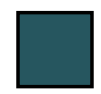

Residential

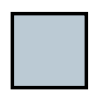

Commercial

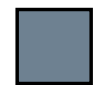

Education

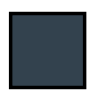

Religious

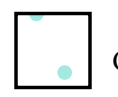

Civic

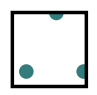

Hospitality

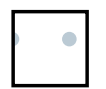

Retail

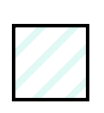

Mixed Use -
Hospitality/Retail + Residential

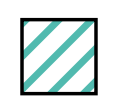

Mixed Use Hospitality/Retail + Commercial

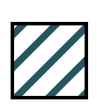

Mixed Use Commercial + Residential

Mixed Use Hospitality + Retail

Mixed Use -

Hospitality/Retail

+ Recreation/Leisure

Site Outline 


\section{Catalyst Site 06}

Corner of Victoria Street and Willeston Street, side of the Wilson Carpark building

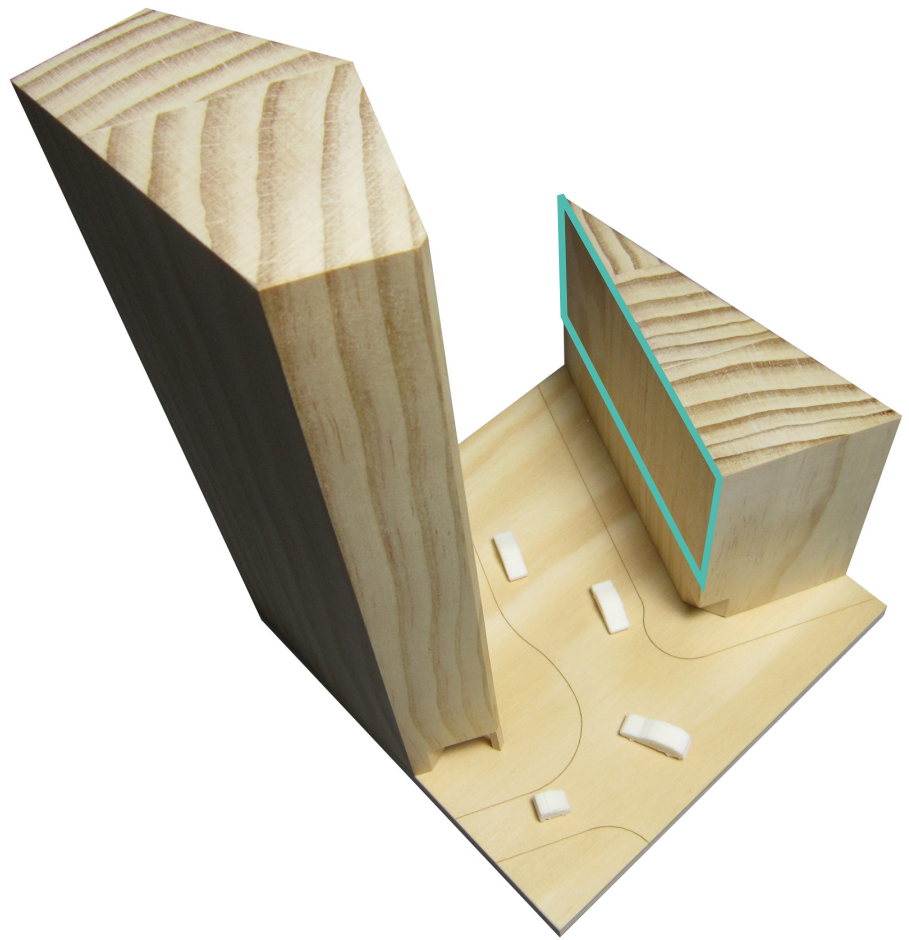

Catalyst site six is an Elevation typology, located on the side of the Wilson Carpark building on the corner of Victoria Street and Willeston Street. The side of this carpark building offers an ideal residual space for a house, as the intervention will not be blocking any essential outlook and will not detract in any way from the operation of the building. Being surrounded by high rise office buildings and backing onto a public carpark building, privacy will be a main concern. The surrounding high rise buildings may also affect the amount of sunlight reaching the site. This site is also well positioned for all of the central city amenities (Fig 3.27).

\section{Elevation}

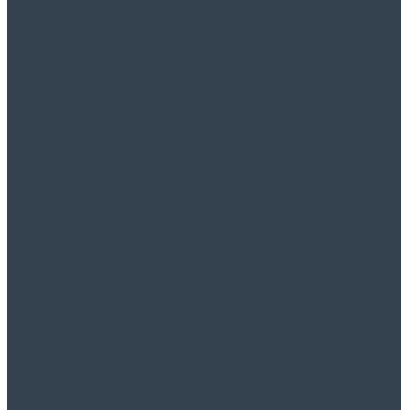

Fig 3.24 (Top) Victoria and Willeston Street site model showing location of site

Fig 3.25 (Above left) Photograph of the site

Fig 3.26 (Above right) Elevation site typology 


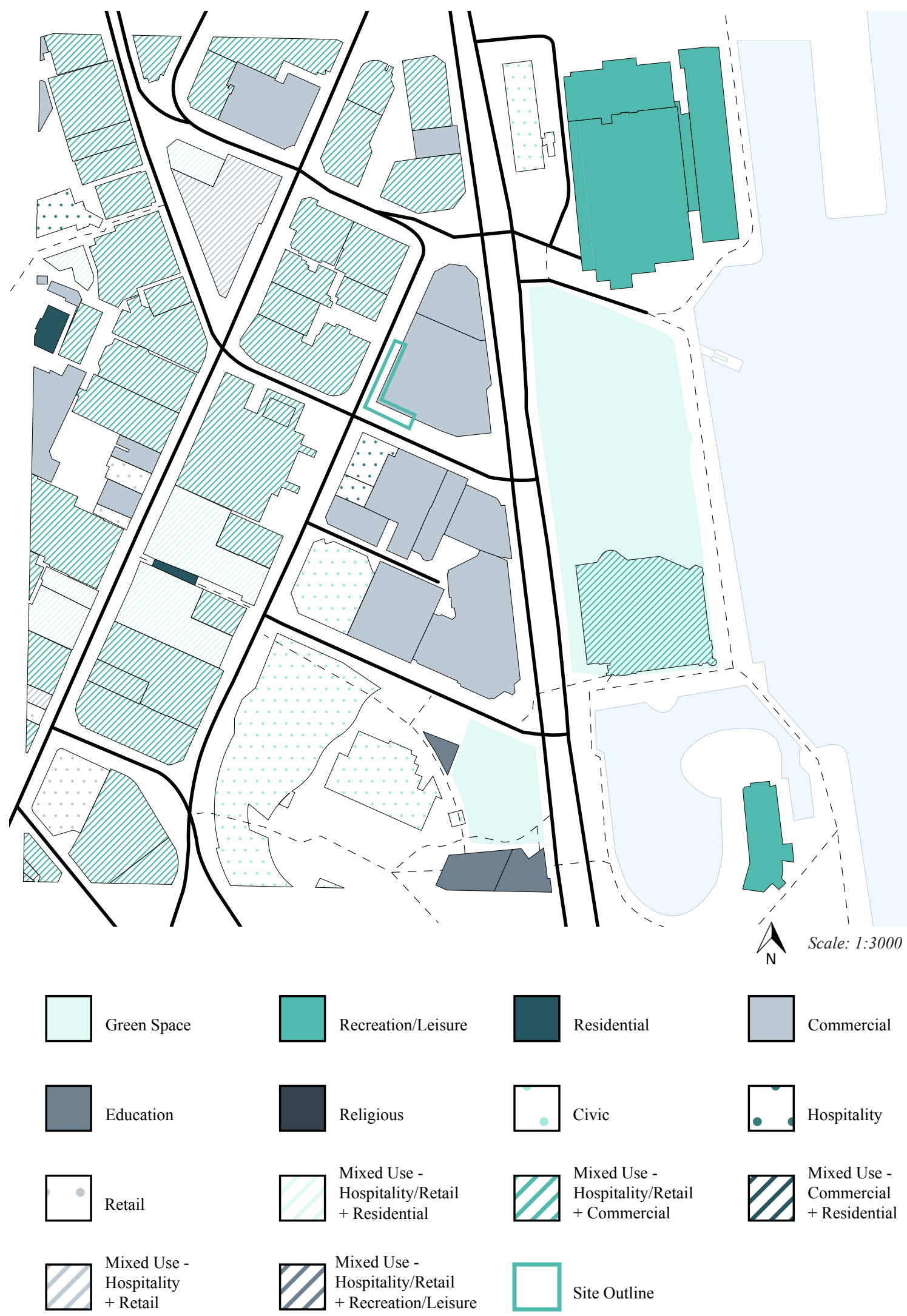




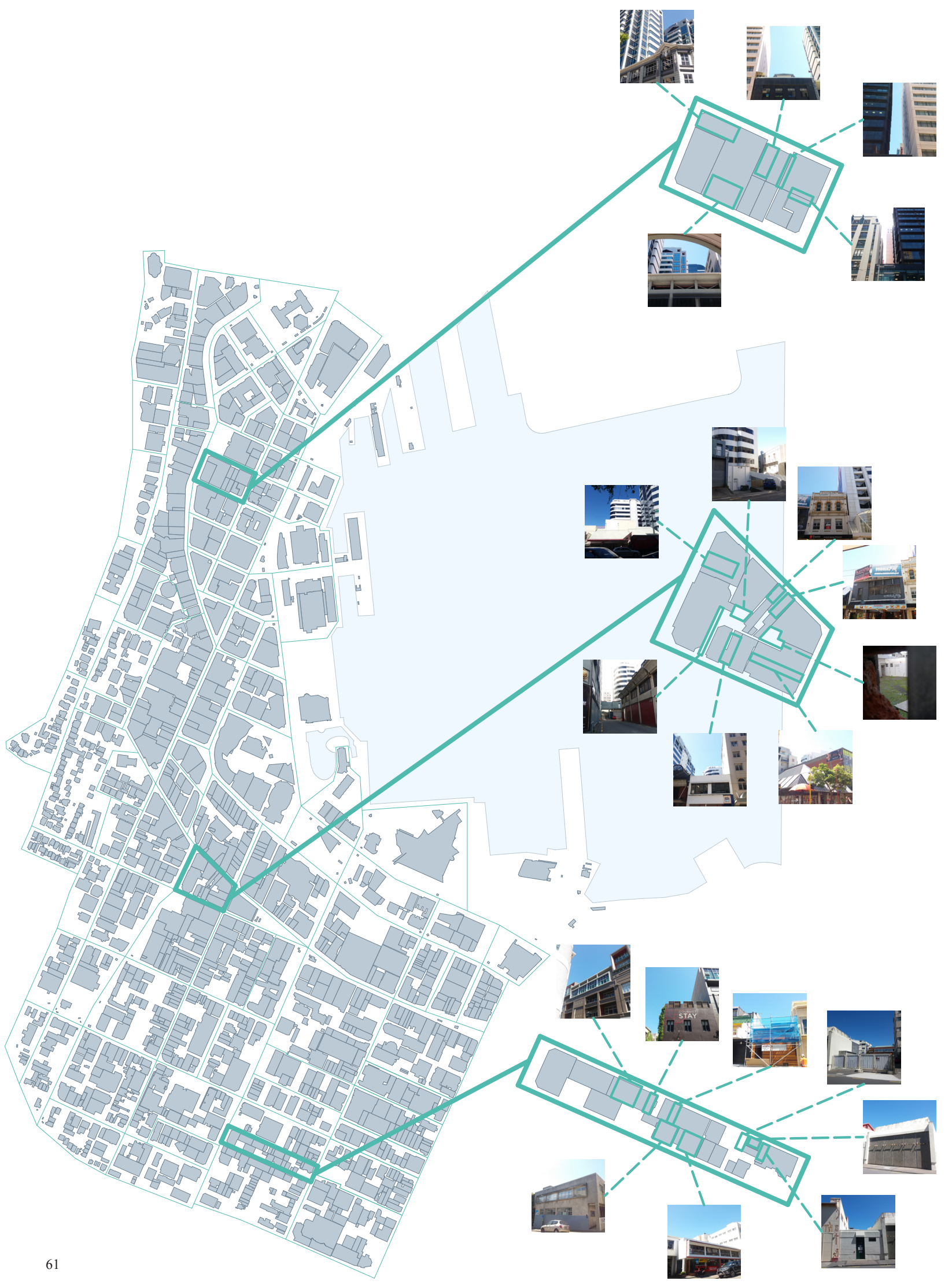




\section{Justification of Site}

To ensure the use of residual space was a valid approach for a new typology of housing, the potential number of new homes this scheme could propose for the city of Wellington was calculated. To do this, three city blocks were selected at random and surveyed to find all of the residual space suitable for housing which met the predefined criteria for site selection. The average number of residual sites suitable for potential homes across each block was calculated to be seven. Based off of this average, the estimated number of residual sites suitable for housing across the city worked out to be 665 potential sites.

$95=$ Total number of blocks in Wellington City

Block One $=5$ potential housing locations

Block Two $=8$ potential housing locations

Block Three $=8$ potential housing locations

$7=$ Average number of potential housing locations per city block

$665=$ Estimated number of residual sites suitable for homes in Wellington City 


\section{4}

INITIAL DESIGNS 


\section{Form Studies}

An architectural form study was carried out in an attempt to distinguish a type of form that could be successfully applied across each of the different site typologies.

To do this, ten different techniques were selected and modelled around the context of the individual sites, taking into account the key qualities and challenges each site possesses. 

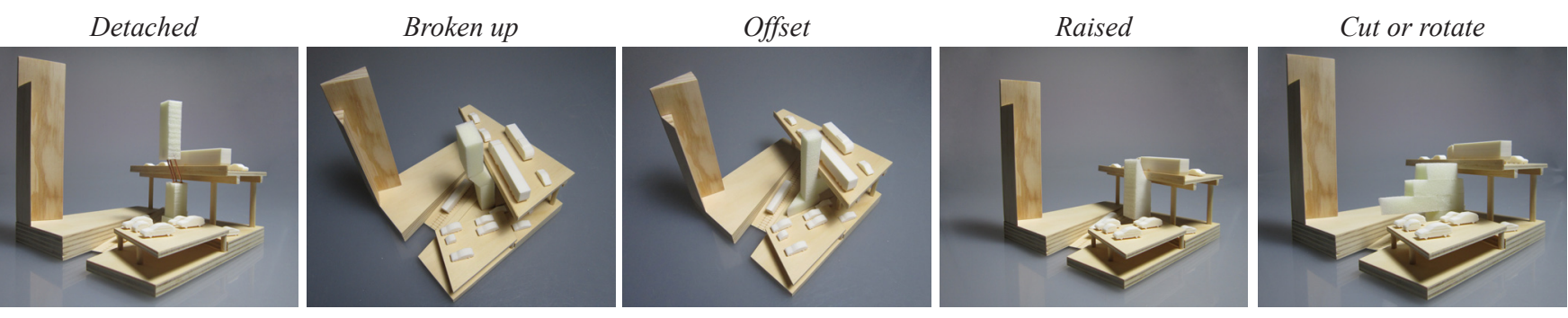

Site 01 - Clifton Terrace Carpark
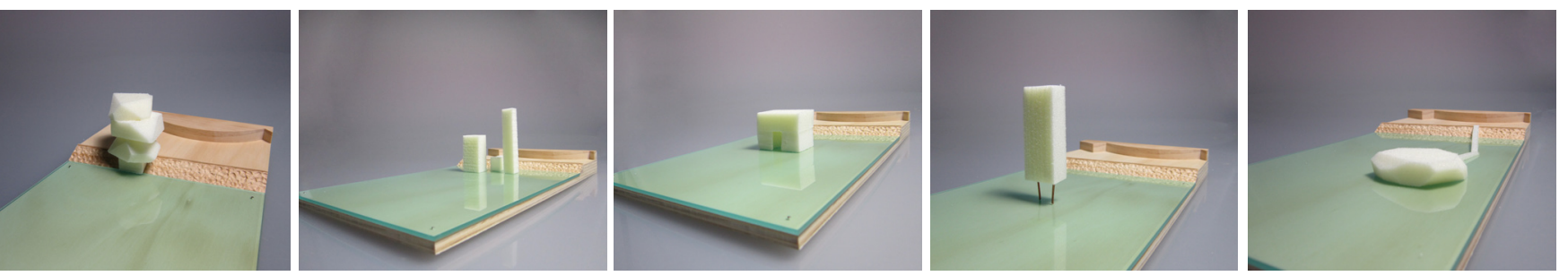

Site 02 - Wellington Waterfront
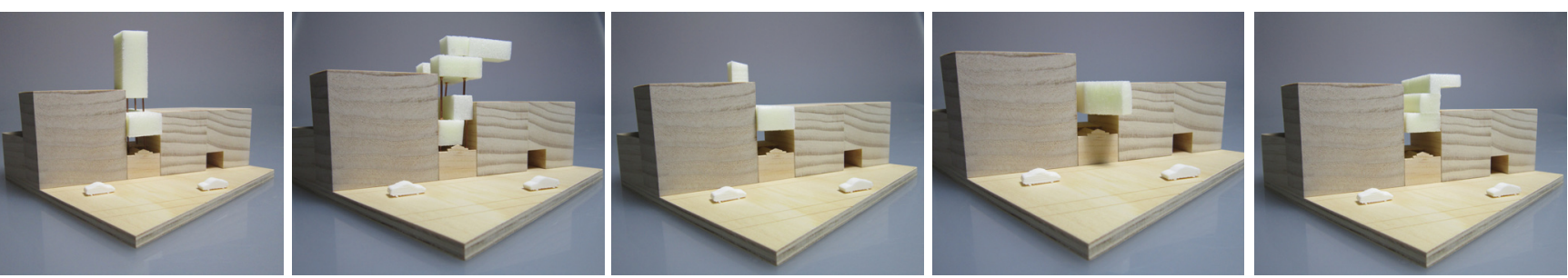

Site 03 - 21 Tory Street
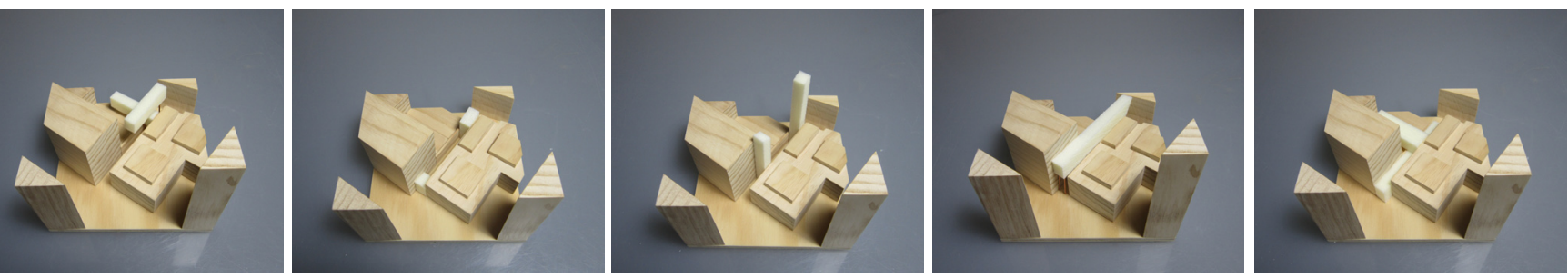

Site 04 - Lukes Lane
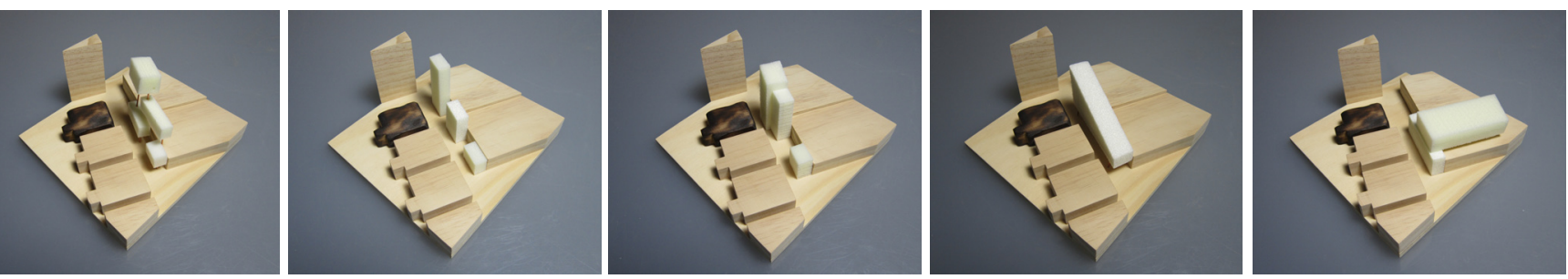

Site 05 - Footscray Avenue
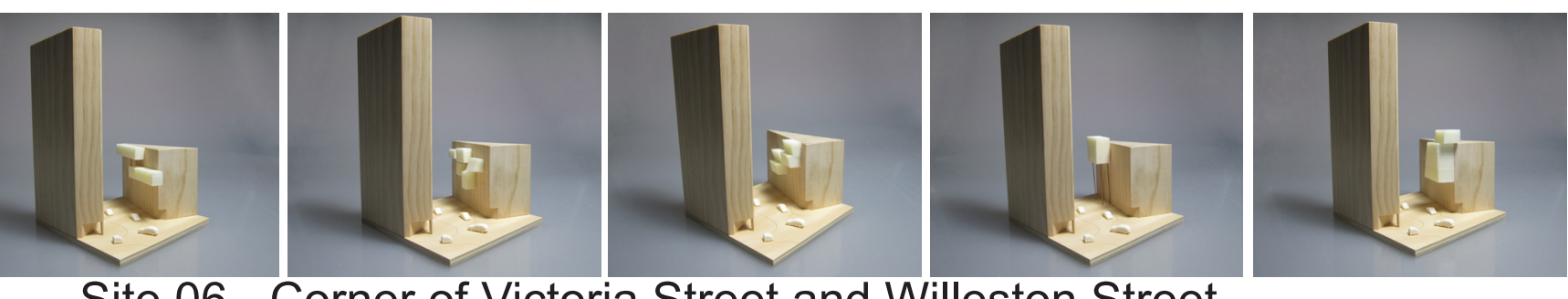

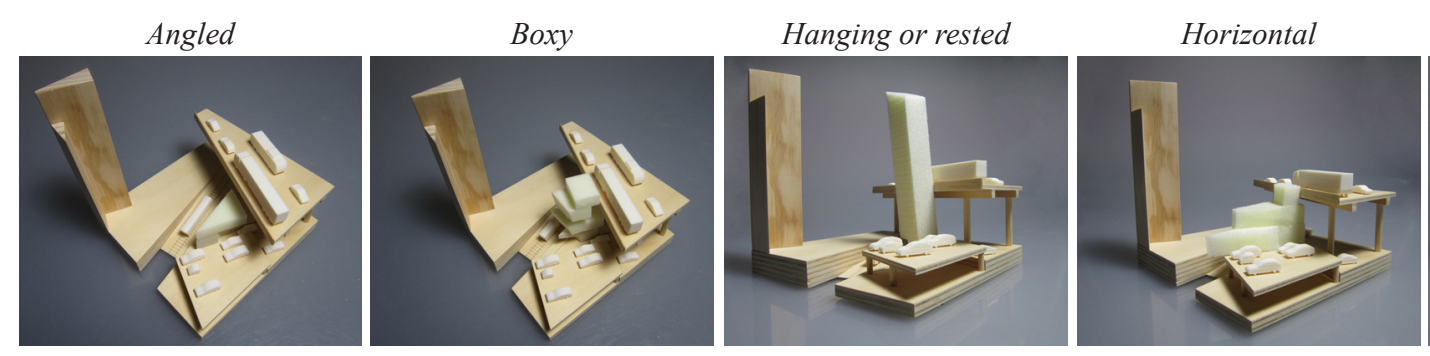

Filling the gap
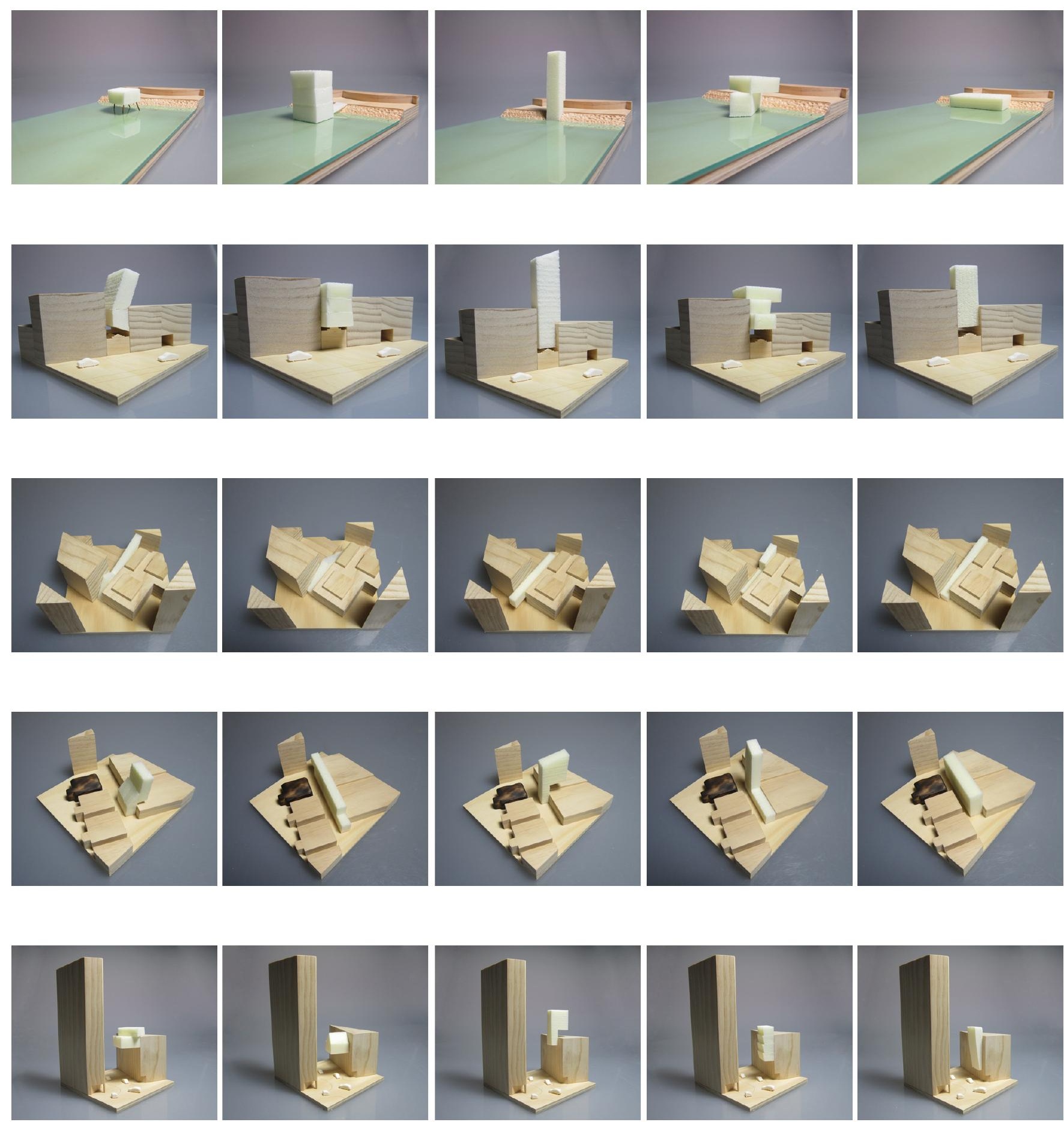


\section{Most Successful Outcomes}

An evaluation of the form studies found the more successful outcomes took cues from the massing of the surroundings to help the form appear as though it belonged. However, no one type of form worked successfully across each of the six site typologies. The detached and broken up volumes were the most successful.

One of the reasons this type of massing was more successful than others, was because the broken up volumes help to moderate the scale of the housing in comparison to the surrounding built form. Therefore, seemingly making the volumes feel less imposing. These forms work with their unique surroundings rather than against and most make some sort of positive impact. This may be through providing shelter along public walkways, as several of the forms do, or providing a sculpture like form to enliven the surroundings. The gaps between the volumes and the exterior horizontal shelves produced, may offer a suitable location for private outdoor spaces to be integrated into the form.

The findings from this study will be beneficial during the design development phase, as the housing will evolve spatially from the forms developed within this study with knowledge of the more successful approaches. 


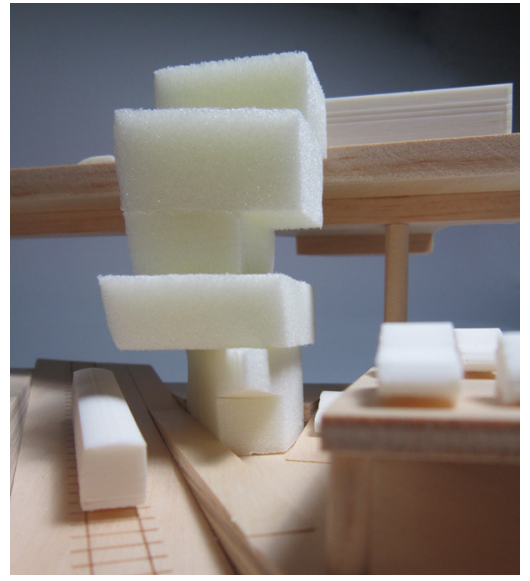

Catalyst Site 01 - Clifton Terrace Carpark

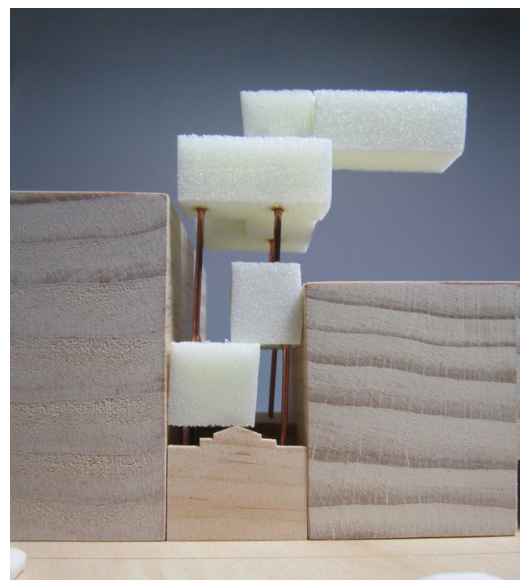

Catalyst Site 03 - Tory Street

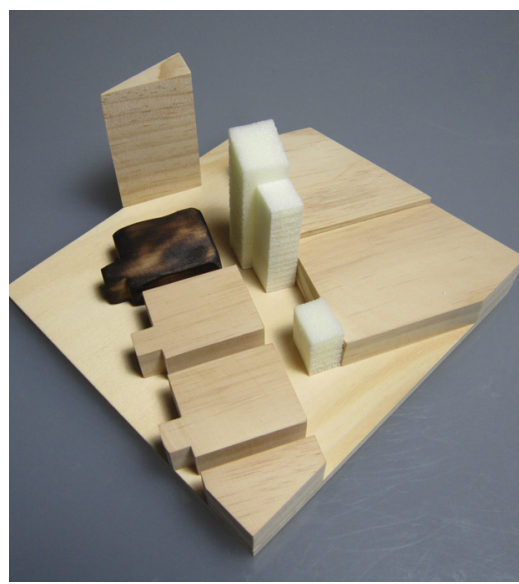

Catalyst Site 05 - Footscray Avenue

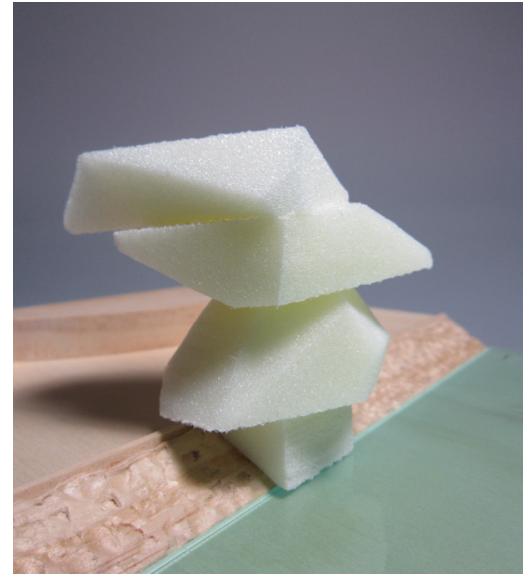

Catalyst Site 02 - Wellington Waterfront

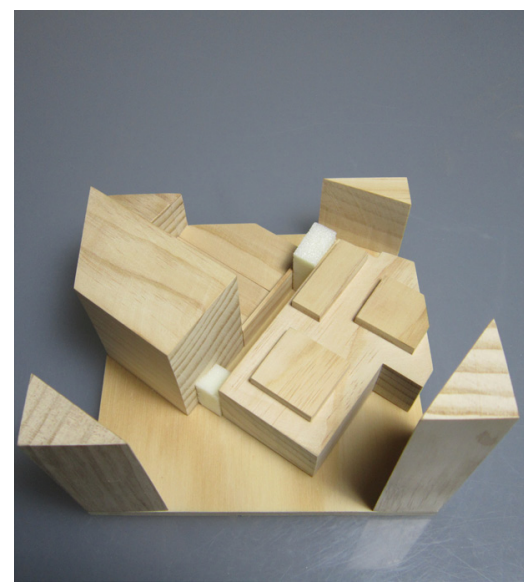

Catalyst Site 04 - Lukes Lane

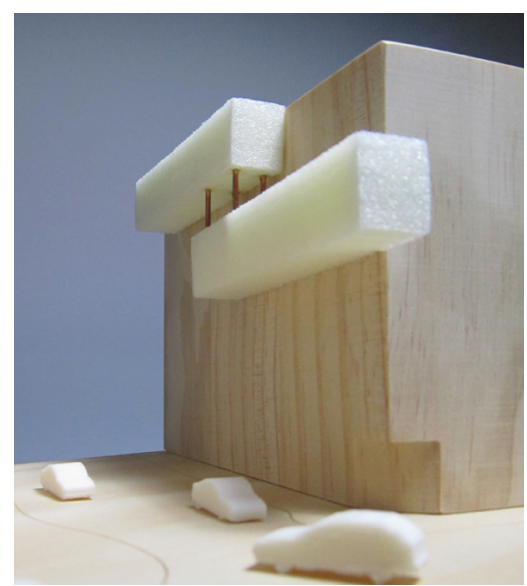

Catalyst Site 06 - Victoria Street 
05

DEVELOPED DESIGNS 


\section{Key Areas of Focus}

One of the intended outcomes of this research portfolio was to establish a list of strategies in order to make it a more viable option to design and build residual space homes in the future. In order to do that, the scope of the housing was narrowed down into five key areas of focus which will develop into strategies. The designs for each of the six catalyst sites will also be developed as a way of testing and refining the architectural strategies. 

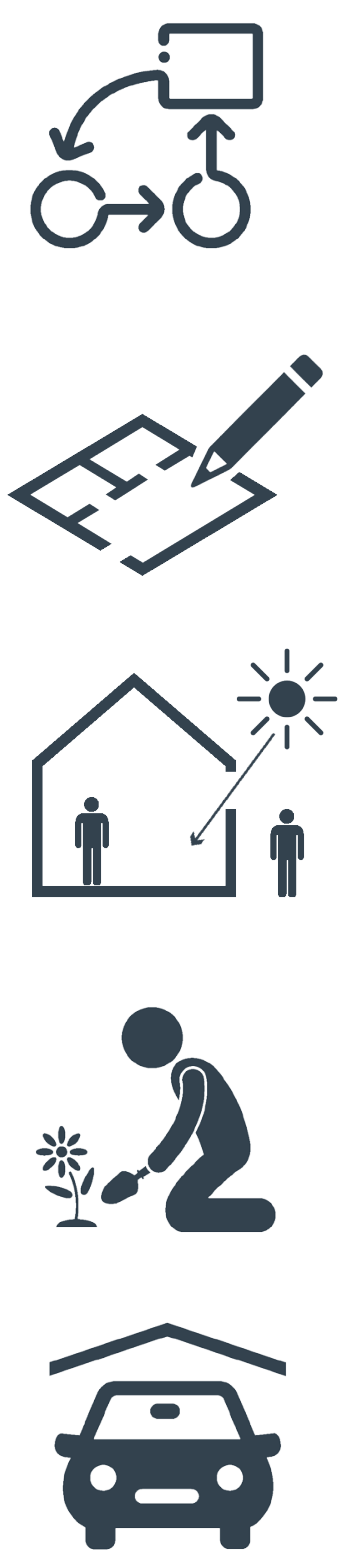

\section{Spatial Planning}

- The organisation of spaces within the home, particularly relating to the privacy threshold

\section{Flexible Living}

- The ability for the design to be adaptable to the needs of the occupant over time

\section{Lighting and Privacy}

- Methods to achieve optimal lighting in an urban setting while retaining acceptable levels of privacy for the occupant

\section{$\underline{\text { Outdoor Connection }}$}

- Methods for creating private outdoor space, designing a suburban backyard in an urban context

\section{Methods for Accommodating a Car}

- Creative and flexible parking solutions 


$$
\stackrel{\overrightarrow{0}}{0}
$$




\section{Spatial Planning}

Due to the small footprint of many residual sites, the most logical solution is to expand upwards and capitalise on vertical space; stacking floors sometimes containing one single space, linked by stairs acting as a vertical corridor linking room to room (Pollock, 2015). This is in contrast to the largely spacious, conventional horizontal layout of spaces in the suburban context, due to the possibilities offered by large section sizes. Hence, the vertical layout and positioning of spaces within the home in an urban environment becomes very important. Particularly in terms of obtaining a distinction between the social areas of the home such as the living and kitchen, and the private, quiet areas such as the bedrooms. In the context of the suburban home, the occupant generally has a considerable amount of control over the level of social interaction or privacy they desire. The horizontal spatial arrangement usually relies on the use of hallways as a separation and threshold between the social and private areas of the home. In the present architecture of the urban environment, particularly in apartments, this separation is difficult to achieve, largely due to the compact nature of apartments and poor design, especially in regards to family living.

Due to an absence of literature referencing what New Zealander's expect from their homes, a British report conducted by Ipsos MORI was referred to as a substitute. A summary of the key findings from the Ipsos MORI (2012) report on what people need and expect from their homes, relating to spatial planning is as follows:
- A large main living area for eating and socialising, either with members of the household or for entertaining guests

- Space for private, quiet time away from other members of the household

- Dedicated space for domestic utility tasks such as washing, drying and ironing clothes

A clear distinction between social and private spaces appears to be very important to people. Social spaces are required to be flexible and adaptable spaces for socialising, meals, relaxing and working (Ipsos MORI, 2012). The main living areas are expected to have a sense of spaciousness, a quality which is currently poorly designed for in the urban apartment typology. This is particularly less than ideal for family living, as urban apartments typically have insufficient space for children's play, storage and cooking family meals (Witten \& Carroll, 2011). In order to create the feeling of spaciousness in the main living areas, an open plan layout may be a good solution to accommodate for varying family requirements, as well as entertaining on a small or large scale. An open floorplan makes a small footprint feel larger, more spacious and comfortable than it truly is. This can be achieved by eliminating interior walls between the social kitchen, living and dining areas. In the case of small footprints, an open mezzanine level may be considered to provide additional space. The supplementary volume provided by a double height space can make a room feel twice the size, much more comfortable and full of light. 


\section{$\underline{\text { Required Programme }}$}
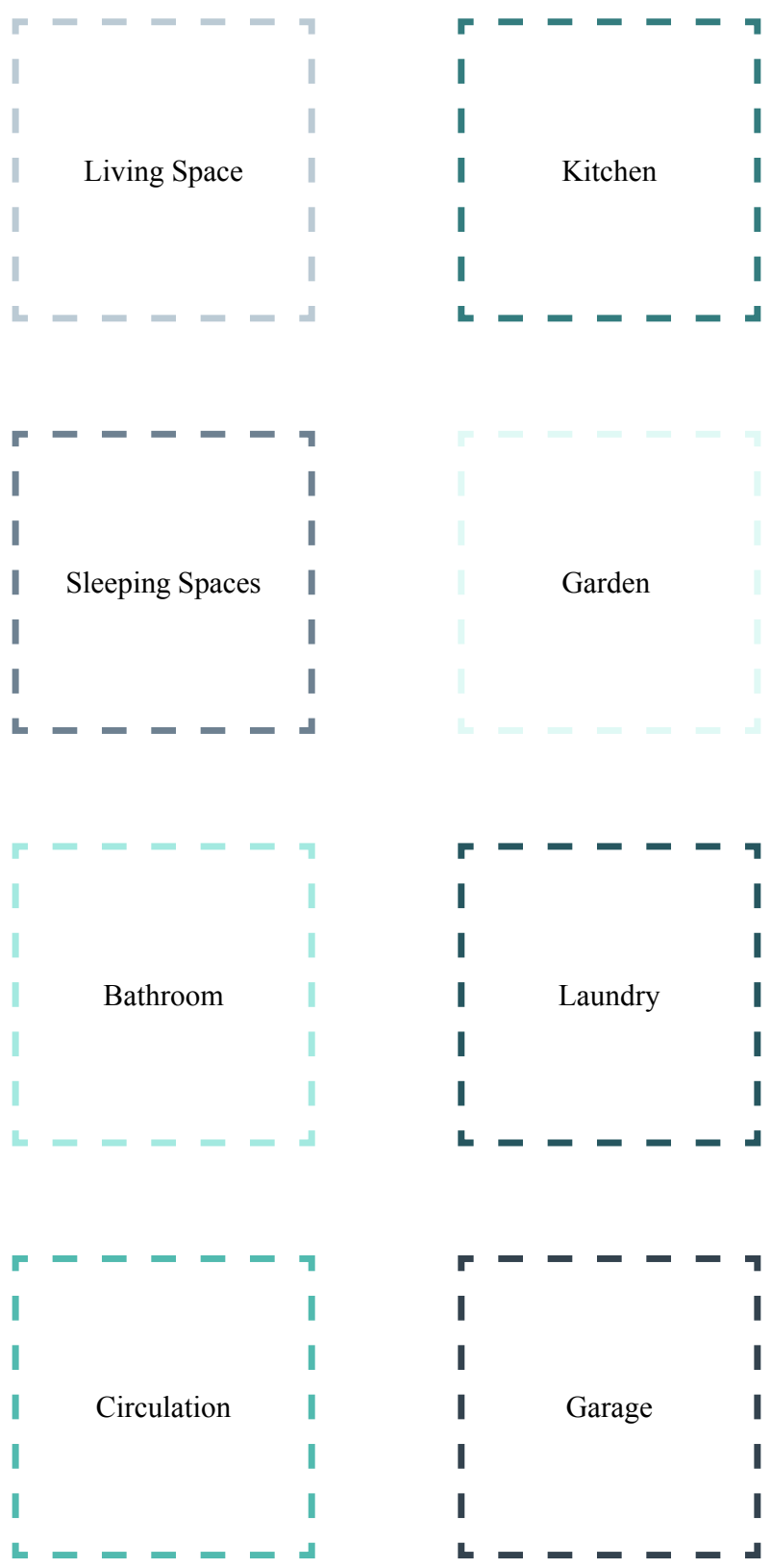

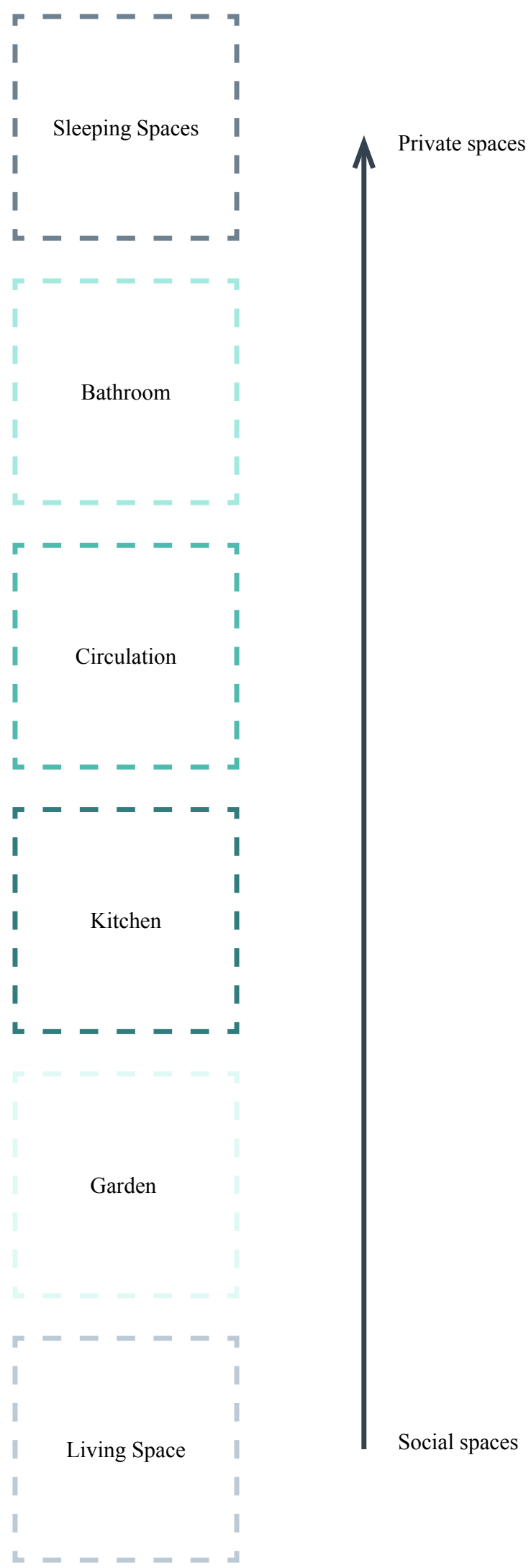


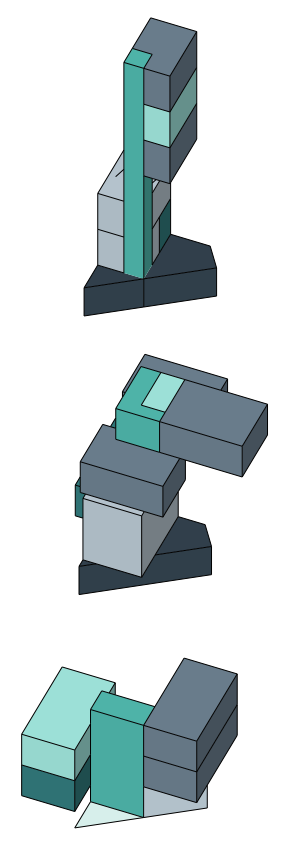

\section{Site 01}

Clifton Terrace Carpark

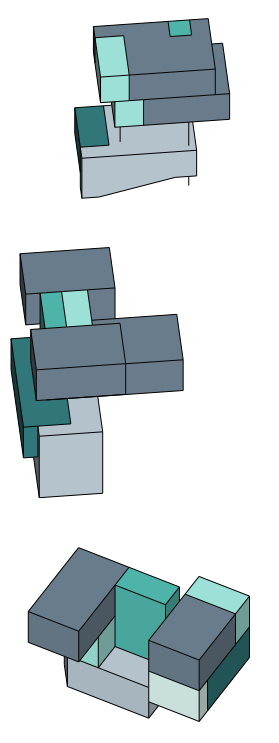

Site 02

Wellington Waterfront

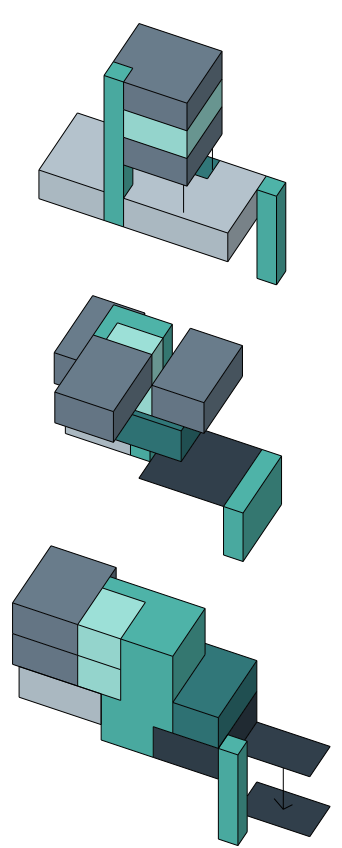

Site 03

Tory Street

\section{Iterative Study of Spatial Planning}

In order to explore the possibilities of spatial planning across the six sites, an iterative study was carried out. The key programme was tested within the sites to explore aspects such as the different relationships between spaces, particularly in terms of vertical layout and positioning, efficient adjacency planning, flexibility and visual connections. Paying particular attention to the distinction between social and private spaces. 


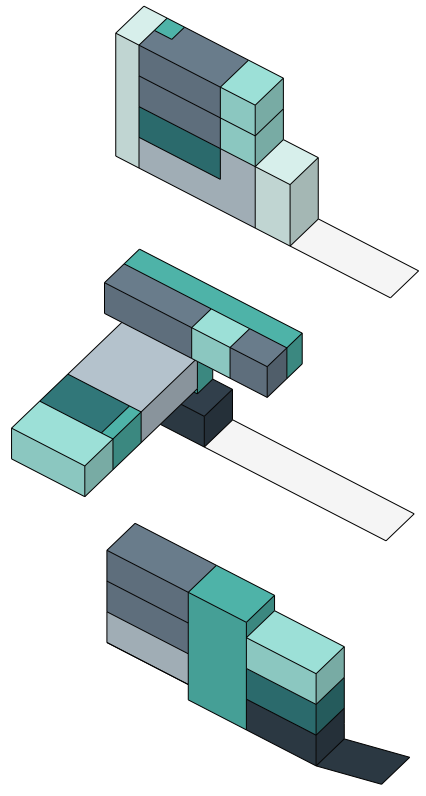

Site 04

Lukes Lane

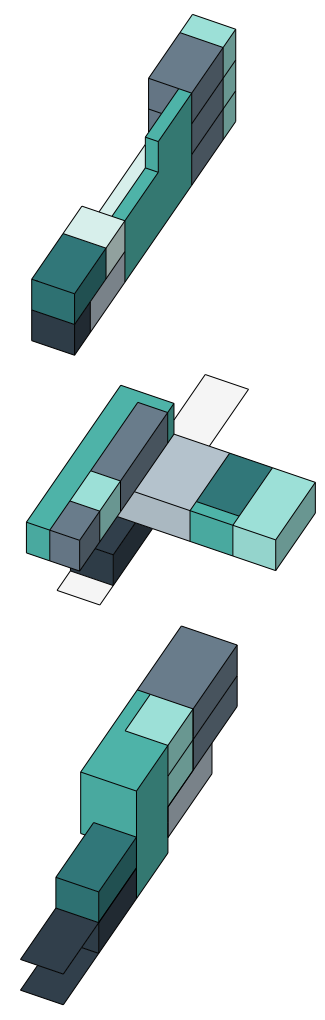

Site 05

Footscray Avenue
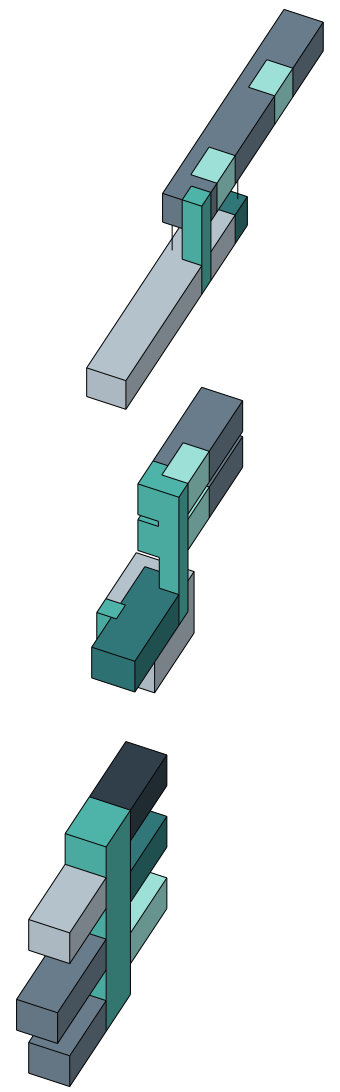

Site 06

Victoria and Willeston Street
Entry/car parking

Bathroom

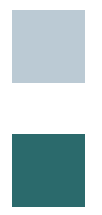

Living Space

Kitchen

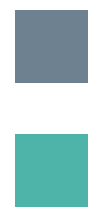

Sleeping Space

Circulation 


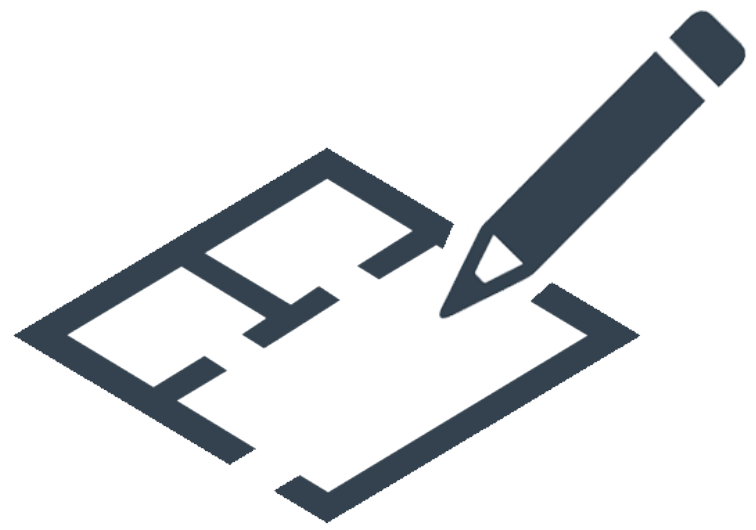




\section{Flexible Living}

In order for the housing to be adaptable to suit the varying needs and requirements of family living, as well as accommodating for the inclusion of the key suburban qualities in constrained residual space, the housing will require a degree of flexibility. Traditionally, this could mean combining different spaces or rooms within the home in order to eliminate surplus or redundant spaces. A technique often used in the design of compact housing or apartments. For small homes in particular, efficient floorplans eliminate wasted space and limit unnecessary lengthy circulation spaces through good design.
Another method to allow for flexible living is an open plan layout. By eliminating interior walls, adjacencies between spaces become more fluid and blurred, allowing for greater flexibility in space usage both now and in the future (YR Architecture + Design, 2017). This technique also allows rooms to serve more than just a singular use by blurring the programmatic boundaries that define and constrain the use of the space, allowing the occupant more creativity to adapt the space to their specific needs. In an open plan layout, furniture may function as an adaptable space divider for an alternate method of room separation (YR Architecture + Design, 2017). 


\section{$\underline{\text { Potential Space Combinations }}$}

In order to efficiently utilise space within these residual space homes, the laundry room will be integrated into the kitchen space. The laundry appliances could be concealed from view and blur into the kitchen design if required for aesthetic purposes. This strategy will eliminate an unnecessary room, and functionality wise will minimise the required plumbing by grouping the utilities together. Other spaces which may be combined as flexible space within the houses include the car parking space and the DIY area, as is common in suburban homes, as well as the garage combined with functional outdoor space, and the combination of parking, DIY and living space. Where possible, open plan spaces will also be used to allow for and invite personal adaptation and flexibility within the home as required by the needs and expectations of the occupant. 

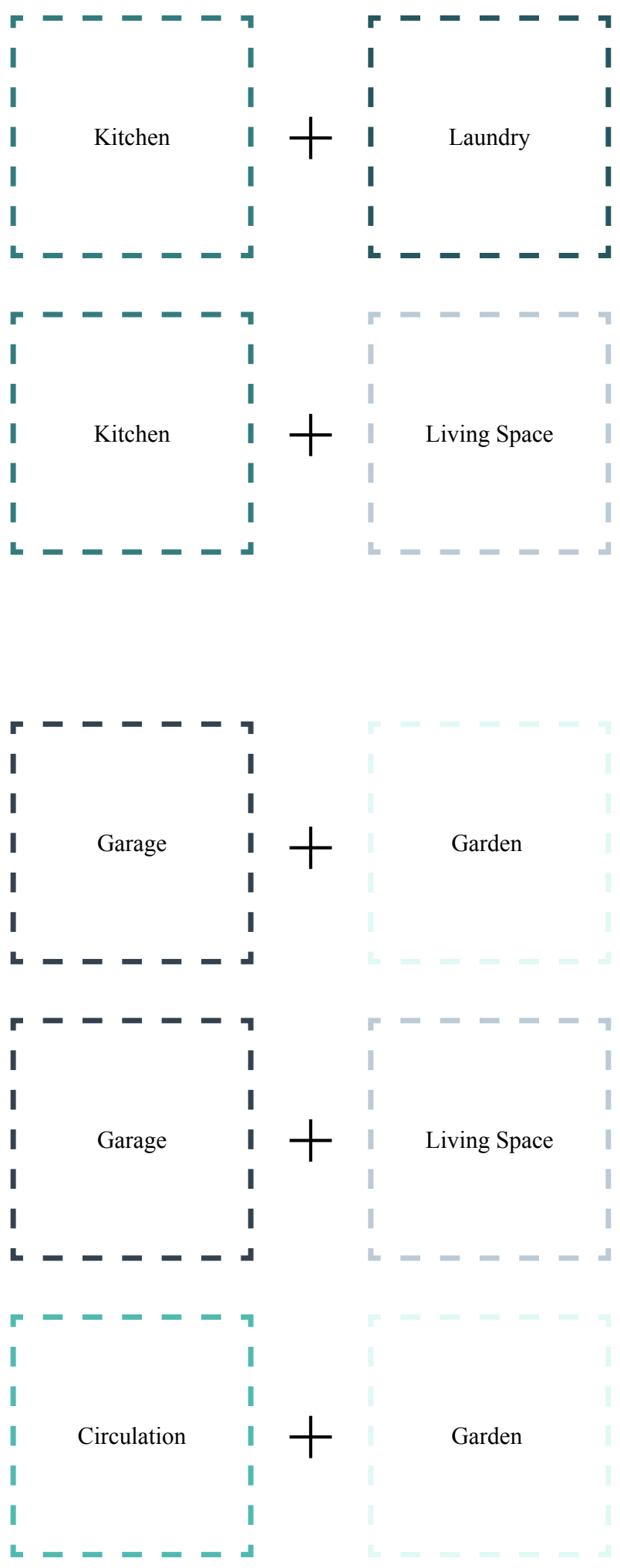


\section{$\underline{\text { Flexible Space Configurations }}$}

In order for the homes to be adaptable to the requirements of the occupant, several of the rooms in the houses are flexible spaces and these rooms are pointed out within the floorplans. These rooms are essentially empty spaces with no predefined set function, which the occupant may configure to suit their needs.

Provided are examples of some of the possible ways to configure these spaces. No structural walls are required within these rooms so separations may be provided by lightweight, temporary walls or with movable freestanding wardrobes which may provide functional separation. The room size for the following plans is based on the average dimension of the flexible space rooms across the six house designs. 


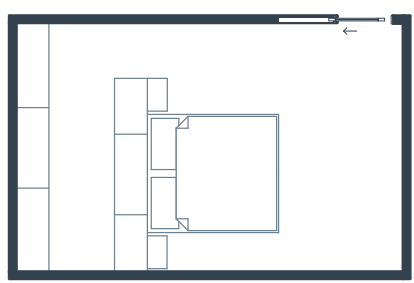

Double Bed

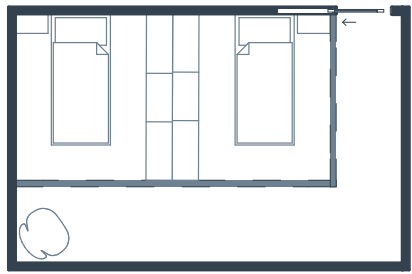

Single Bed Shared

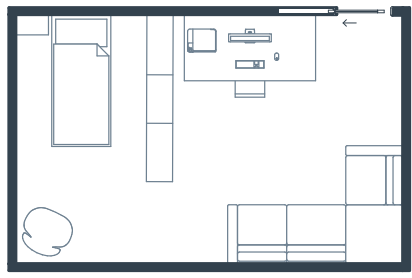

Shared Bed and Office

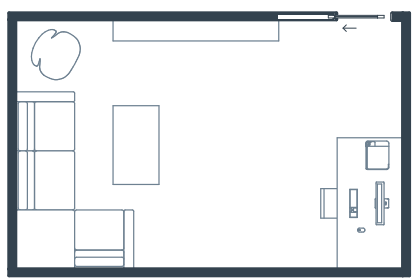

Office

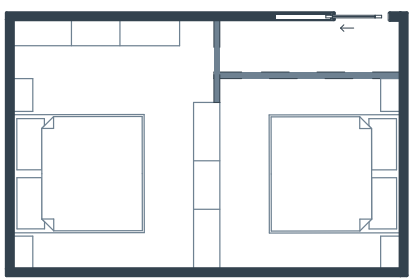

Double Bed Shared

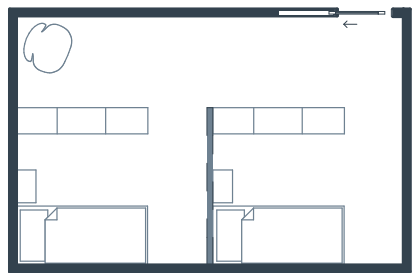

Single Bed Shared

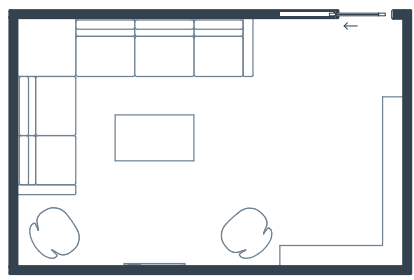

Second Private Living

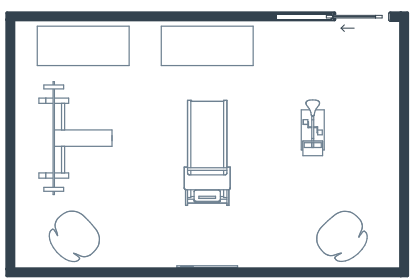

Recreation Room 


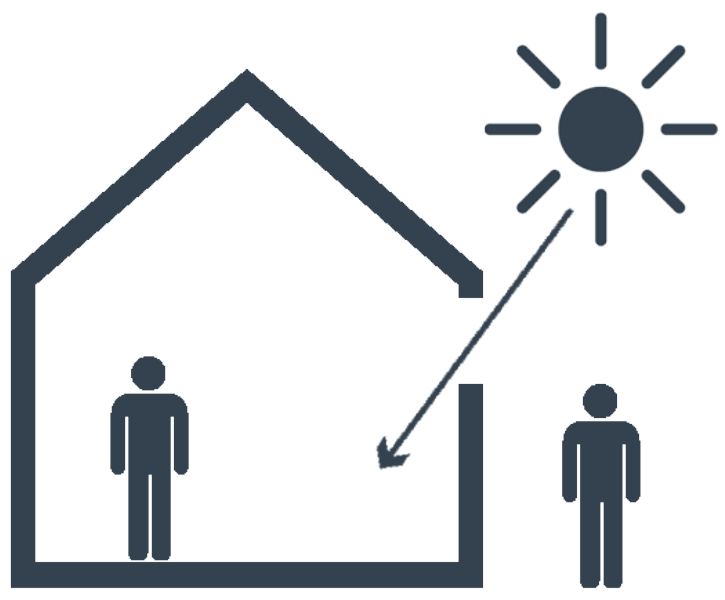




\section{Lighting and Privacy}

Light and the feeling of wellbeing related to it was a key concern for participants in a number of studies into urban living. In the Ipsos MORI (2012) study, participants felt that wellbeing was encouraged by light, airy rooms and therefore it was important to have as much light as possible within their homes. In this study, participants generally wanted large windows for natural light although they were also concerned how this would negatively impact their privacy, as they were aware in some situations windows would provide an opportunity for people outside to look in. The Witten and Carroll (2011) study produced similar findings, with parents concerned about the limited amount of natural light reaching windowless bedrooms, kitchens and bathrooms. As well as a lack of privacy in apartments where neighbouring buildings had direct sight lines onto balconies and into living areas. This research concludes that it is important to occupants that their home is well designed to receive the maximum possible amount of natural light but in an urban environment they are concerned about the impact it may have on their privacy. A strategy should be found that would allow for ample daylight with limited consequences on occupants' privacy. 


\section{$\underline{\text { Windows }}$}

Windows should be located with some thoughtfulness.

Windows located high up on a wall can still provide light and certain views while preventing direct sight lines, providing privacy for the occupants. The interior function and use of spaces should dictate window placement rather than exterior appearance. Thin horizontal windows located at eye level in certain locations such as over the kitchen sink or above a breakfast bar, allow for an exterior outlook in locations where an occupant will be paused to appreciate it, while the height of the window should prevent direct sightlines into the interior. In terms of privacy, skylights can also offer a suitable option to achieve daylight and ventilation. Within the interior, spaces with natural light feel more spacious and inviting. Open plan layouts and adding translucent panels to doors may allow the natural light to disperse more evenly throughout. 

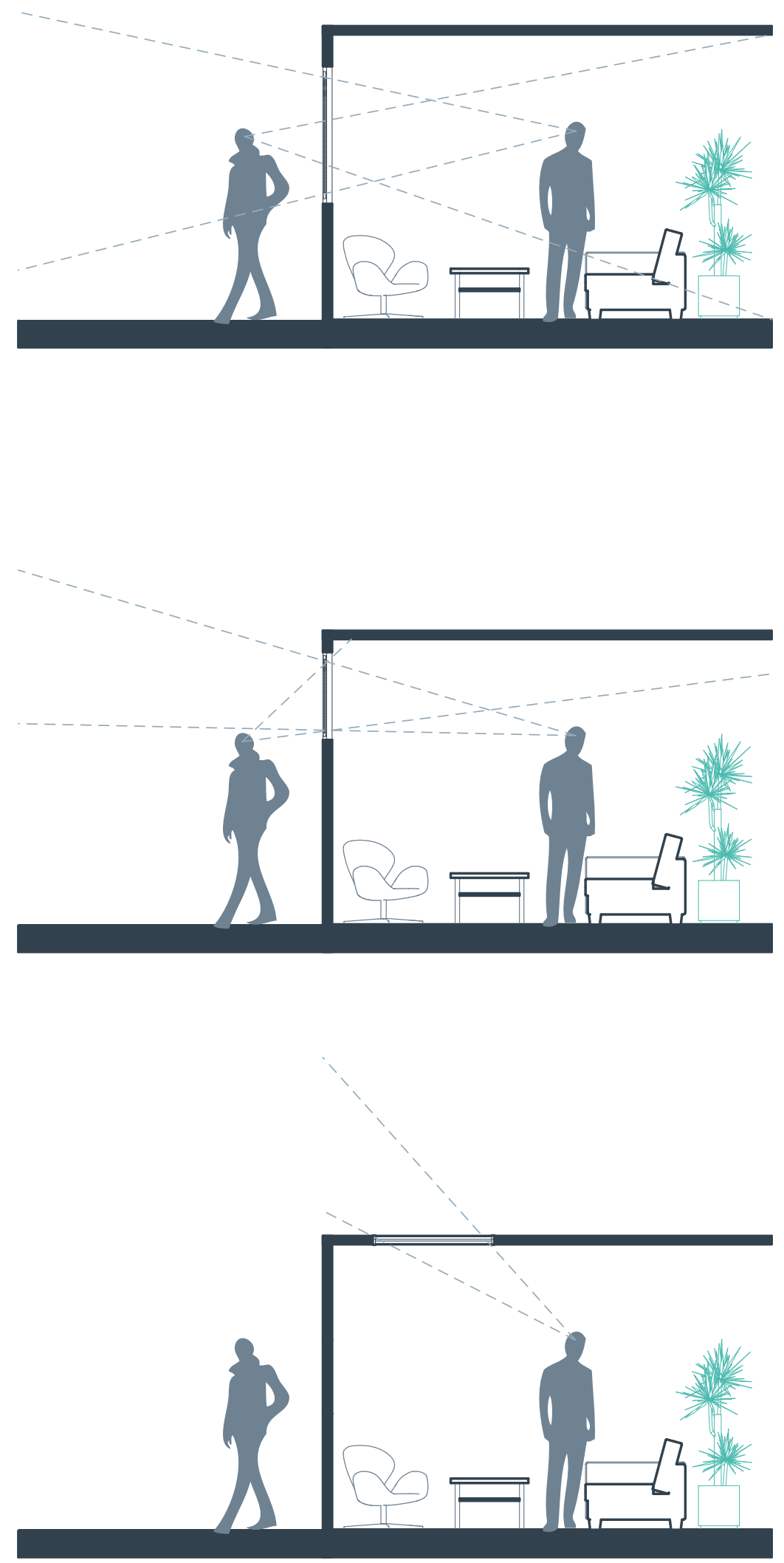

Fig 5.10 The effect of window height on privacy 


\section{$\underline{\text { Polycarbonate }}$}

Polycarbonate is becoming increasingly popular within architecture, due to the both the unique aesthetic qualities and excellent functionality of the product. Polycarbonate is a high performing thermoplastic that is lightweight, strong, durable, provides thermal insulation and allows for light diffusion. The use of polycarbonate has been explored in the built environment for many years and it has been utilised for both a range of commercial and residential projects.

A major advantage of incorporating polycarbonate into architecture is the benefits it provides in terms of light and privacy. Polycarbonate may be used as an alternative to glass in a variety of situations for daylighting. It allows a maximum amount of diffused natural light to enter a space without compromising on the occupants' privacy. This adds to the unique aesthetic qualities offered by the use of polycarbonate, as the building acts permeable by day and then glows from within at night like a beacon brightening up the surroundings, all while maintaining the privacy and security of the occupant within. The polycarbonate allows light from the sun into the building but filters out the glare and harmful UV rays, making it an ideal choice for architectural daylighting (Schwartz, 2014).

As well as allowing daylight into the building, polycarbonate can also provide insulation. Polycarbonate panels improve thermal efficiency by capturing solar energy and transferring it indoors. Polycarbonate delivers a significantly higher insulation value in comparison to double glazed glass (Extech, 2017). It can also be treated to provide protection from infrared radiation to prevent the interior of the building from overheating and reducing the need for cooling during summer months.

Polycarbonate sheets are a useful alternative to glass, as they are nearly unbreakable and able to withstand massive force. The product has a long history in applications where resistance to impact and vandalism was a critical performance feature (Schwartz, 2014). Despite being incredibly strong, the panels are also incredibly lightweight in comparison to glass and other plastics (Bonenfant, n.d.). This is extremely beneficial when considering transportation costs and ease of installation. Additionally, polycarbonate is incredibly durable, even in harsh conditions, and can last outdoors for many years without showing signs of fading or discolouration (Schwartz, 2014).

The House in Tousuien by Suppose Design Office, provides an effective example of the use of polycarbonate walls to maximise natural light without compromising on privacy (Fig 5.11, 5.12, 5.13). The polycarbonate creates a warm, airy, bright quality of light that is evenly dispersed throughout the interior spaces.

In conclusion, polycarbonate offers a desirable, functional alternative to glazing for the purposes of optimal daylight and privacy. This is particularly relevant for the urban environment, where the density of the city means achieving satisfactory levels of daylight within a building, while allowing the occupant optimal privacy, is difficult to achieve. 
Fig 5.11 (Top) House in Tousuien interior

Fig 5.12 (Left) House in Tousuien exterior day

Fig 5.13 (Right) House in Tousuien exterior night 


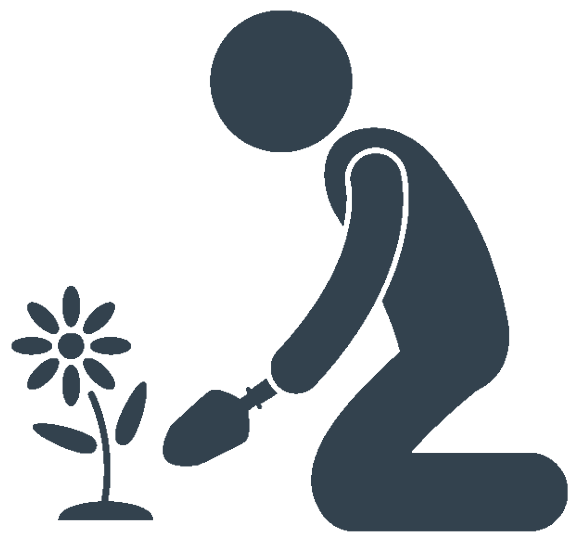




\section{Outdoor Connection}

In a study carried out on New Zealand families currently living in inner city medium and high rise apartment blocks it was found, "A lack of outdoor space, especially safe places for children to play, was seen as a major drawback" (Carroll, Witten \& Kearns, 2011, p.361). In the same study, all of the participants involved considered a backyard to be part of the 'ideal' family environment, and the lack of private outdoor space was the major reason they would eventually move from their apartments. However, "In situations where there were outdoor play areas for children, these were greatly appreciated by parents, even if their children needed supervision" (Carroll, Witten \& Kearns, 2011, p.361). Eight of the ten households included in this study wanted one day to move into a house with a backyard, in order to do things such as grow vegetables.
The garden is a vital aspect of suburban living, as suburban homes are focused around the garden outlook and outdoor living. Outdoor living is an important extension of the main social and living space of the home and is one of the best ways to gain a feeling of space in a small home, blurring the interior and exterior with habitable spaces (YR Architecture + Design, 2017). This housing aims to retain the qualities of the suburban outlook and the 'ideal' backyard in a compact urban setting. 

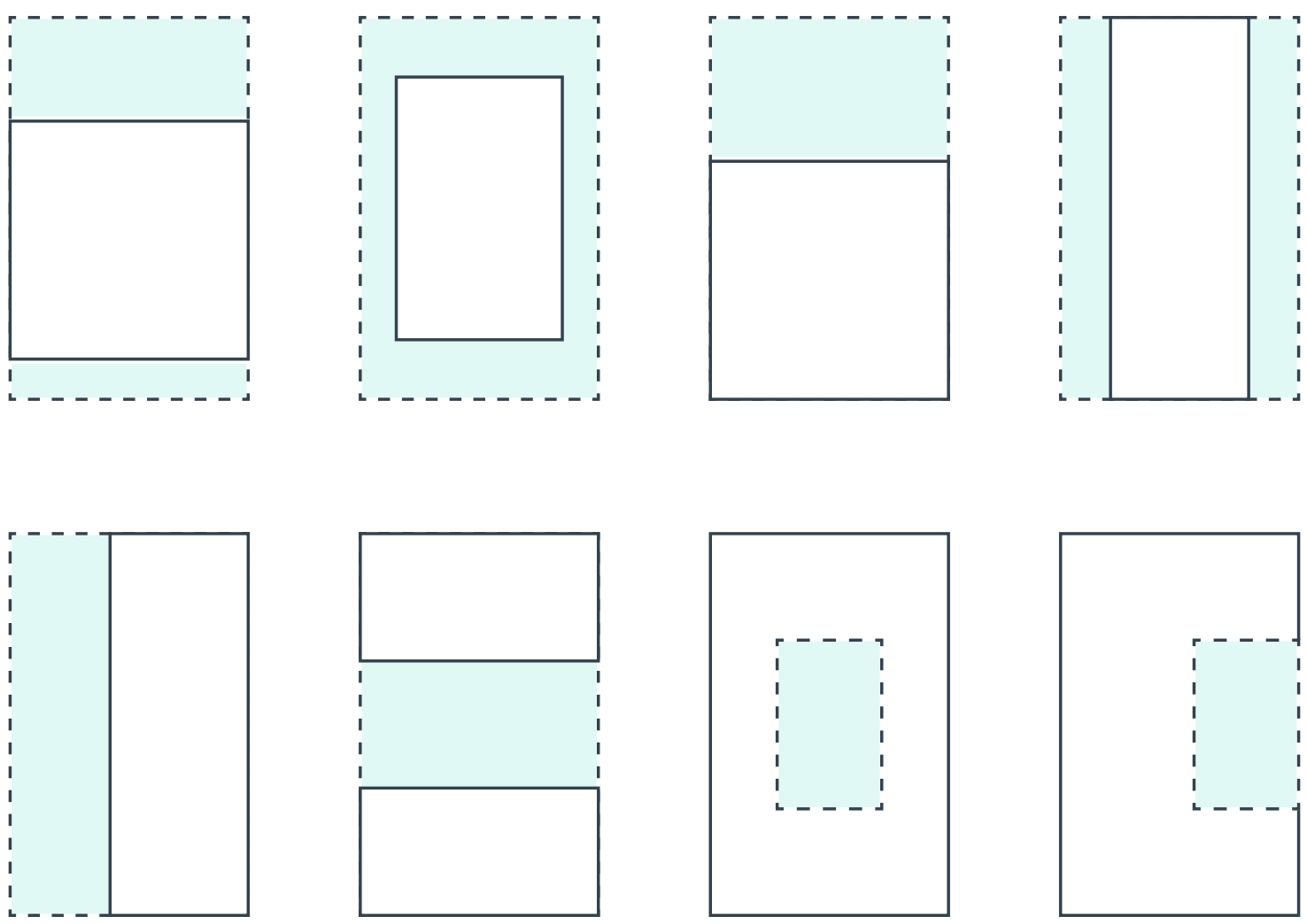

\section{Private Outdoor Space}

Each dwelling should accommodate for private outdoor space. This may be in the form of courtyards, rooftop terraces or enlarged balconies. The space should be suitable for children's play, entertaining, and relaxation and should include space for a clothesline. The space may also be adapted for DIY purposes. To make living areas feel more spacious, where possible the space should join onto garden areas to create indoor-outdoor flow. In areas where outdoor gardens cannot be viewed from the living or kitchen areas, indoor planting may be incorporated. As suburban housing is focused around the garden, where this is difficult to achieve on some urban sites it is still compensated for. 

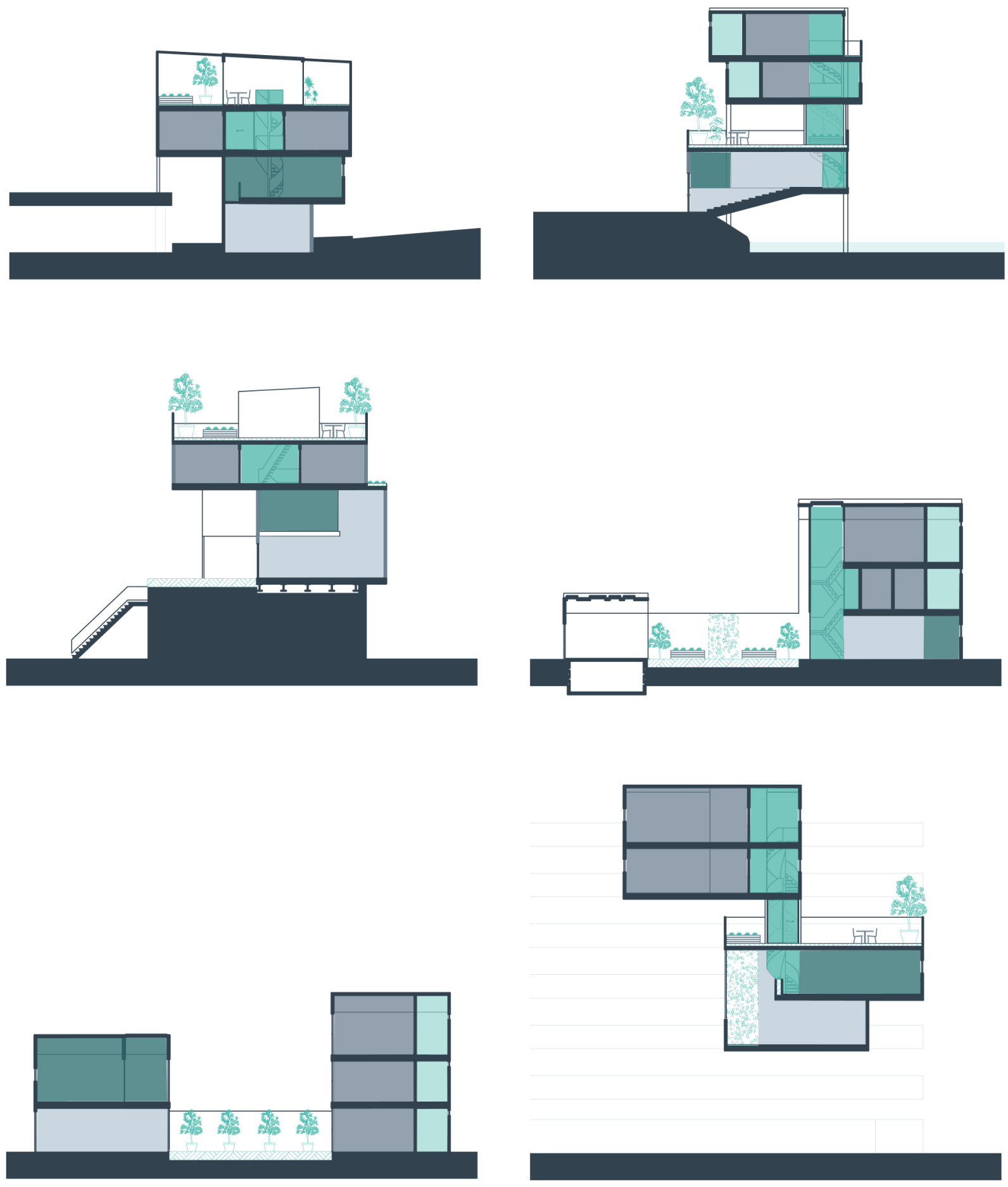


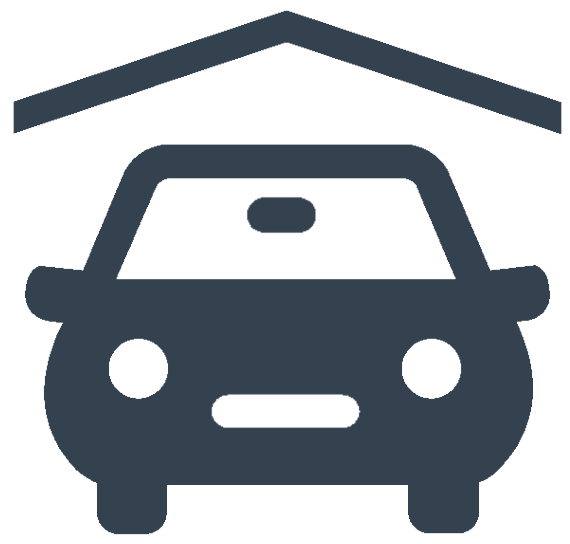




\section{Methods for Accommodating a Car}

In the study carried out by Carroll, Witten and Kearns (2011) on New Zealand families currently living in medium and high rise apartment blocks, all participants commented on problems of limited and expensive parking. More car parking was a frequent suggestion. Those with family or friends outside of the city area often drove out of the city to spend their weekend time with them. At this point in time the car still remains an essential part of everyday life or a valued possession which symbolises a degree of freedom and independence for many people. Therefore, the car has been accommodated within the designs of the houses.

In the suburban context, the garage is the fundamental solution to car parking and the garage is often a focal point of a home. This is in some part due to the archetypal positioning of the garage at the front of the house. In New Zealand culture, the garage is a multifunctional space. Aside from car parking, the garage often serves other purposes such as an additional storage space, workshop or DIY area, a social space, gym, home office or additional sleeping space.
It is very likely that at some point in the, possibly near, future personal cars will become obsolete, as services such as ride sharing become more popular and improvements are made to public transport systems. To allow for this very real possibility, it is important that the car parking solution for each house is designed in a way that either allows the space to be multi functional, so it is a useable space whether accommodating for a car or not. Or, where the site is unable to accommodate internal parking, the parking is designed as part of the buildings exterior. Therefore, there is no negative impact on the usable space within the house whether required for parking or not and the space could perhaps be adapted to store other objects or forms of transportation. The solutions should, as much as possible, avoid swapping habitable space for car storage. In some cases this may have an impact on the exterior appearance of the home. 


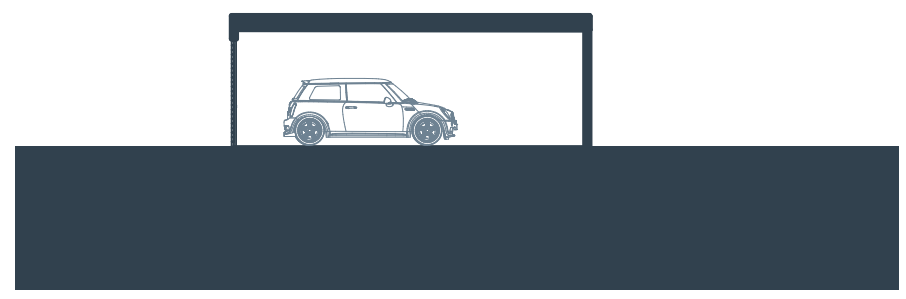

Traditional Garage

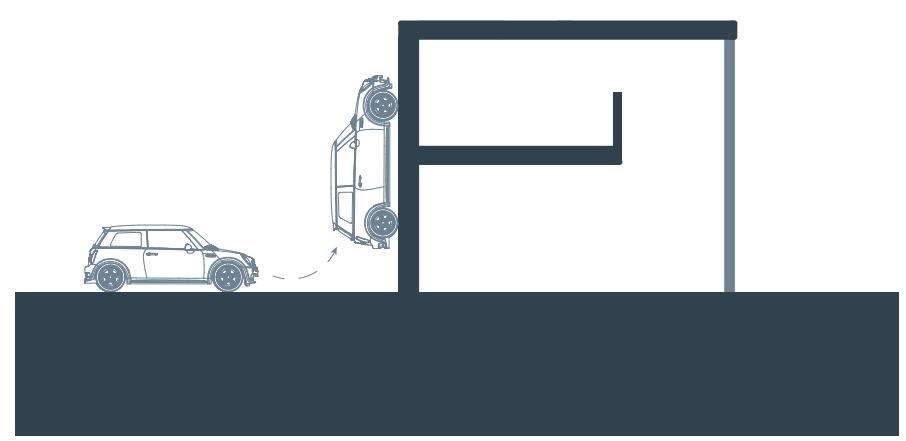

Vertical Exterior Storage

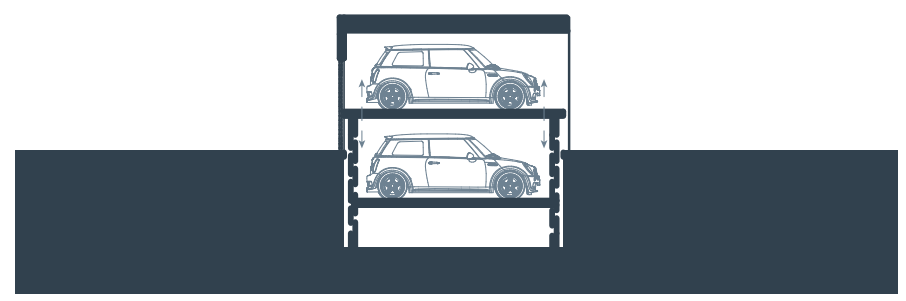

Underground Lift/Vehicle Stacking 


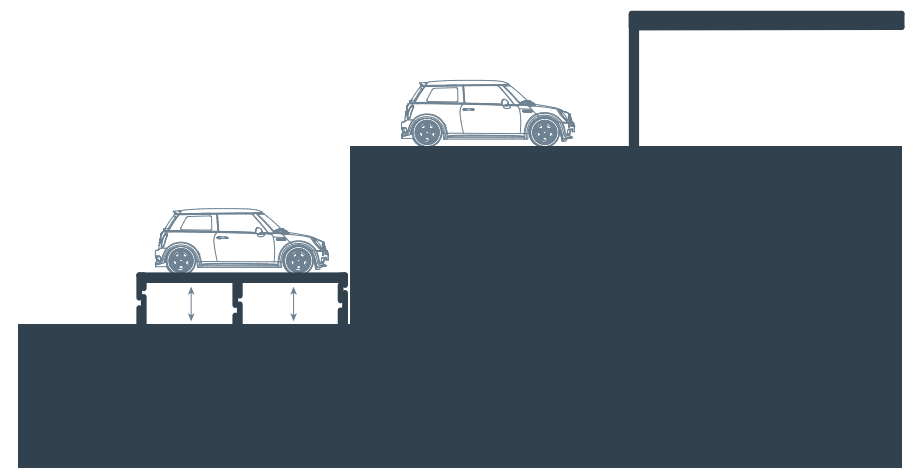

Vehicle Lift

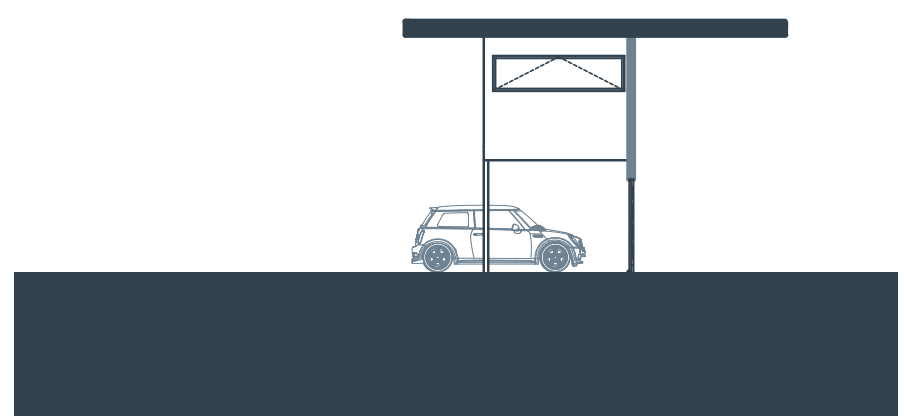

Exterior Sheltered

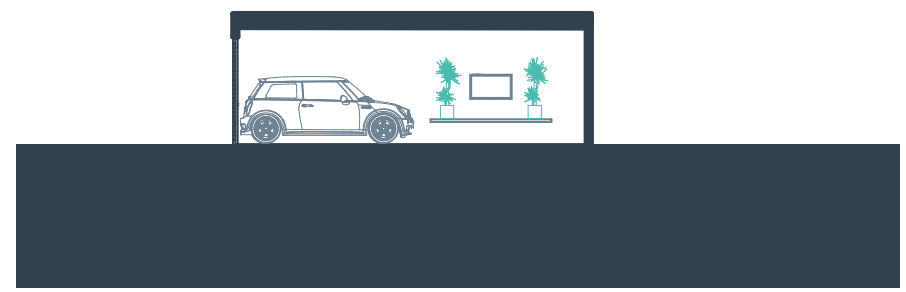

Flexible Garage/Living Space 

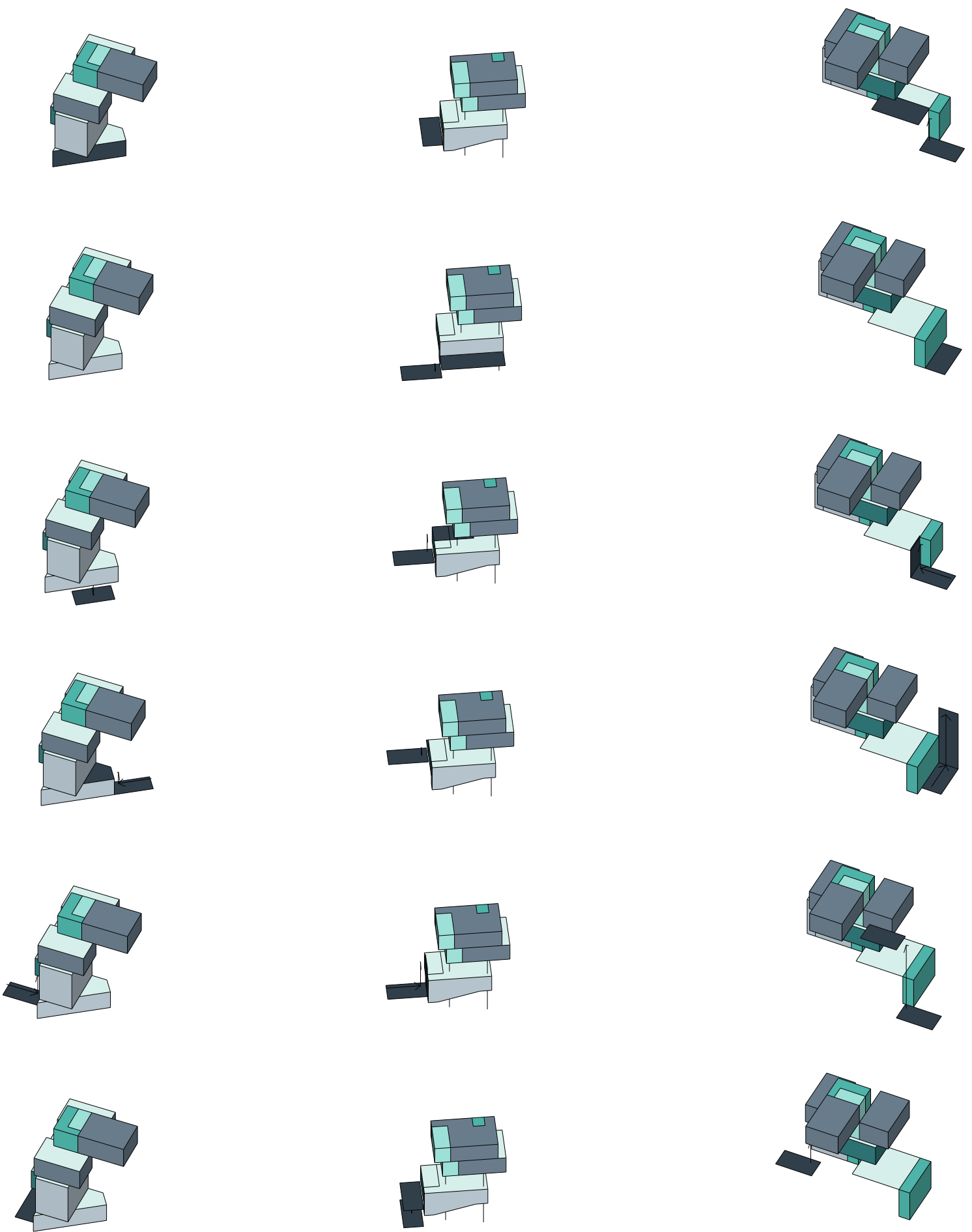

Site 01

Clifton Terrace Carpark

\section{Site 02}

Wellington Waterfront
Site 03

Tory Street 

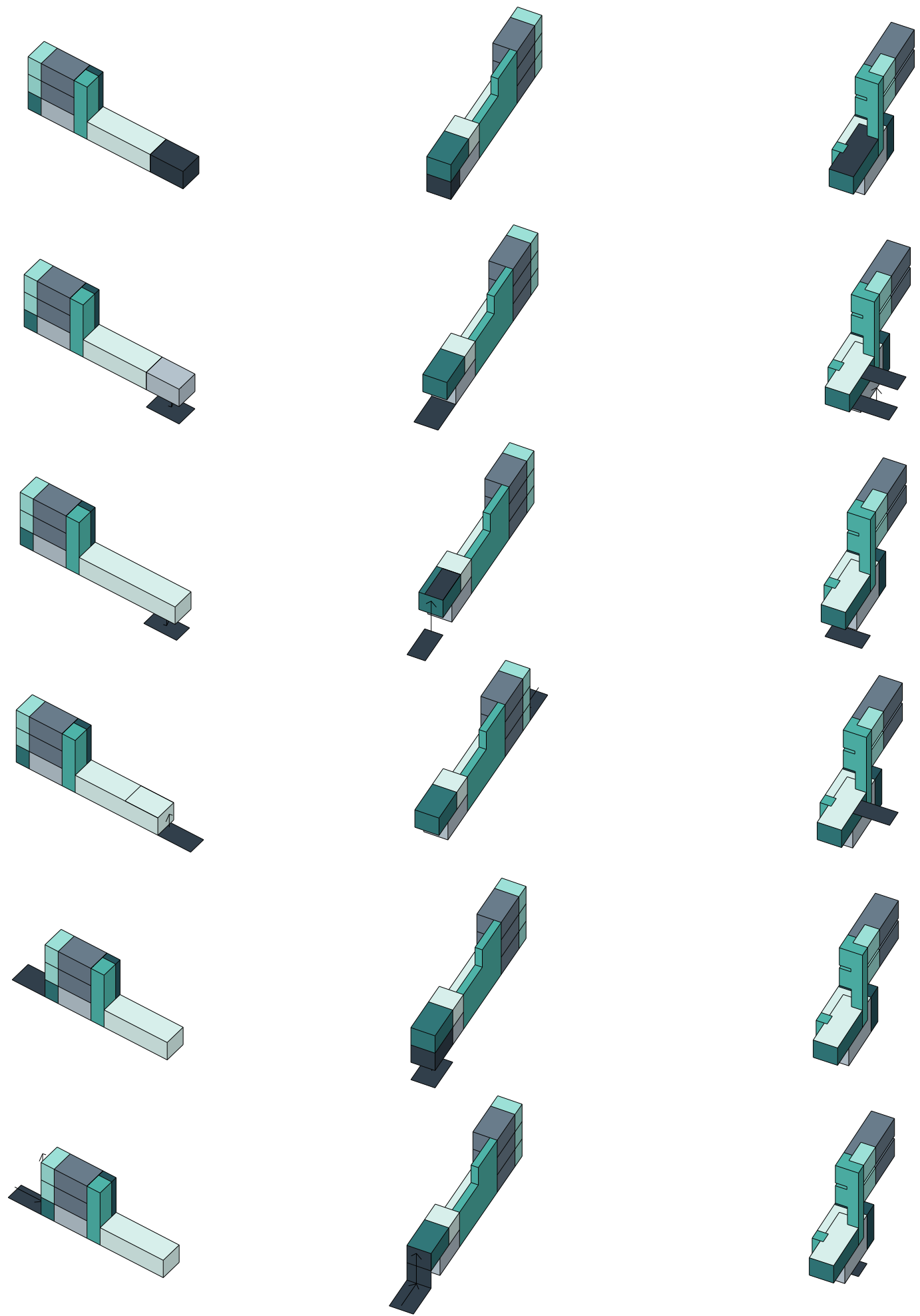

Site 04

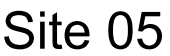

Lukes Lane

Site 06

Victoria and Willeston Street 


\section{6}

FINAL DESIGNS 
FINAL DESIGN

Catalyst Site
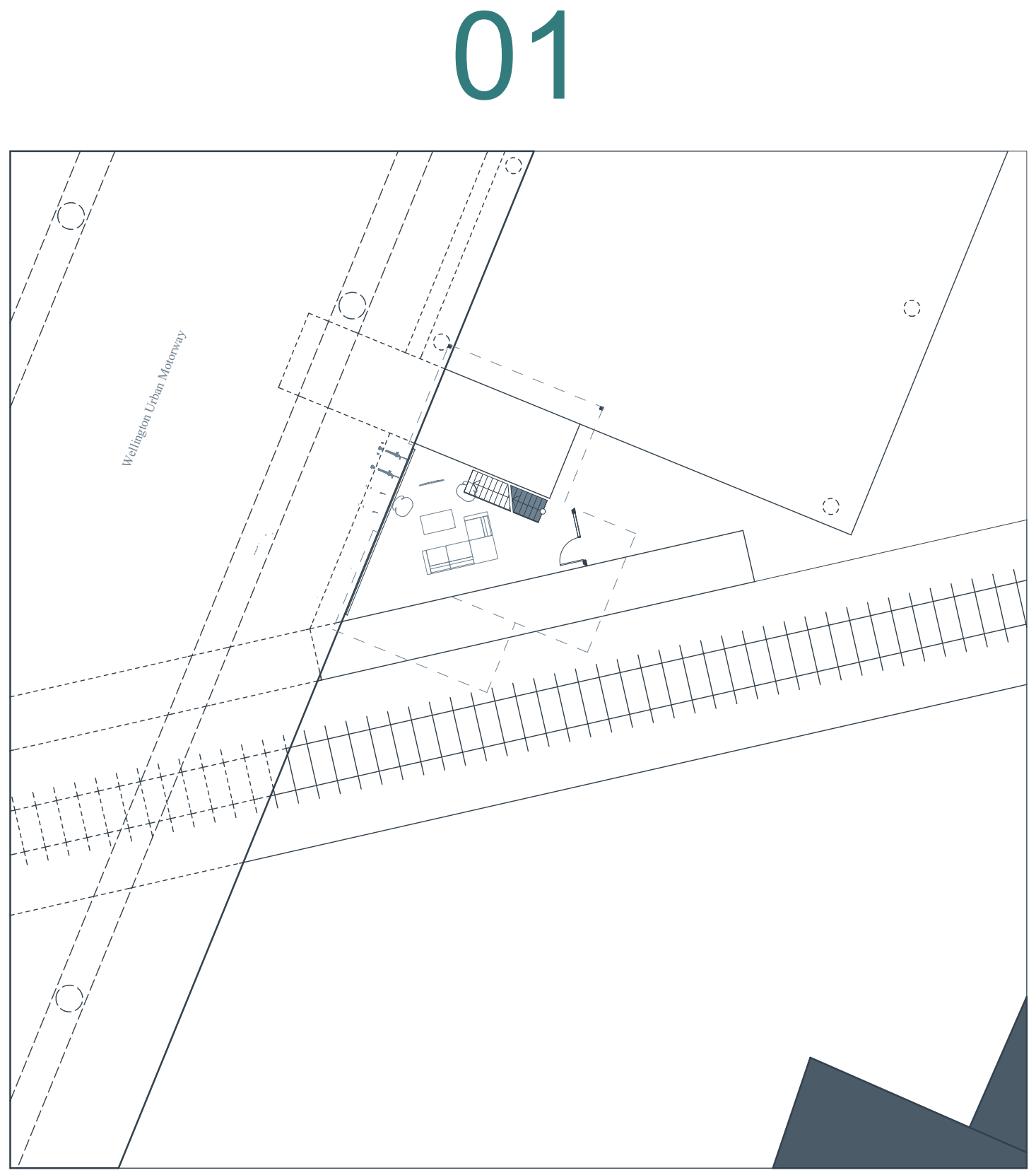


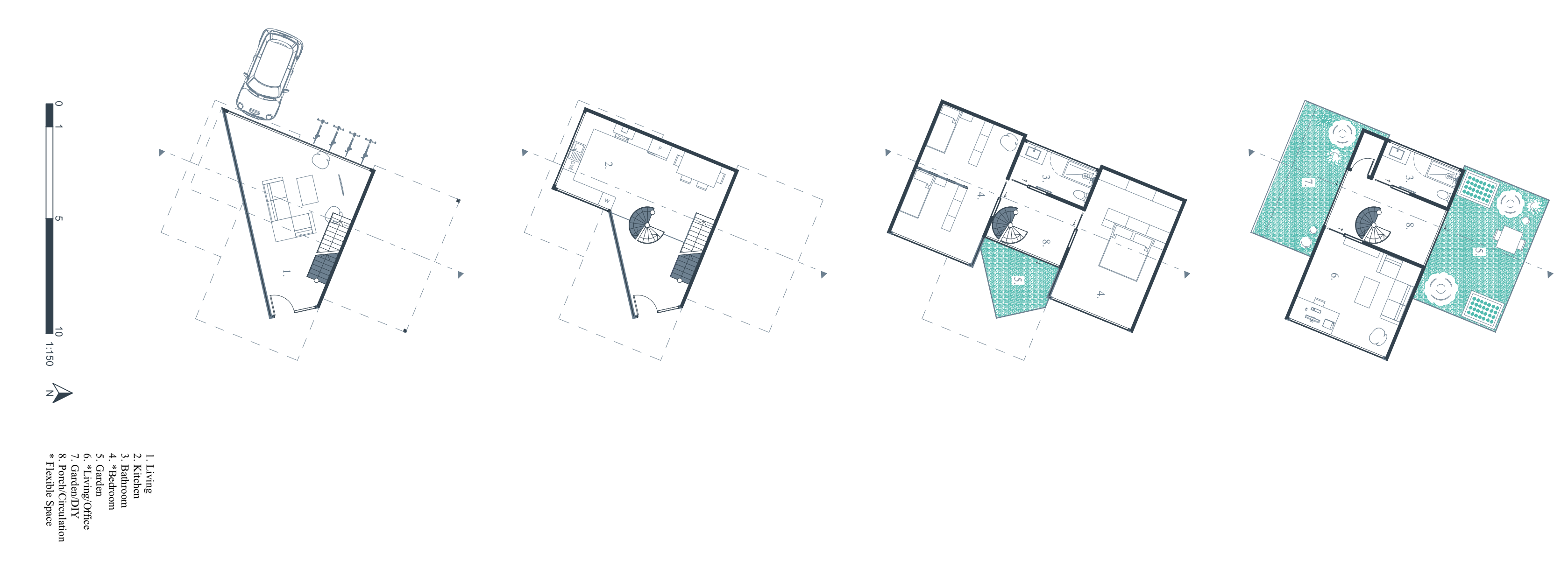


Spatially the house is arranged with the public, social spaces taking up the lower levels and the quiet, private spaces on the upper levels. Creating a vertical progression between the most social space to the most private space. Establishing a vertical interpretation of the horizontal suburban spatial hierarchy. The form of the house is a reaction to the different levels, edges and slopes surrounding the site.

Polycarbonate is applied to a number of the exterior walls as a way of softening the hard concrete surroundings. The polycarbonate combined with strategically placed windows to capture views, allows for natural light to fill the home without impacting on privacy.

The compact, ground floor living space is open plan to create a feeling of spaciousness and accommodate for varying family requirements. The living space is open to the mezzanine kitchen level above, producing a double height space. This extra volume contributes to making the room feel larger, lighter and more comfortable

Outdoor space is incorporated into this home through enclosed roof terraces. For privacy from the motorway overhead, the garden spaces are enclosed with mesh panelling which is designed to imitate suburban boundary planting. The mesh filters light through into the garden spaces while also providing privacy. Circulation space between the two terraces also functions as a covered porch space, which can be opened up on either side, connecting the two gardens by creating indoor-outdoor flow. With the inclusion of a fold down bench, this outdoor space may also be used as a space for DIY and there is also considerable space available for a clothesline.

An experimental, vertical solution for car parking is used for this house. This involves hanging the car from the back wall of the house using a car lift. The car will be hung alongside vertical bicycle storage racks.

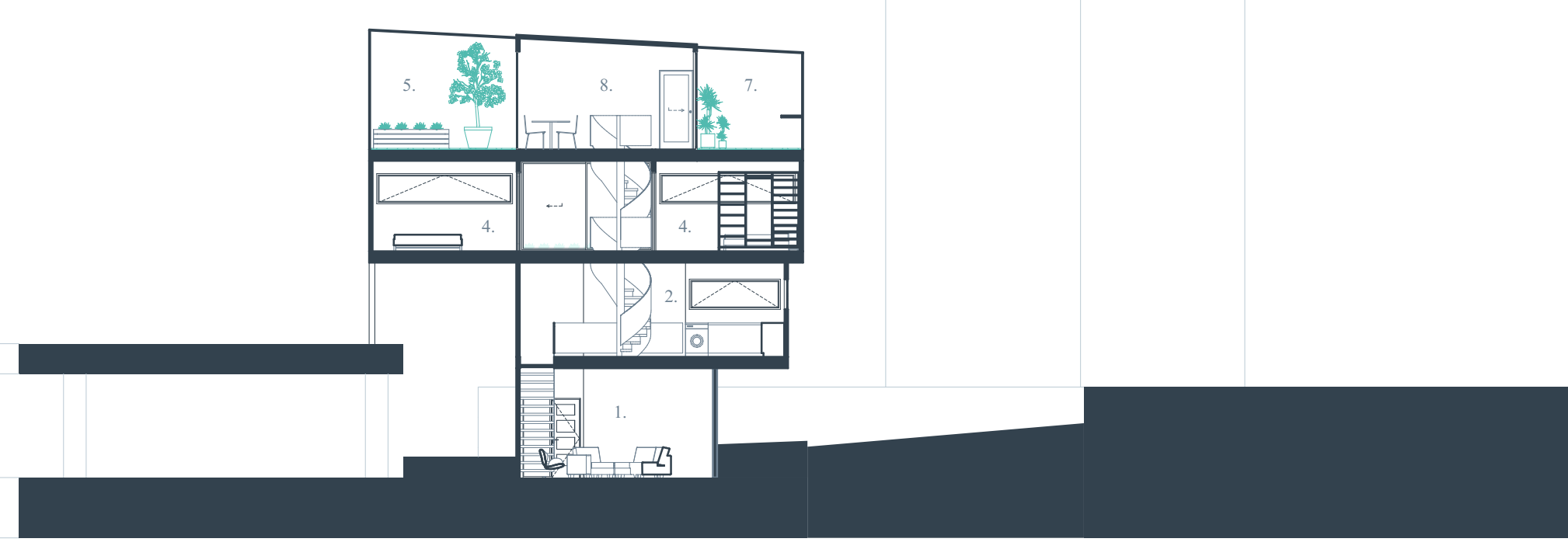



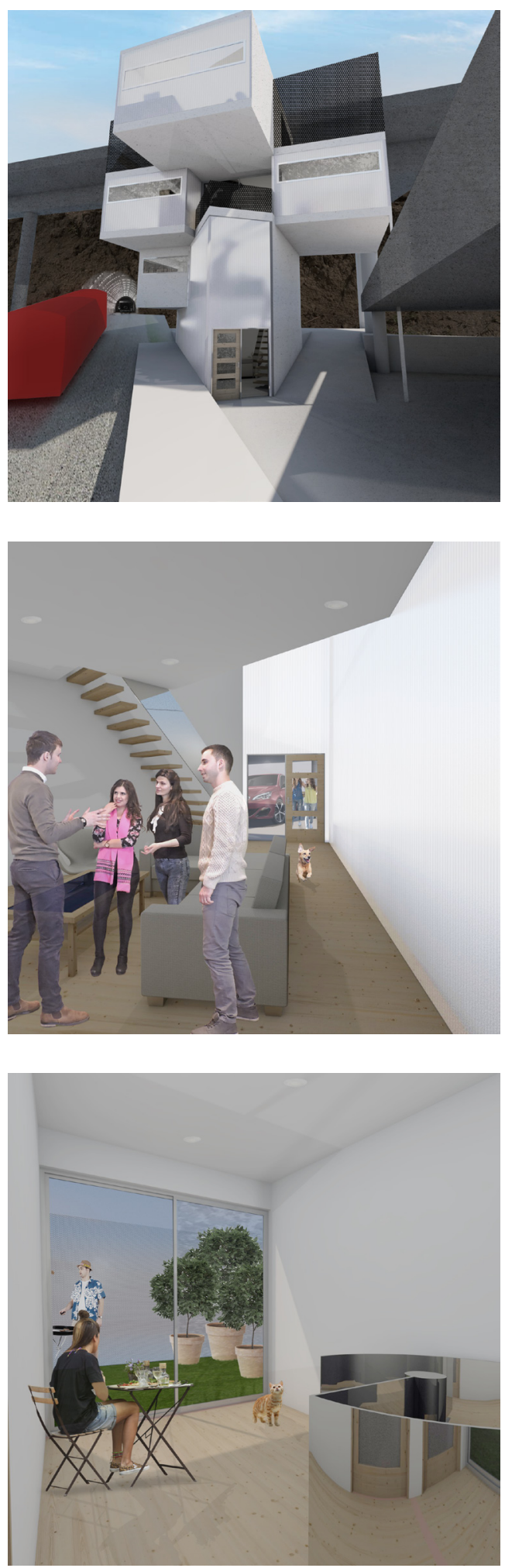

Fig 6.03 (Opposite) Clifton Terrace section

Fig 6.04 (Above top) Exterior render

Fig 6.05 (Above middle) Living space render

Fig 6.06 (Above bottom) Outdoor connection render 


\section{FINAL DESIGN}

\section{Catalyst Site}
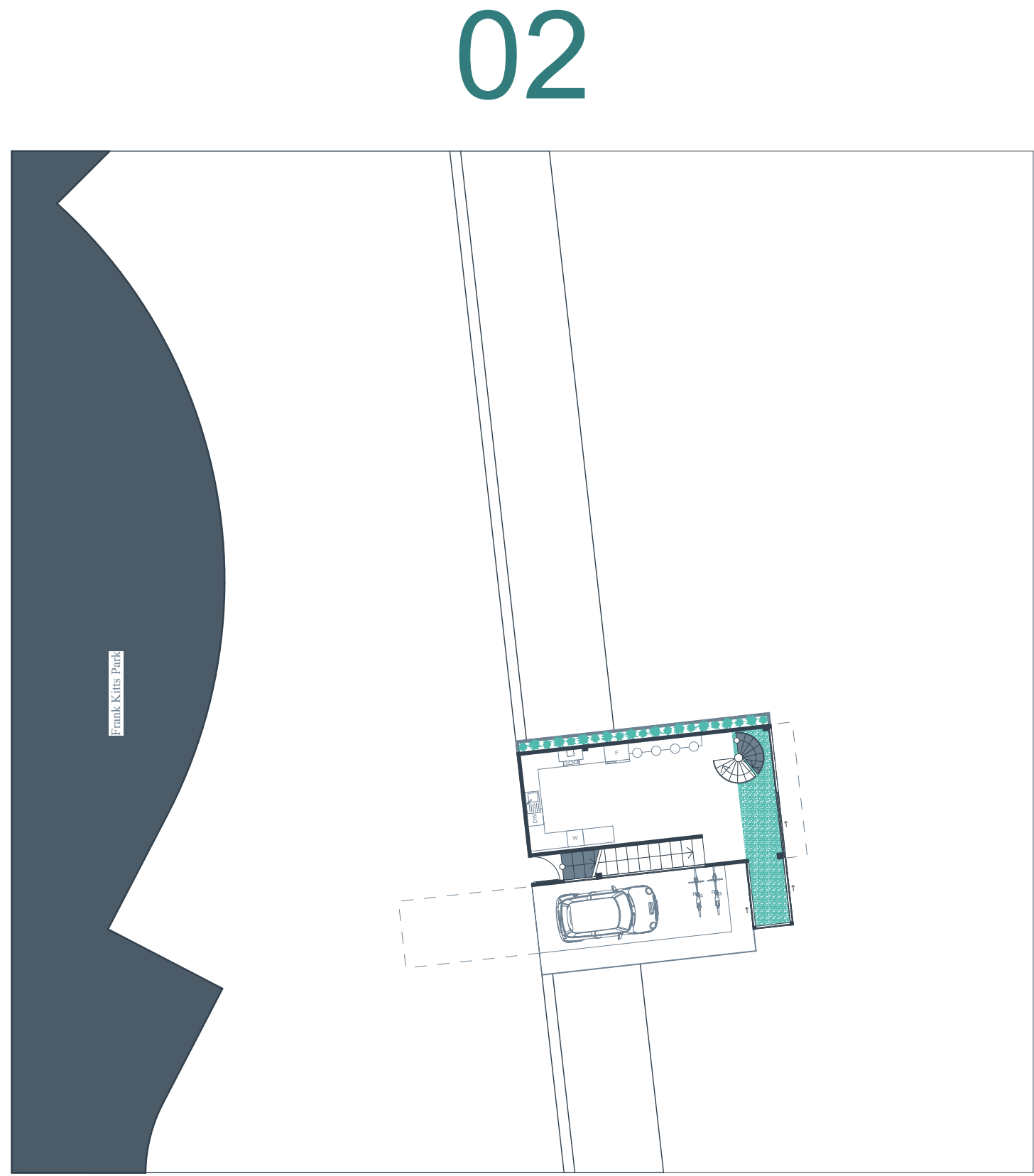

Fig 6.07 (Above) Wellington Waterfront site plan 

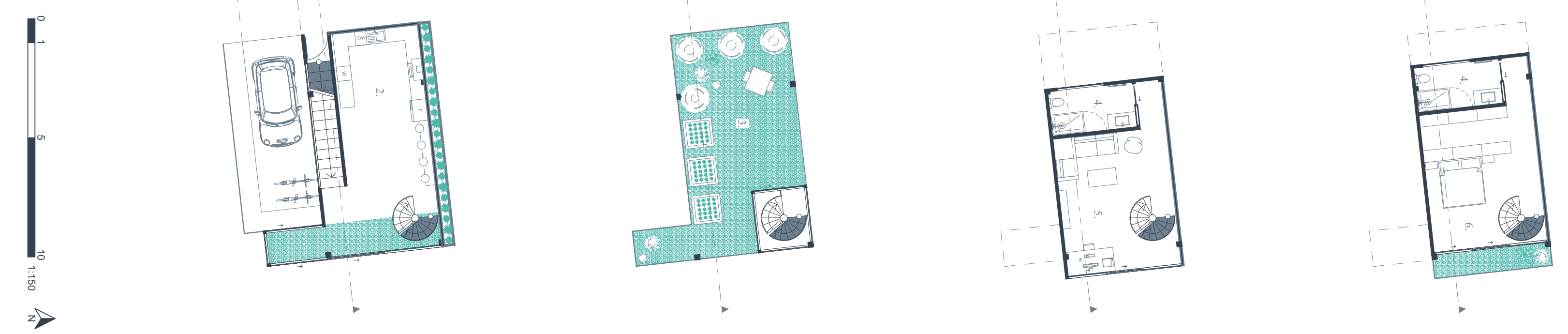

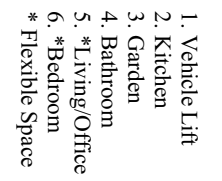


Spatially this house is also arranged with the public, social spaces taking up the lower levels and the quiet, private spaces on the upper levels. For this home, the outdoor terrace provides a distinct spatial separation between the public and private areas of the home. This separation was designed to break up the solid mass of the house and provide the impression of sight lines continuing through the gap in the form. Lessening the effect the building has on blocking the view of the waterfront from the surrounding public space.

Polycarbonate is required for privacy on the three sides of the home viewable from the land side of the site, due to the busy surrounding public space. Large, full height sliding doors allow the side of the house facing the privacy of the water to be opened up for ventilation and this results in a blurring effect between inside and outside.

The living area and outdoor area are both open plan and highly flexible to the requirements of the occupant. Mesh balustrades offer a degree of privacy around the perimeter of the outdoor space while still allowing light to filter through. To achieve additional privacy, movable planting can be shifted around the space as necessary to increase the level of protection.

Car parking and bicycle storage is provided at the side of the house and is accessible off of the living area. As this space is slightly raised from ground level access is provided by a small vehicle lift. This space can also be used for DIY or as an additional outdoor area.

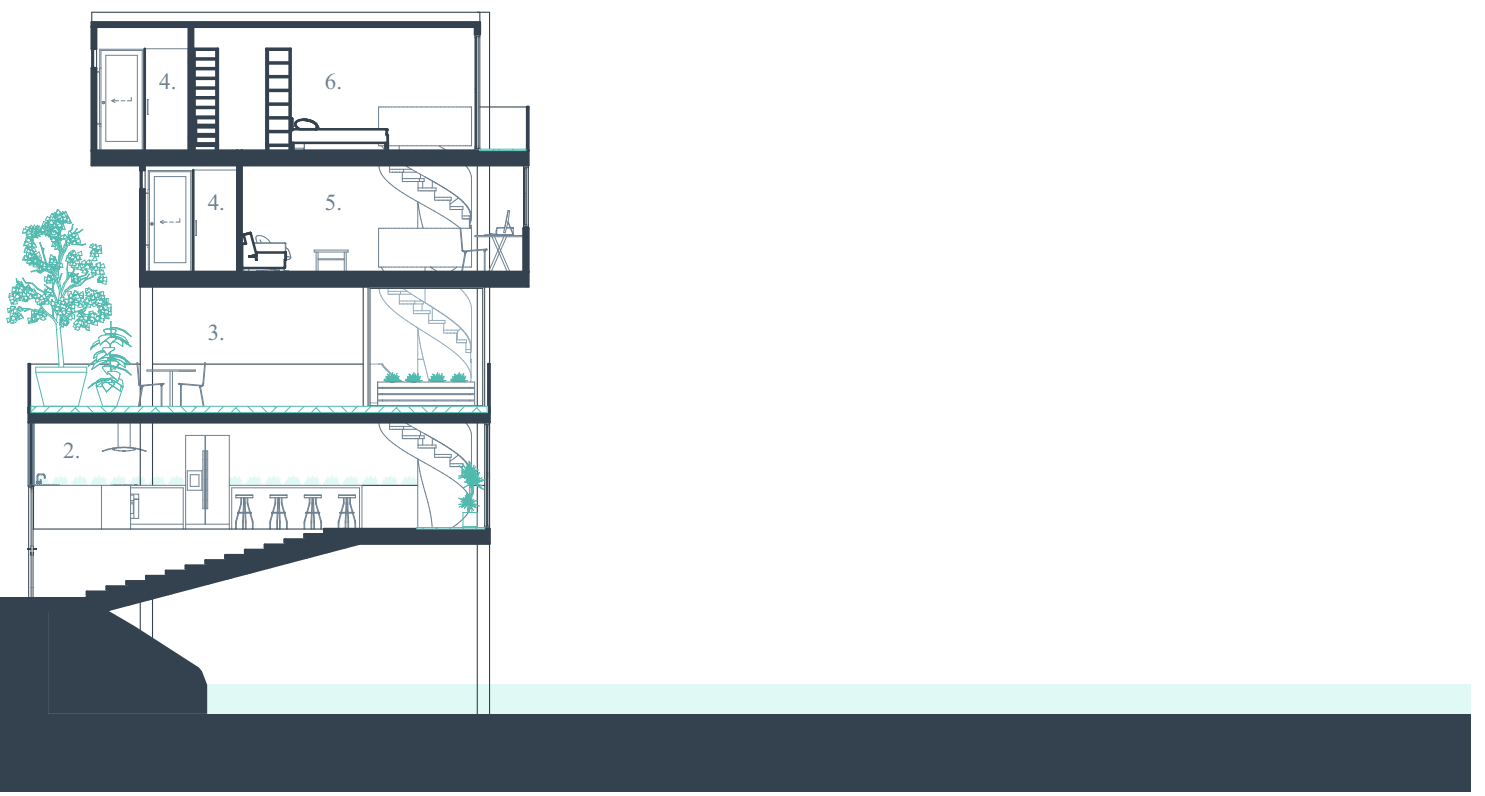



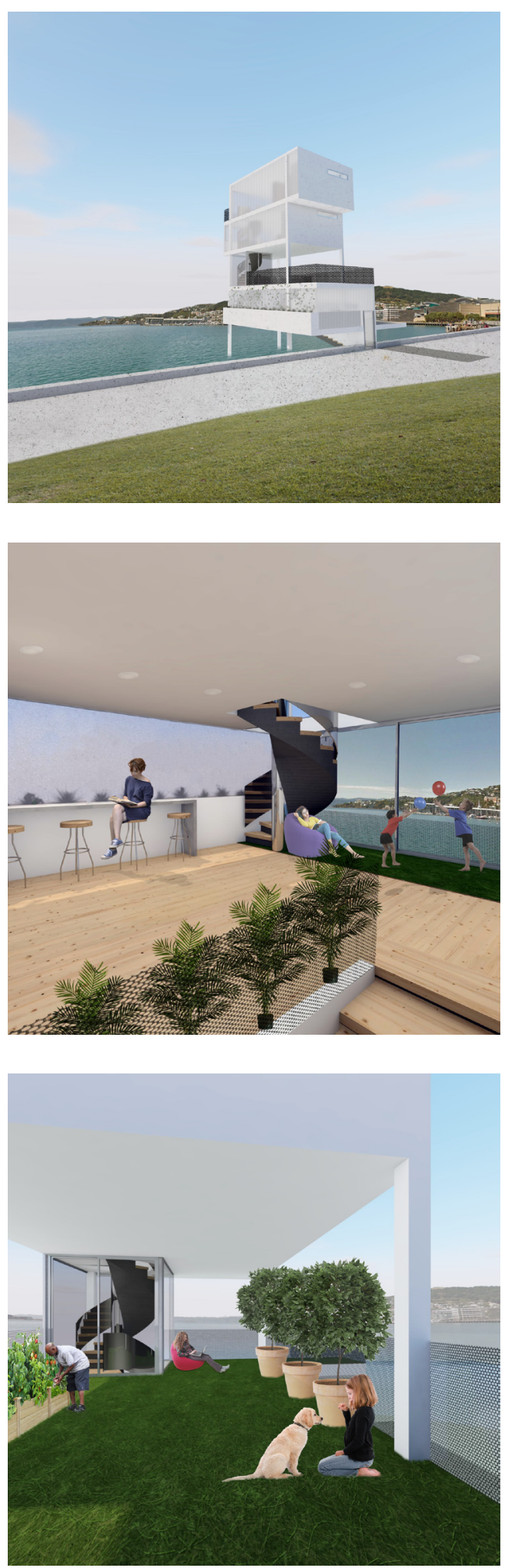

Fig 6.09 (Opposite) Wellington Waterfront section

Fig 6.10 (Above top) Exterior render

Fig 6.11 (Above middle) Living space render

Fig 6.12 (Above bottom) Outdoor connection render 


\section{FINAL DESIGN}

Catalyst Site

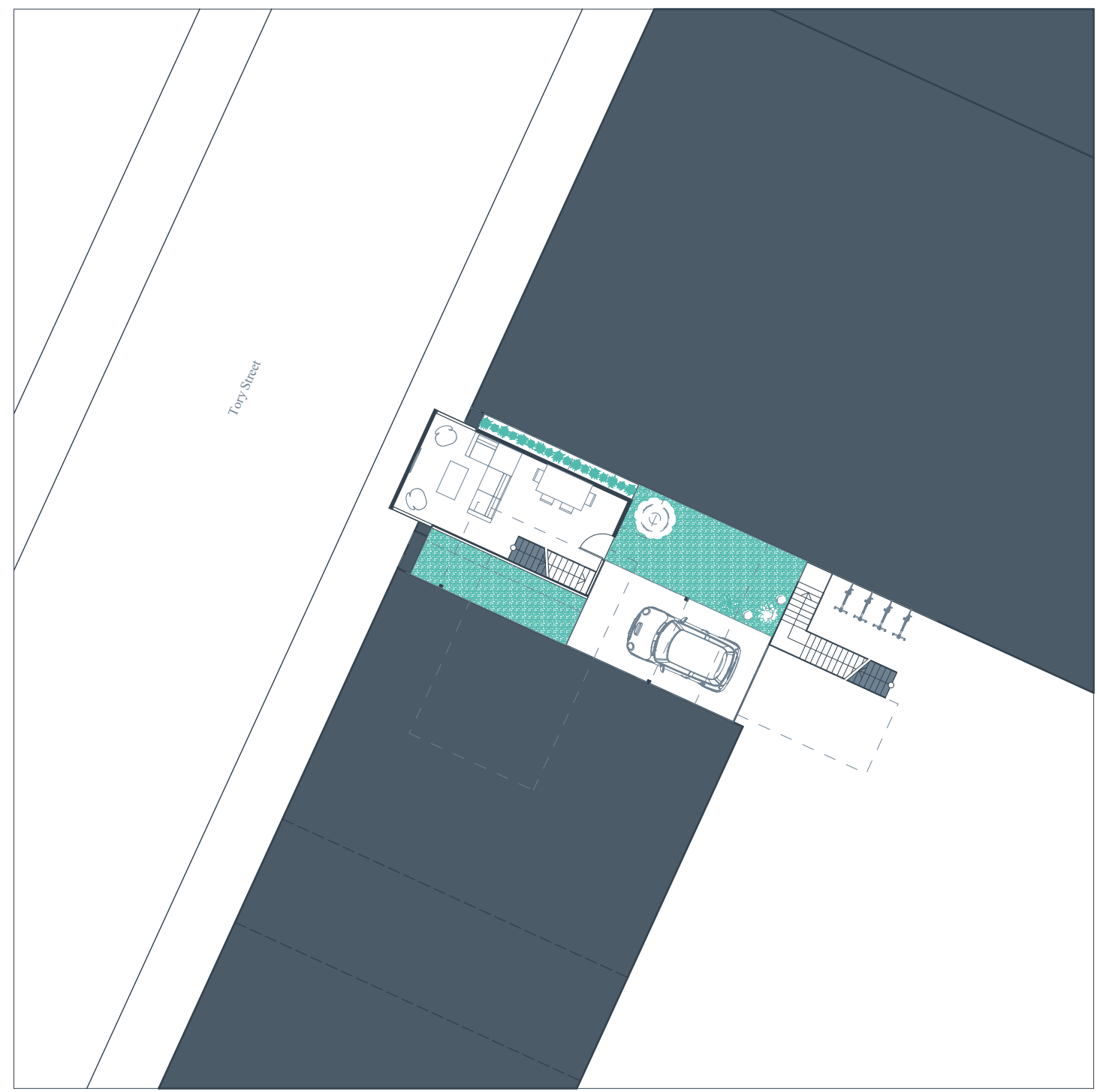

Fig 6.13 (Above) Tory Street site plan

Fig 6.14 (Opposite) Tory Street floorplans 


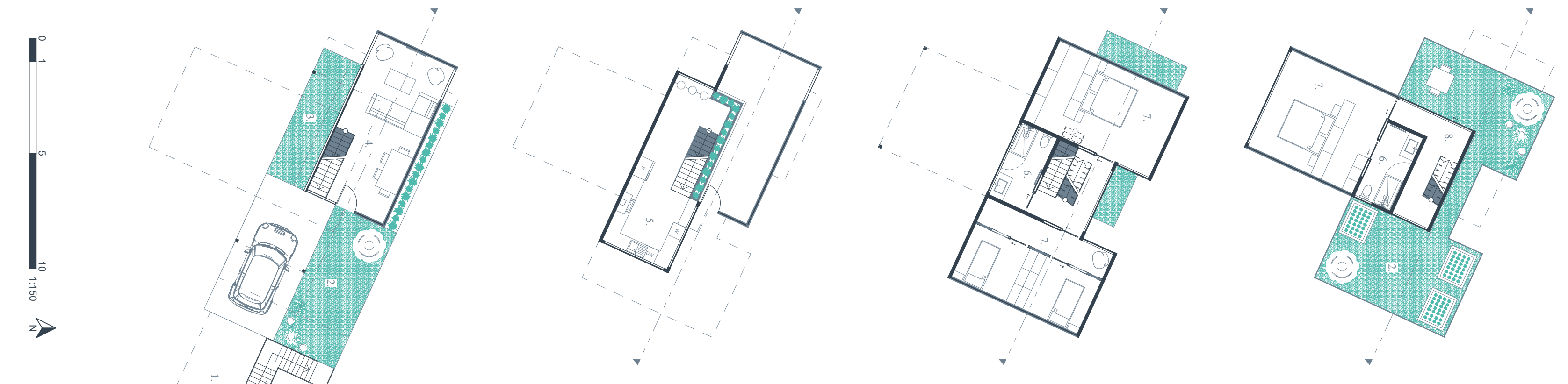

洋筒 
Once again, this house is arranged with the public, social spaces taking up the lower levels and the quiet, private spaces on the upper levels. Creating a vertical progression between the most social space to the most private space.

Polycarbonate is used on many of the exterior walls to provide optimal daylighting and privacy within the home. Windows are thoughtfully placed to capture specific views while maintaining a maximum amount of privacy.

The ground floor living space is open plan to create a feeling of spaciousness and to enable it to be adaptable and flexible for various user requirements. The living space is open to the mezzanine kitchen level above, producing a double height space. This extra volume contributes to making the room feel more spacious and light filled. Relating to the suburban garden outlook, a planted balustrade on the mezzanine level compensates for the lack of visible exterior planting, due to a focus on privacy, in the living space.

Private outdoor space is provided for both on the ground floor and a rooftop terrace. These outdoo spaces accommodate for a range of activities, similar to a suburban backyard, and are highly flexible to the requirements of the occupant. Mesh balustrades offer additional privacy around the perimeter of the rooftop terrace, while still allowing light to enter the space. To achieve additional privacy, if required, movable planting can be shifted to increase the degree of privacy by providing an extra layer of shelter, similar to boundary planting in a suburban context.

For this house, the car parking space is also elevated to be positioned at the ground level of the home, enabling easy accessibility. A vehicle lift is used to elevate the car up to the allocated, sheltered parking space outside the house. An outdoor area in front of the parking spot, also sheltered by the overhang of the house, provides a suitable space for DIY.

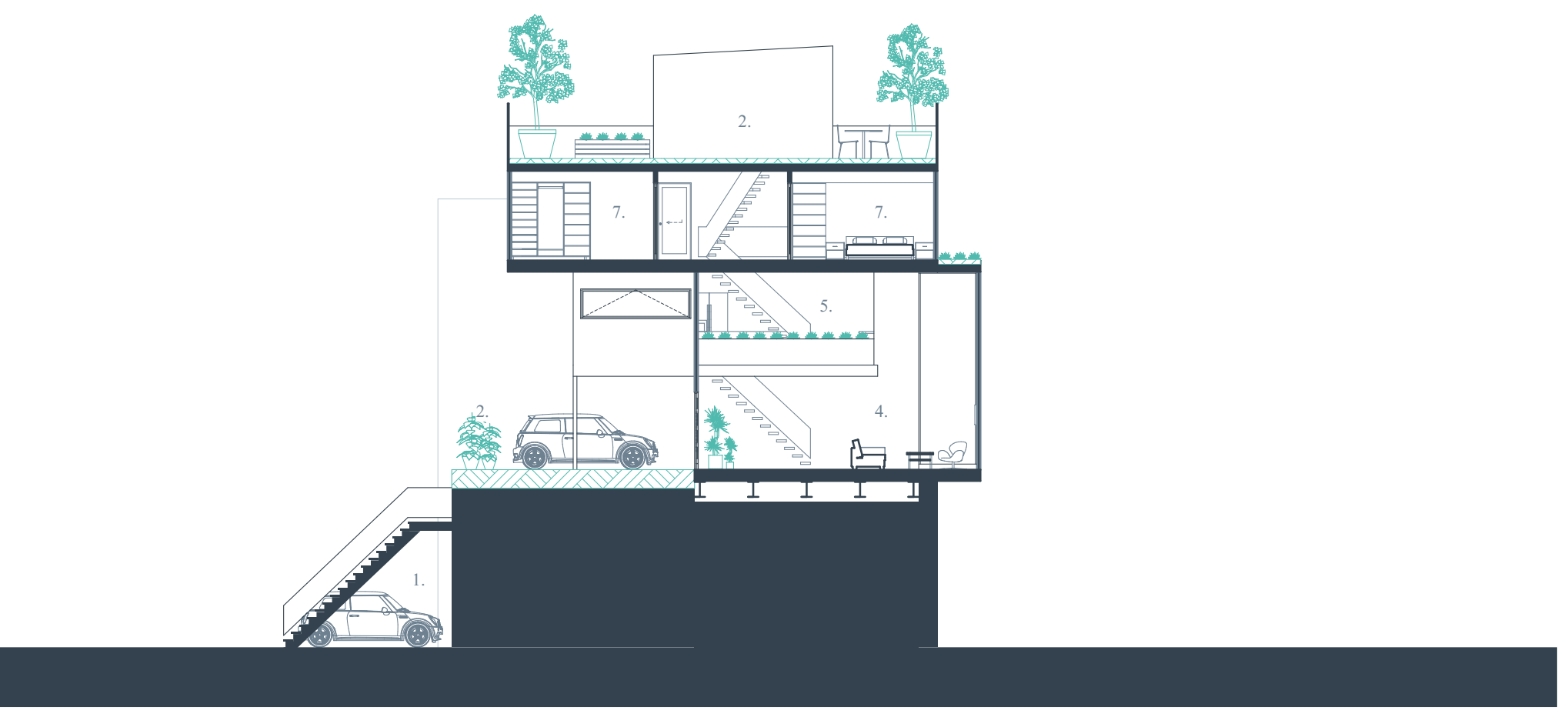



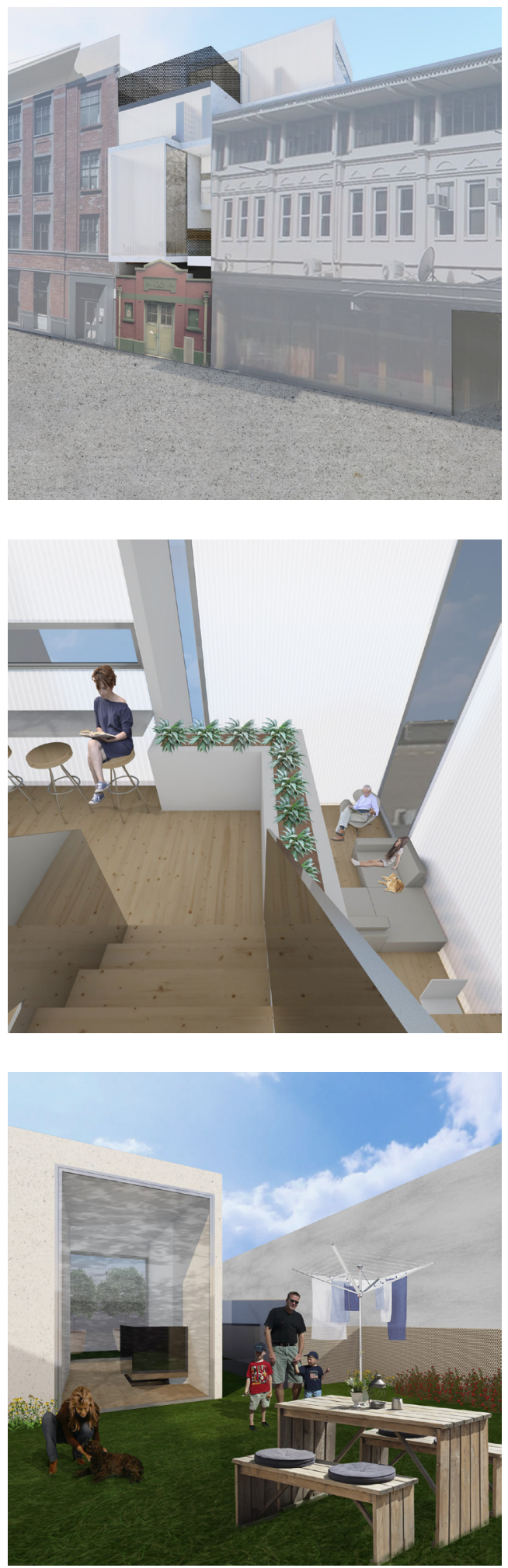

Fig 6.15 (Opposite) Tory Street section

Fig 6.16 (Above top) Exterior render

Fig 6.17 (Above middle) Living space render

Fig 6.18 (Above bottom) Outdoor connection render 


\section{FINAL DESIGN}

\section{Catalyst Site}
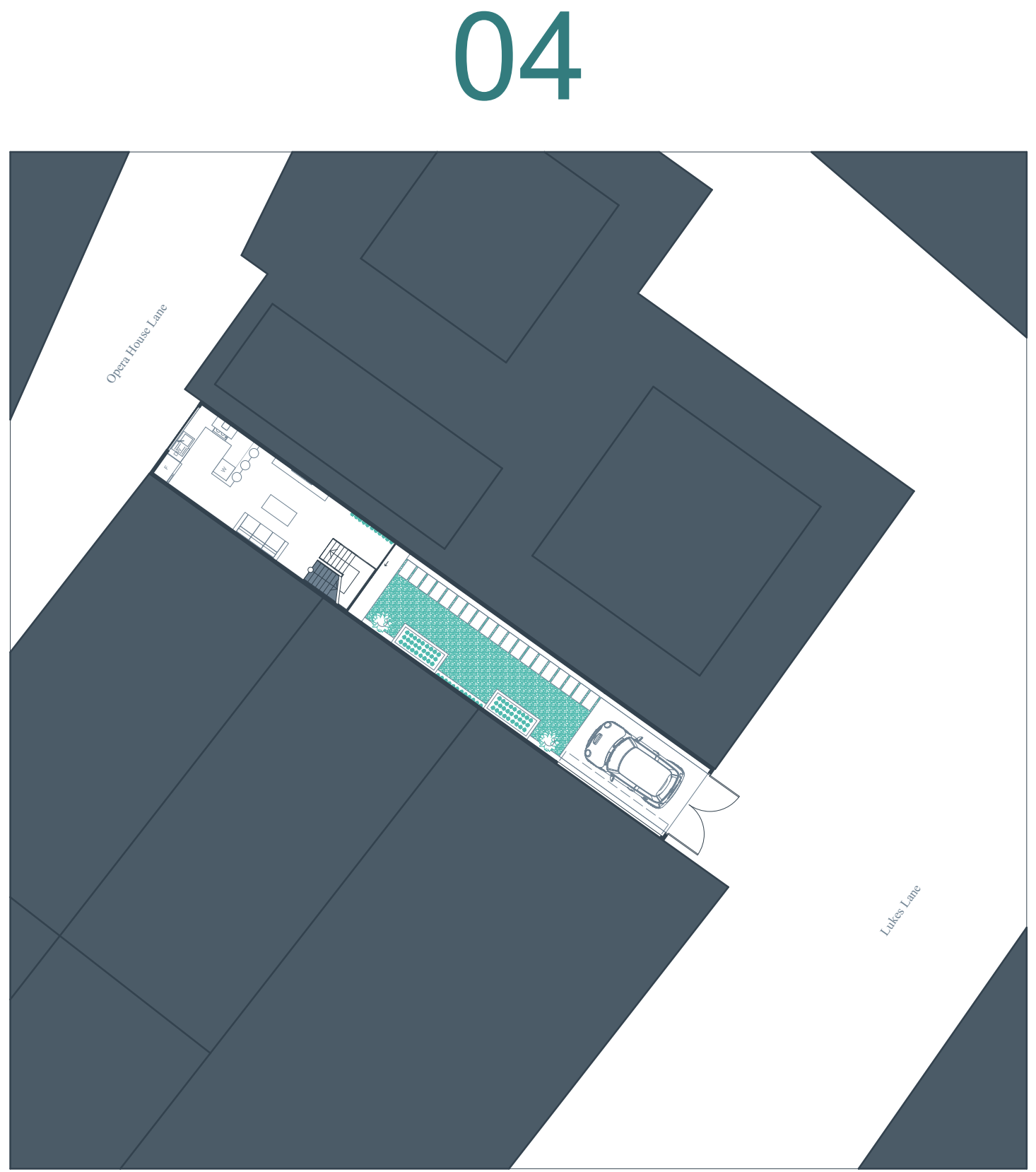

Fig 6.19 (Above) Lukes Lane site plan

Fig 6.20 (Opposite) Lukes Lane floorplans 

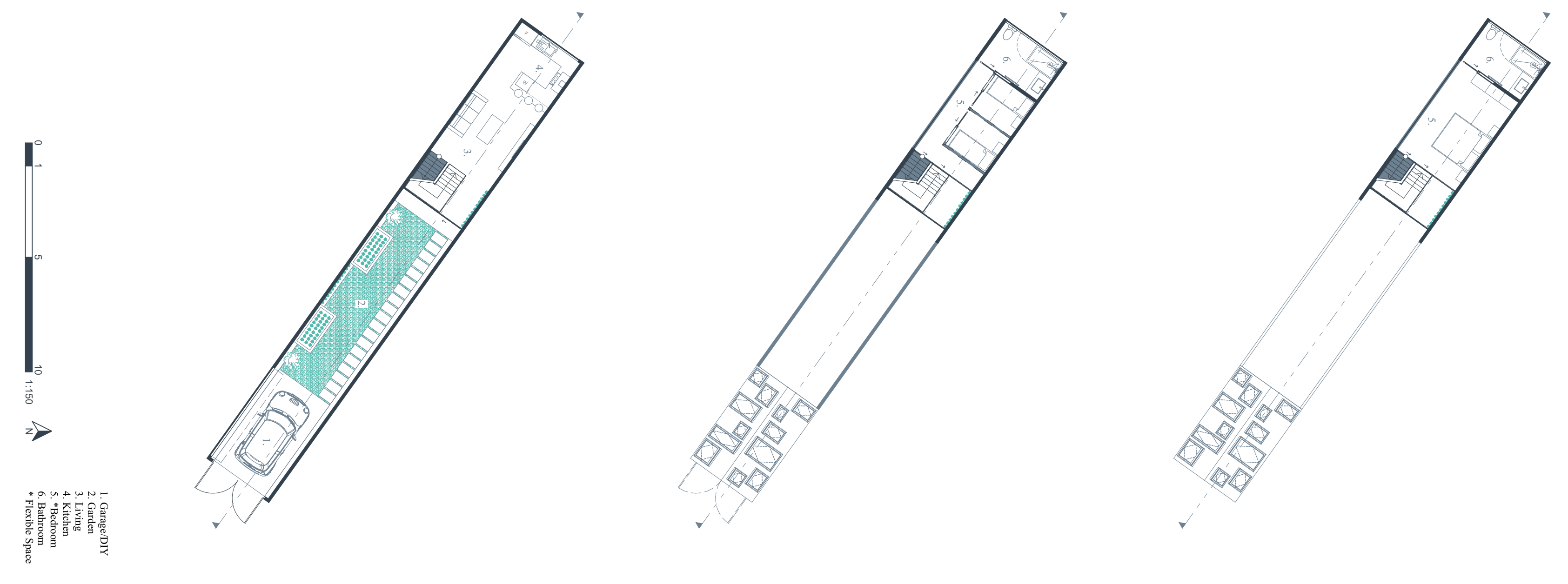
Once more, this house is arranged with the public, social spaces taking up the lower levels and the quiet, private spaces on the upper levels. Creating a vertical progression between the most social space to the most private space.

Polycarbonate is used along the long sides of the house in order to draw natural light through the spaces. Windows are thoughtfully placed to capture specific views to the exterior while maintaining a maximum amount of privacy.

Skylights are utilised to maximise light in the garage due to the narrow enclosed space. Above the stairwell, skylights are also used for ventilation and to draw light through the towering volume. The internal face of the house is entirely glazed, allowing the garden to become the focal point of the home. Recreating the qualities of the suburban garden outlook through an introverted approach in contrast to the extraverted suburban method.

The ground floor living space is open plan to create a feeling of spaciousness and to enable it to be adaptable and flexible for various user requirements. The living space connects directly to the private outdoor space allowing for great indoor-outdoor flow. This outdoor space can accommodate for a range of activities, similar to a suburban backyard, and is highly flexible to the requirements of the occupant.

This house takes the idea of suburban garage and reinvents it as a flexible space. This garage features a car lift which stores the car below the ground, freeing up the garage for other uses. The space is particularly suited for DIY activity or it may be used as a sheltered extension of the garden area. For this house, the garage door also function as the front entrance. For this reason, a side hinged double door is used, allowing the doors to be opened individually and function more like a traditional entry door.

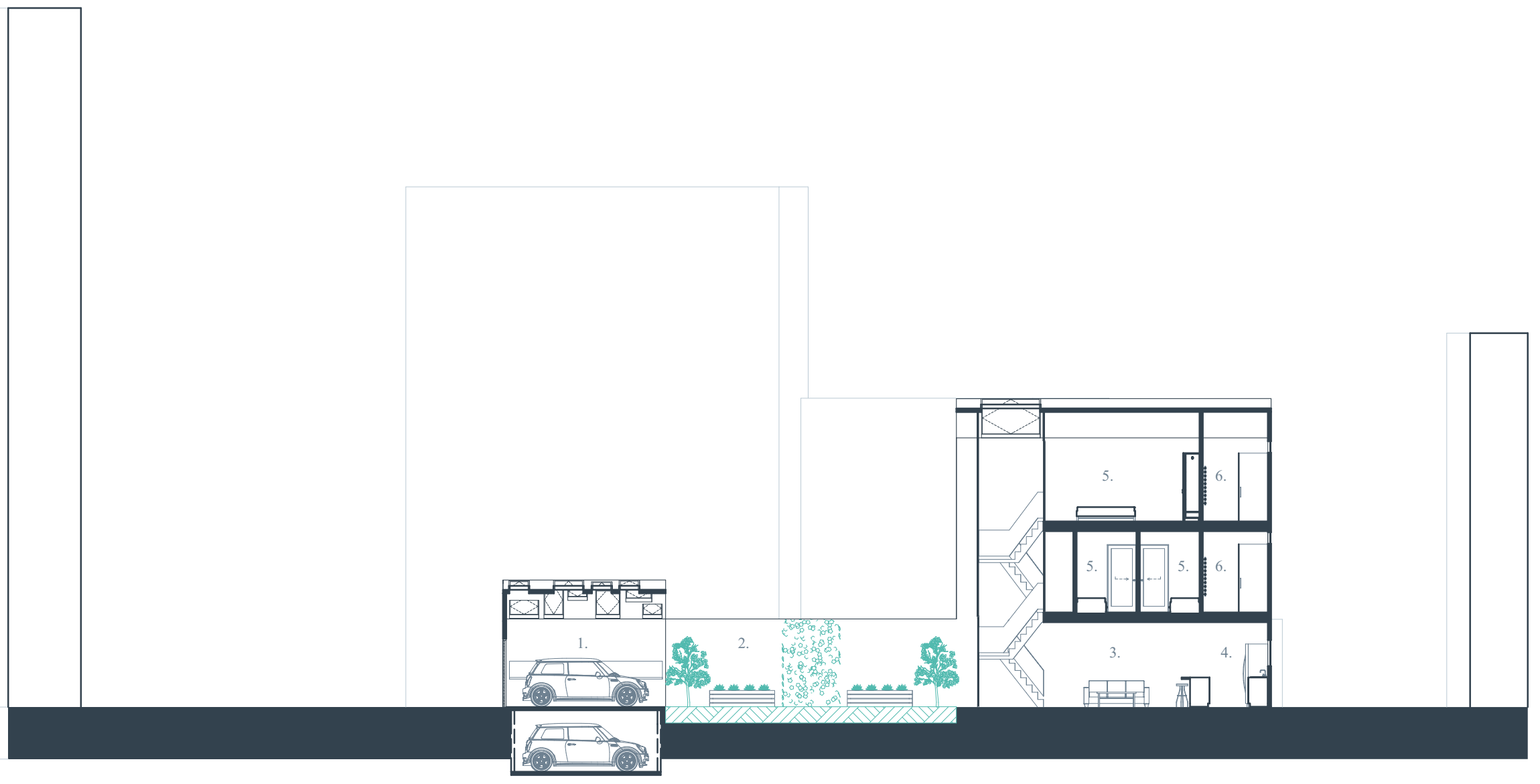



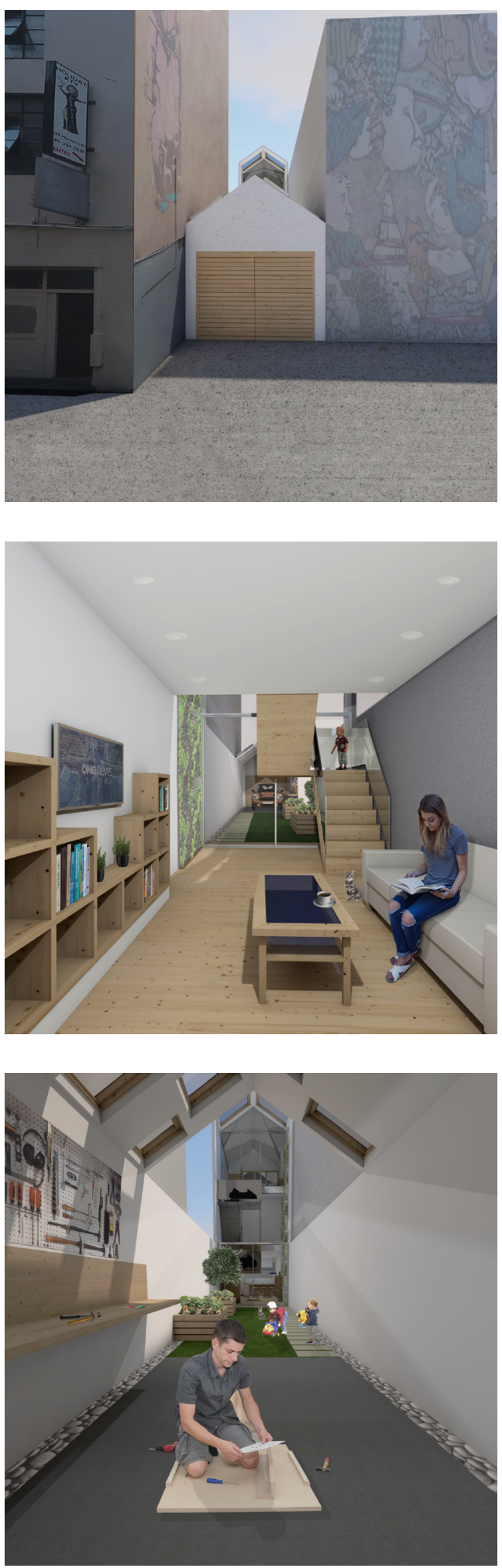

Fig 6.21 (Opposite) Lukes Lane section

Fig 6.22 (Above top) Exterior render

Fig 6.23 (Above middle) Living space render

Fig 6.24 (Above bottom) Outdoor connection render 


\section{FINAL DESIGN}

Catalyst Site

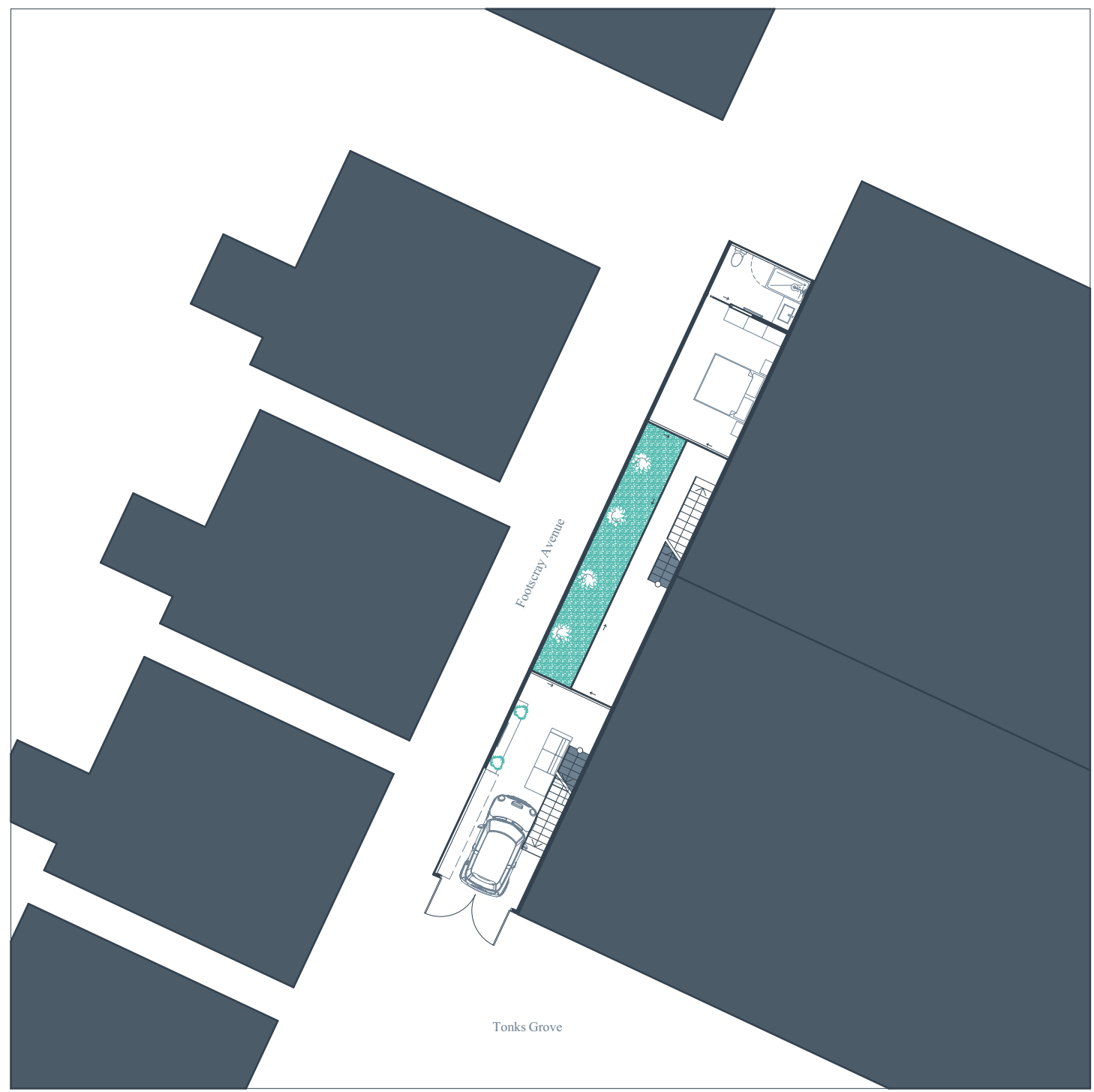

Fig 6.25 (Above) Footscray Avenue site plan 


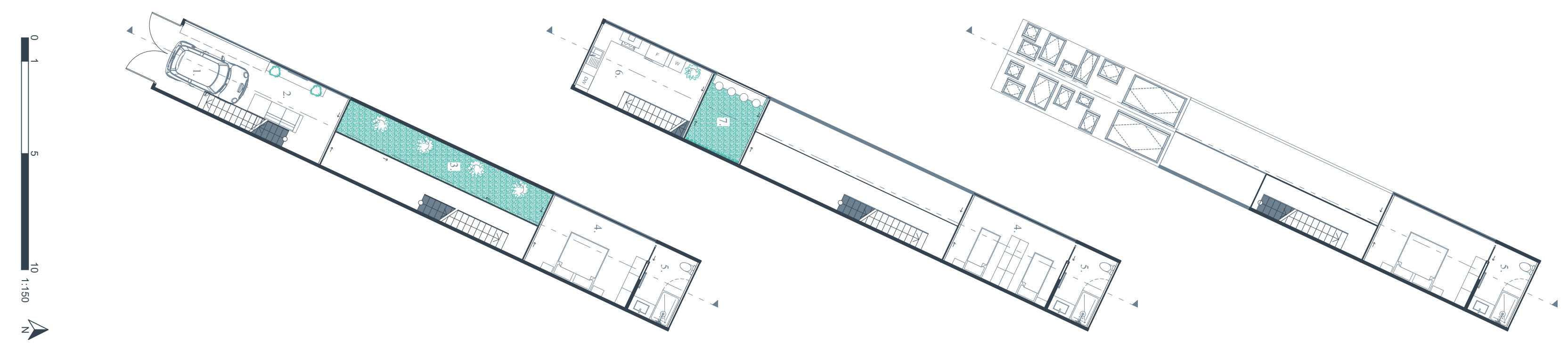

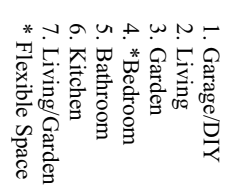


In contrast to the other house designs, the public and private areas of this house are horizontally separated by the both the outdoor space and the horizontal and vertical circulation. This horizontal method is a slightly more suburban approach to spatial separation.

Polycarbonate is used for the exterior walls along the walkway on both the public and private ends of the house, to capitalise on light while maximising privacy. Skylights are utilised above the kitchen to create a bright and airy space. Additional windows are strategically placed to capture specific views while maintaining a maximum amount of privacy.

Similar to the design of the previous house, the private outdoor space is the focal point of the home and all of the interior spaces overlook this garden. Recreating the qualities of the suburban garden outlook through an introverted approach. The living space connects directly

to the private, enclosed outdoor space for an indooroutdoor flow making the compact interior feel more spacious.

In this home, the garage is combined with the living space to create a truly flexible and multifunctional use of space. When not being used for car parking, the extra living space is also suitable for use as a workshop space for DIY. Like the previous narrow house design, the garage door also functions as the front entrance. For this reason, a side hinged double door is used, allowing the doors to be opened individually and function more like a traditional entry door. 

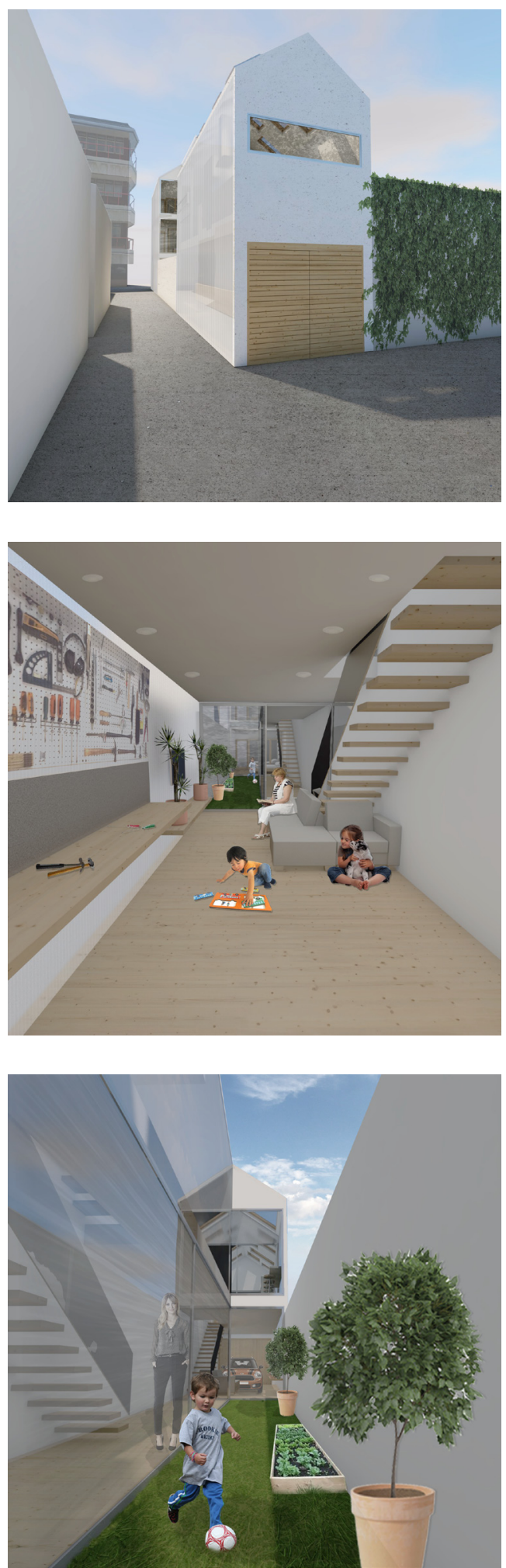

Fig 6.27 (Opposite) Footscray Avenue section

Fig 6.28 (Above top) Exterior render

Fig 6.29 (Above middle) Living space render

Fig 6.30 (Above bottom) Outdoor connection render 


\section{FINAL DESIGN}

\section{Catalyst Site}
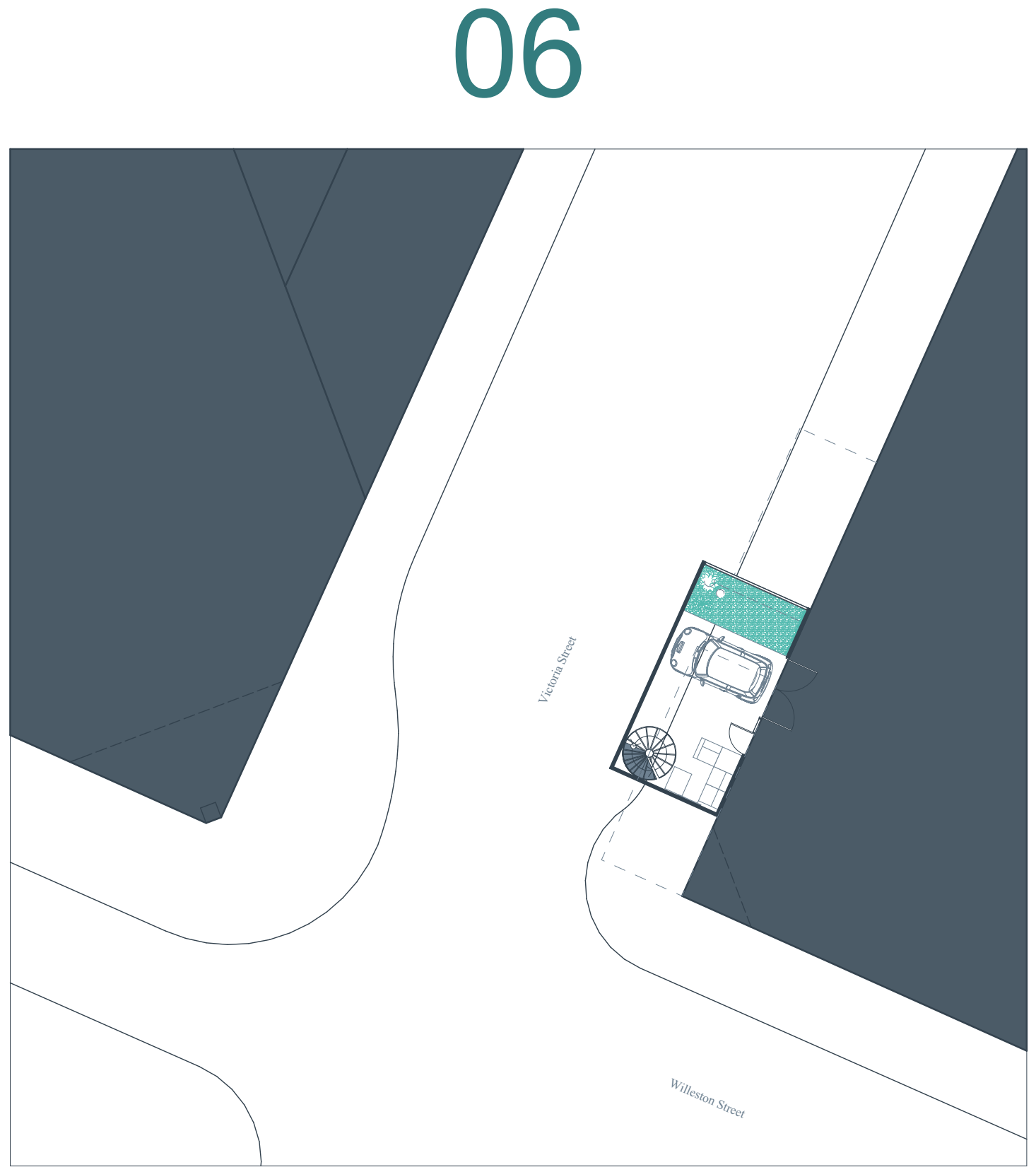

Fig 6.31 (Above) Victoria and Willeston Street site plan 

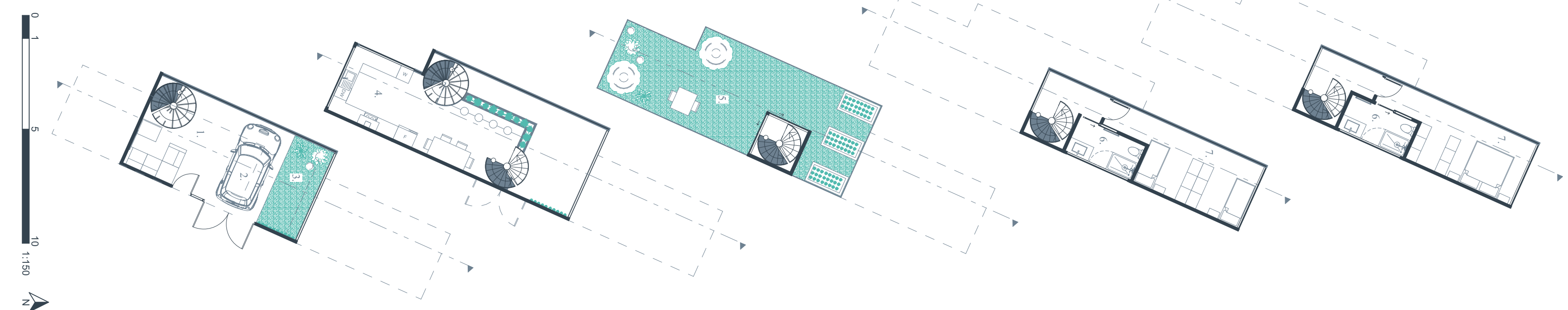

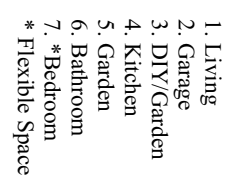


Like many of the other designs, this house is arranged vertically with the public, social spaces taking up the lower levels and the quiet, private spaces on the upper levels. Similar to the design of the house on the waterfront, the outdoor terrace provides a distinct spatial separation between the public and private areas of the home.

Polycarbonate is applied to the long exterior walls facing the street, to provide optimal daylight within the home while also delivering privacy from neighbouring buildings. Windows are thoughtfully placed to capture specific views while maintaining a maximum amount of privacy.

The compact, ground floor living space is open plan to create a feeling of spaciousness and this also enables it to accommodate various user requirements. The living space is open to the mezzanine kitchen level above, resulting in a double height space. This extra volume contributes to making the room feel more spacious and light filled. A planted balustrade on the mezzanine level compensates for the lack of visible exterior planting in the living space.

The outdoor terrace is highly flexible to the requirements of the occupant. A mesh balustrade around the perimeter of the outdoor space offers privacy from overlooking buildings while allowing light to filter through. To achieve additional privacy, movable planting can be shifted around the space as necessary to increase the level of protection.

In this house, the garage is combined with the living space, creating a truly flexible use of space. An interior garden area is located adjacent to the flexible garage space and provides an area suitable for DIY activities.
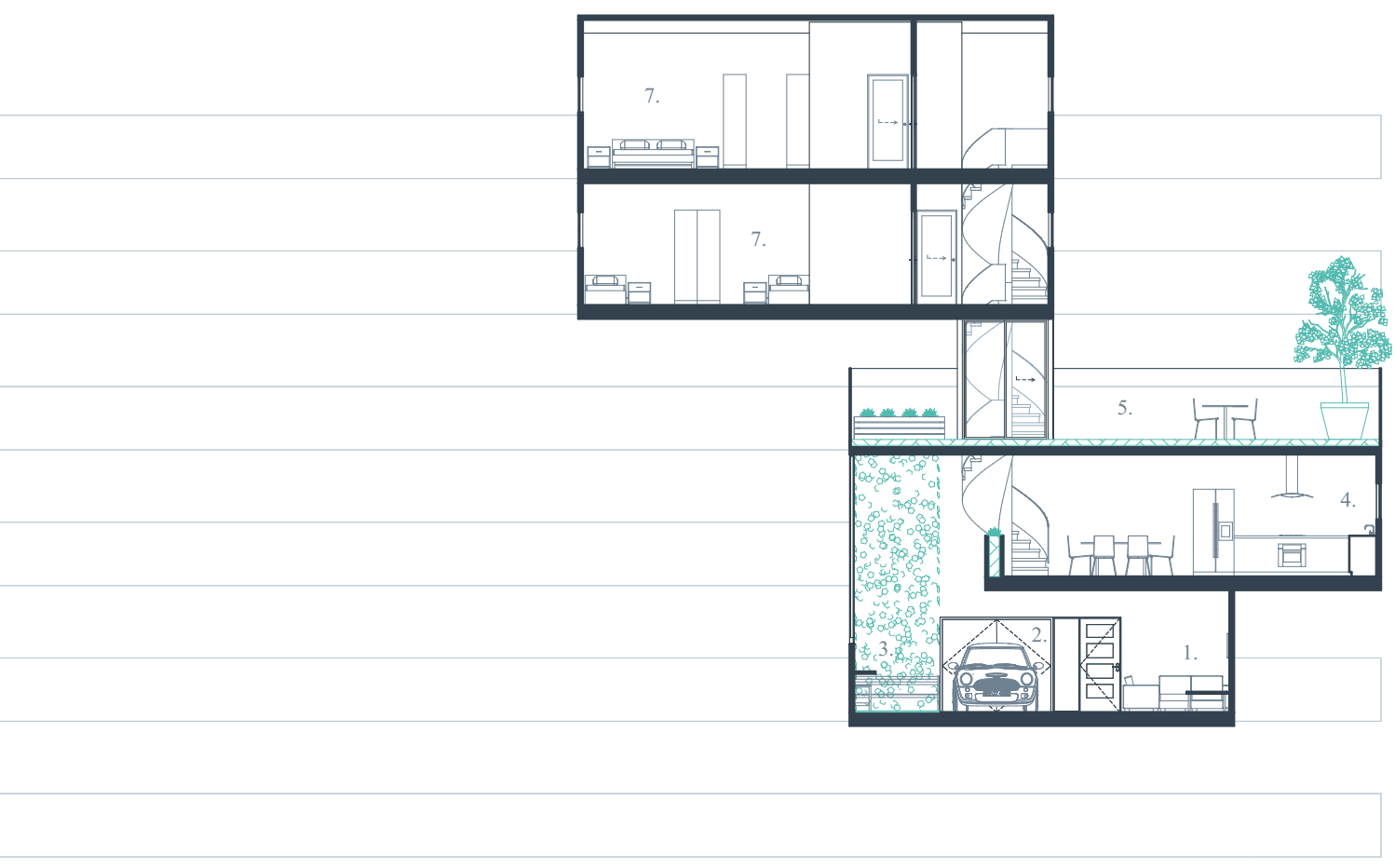

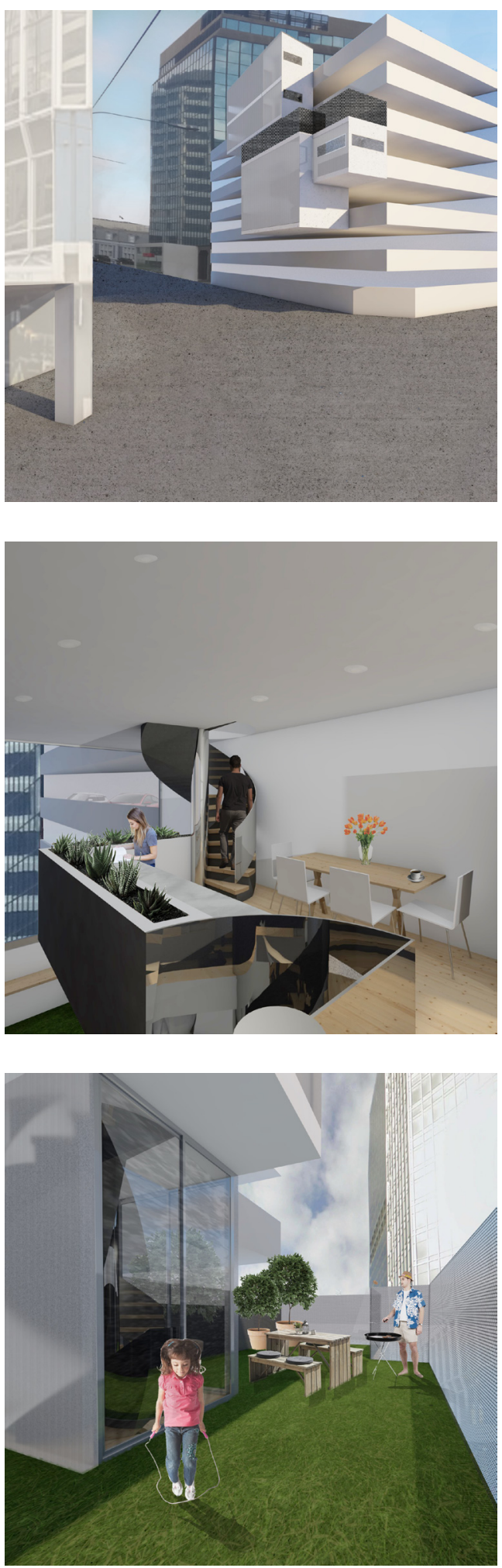

Fig 6.33 (Opposite) Victoria and Willeston Street section

Fig 6.34 (Above top) Exterior render

Fig 6.35 (Above middle) Living space render

Fig 6.36 (Above bottom) Outdoor connection render 


\section{Design Summary}

The six final designs present an architectural outcome for the design of family friendly urban housing, across six different typologies of residual space. The final designs are intended to offer a suggestion of how to successfully design for each of these challenging typologies.

The final designs were developed through a series of design iterations. These iterations were used for testing interventions and experimenting using the areas of focus, across the context of the six catalyst sites in terms of the user requirements, defined through the literature reviews, design guidelines and design development. This was in order to develop a conclusive set of strategies that can be adapted and applied to any residual urban space. Producing an architectural method for designing comfortable family living in residual urban spaces based on the key qualities of suburban living. 


\section{7}

STRATEGIES 

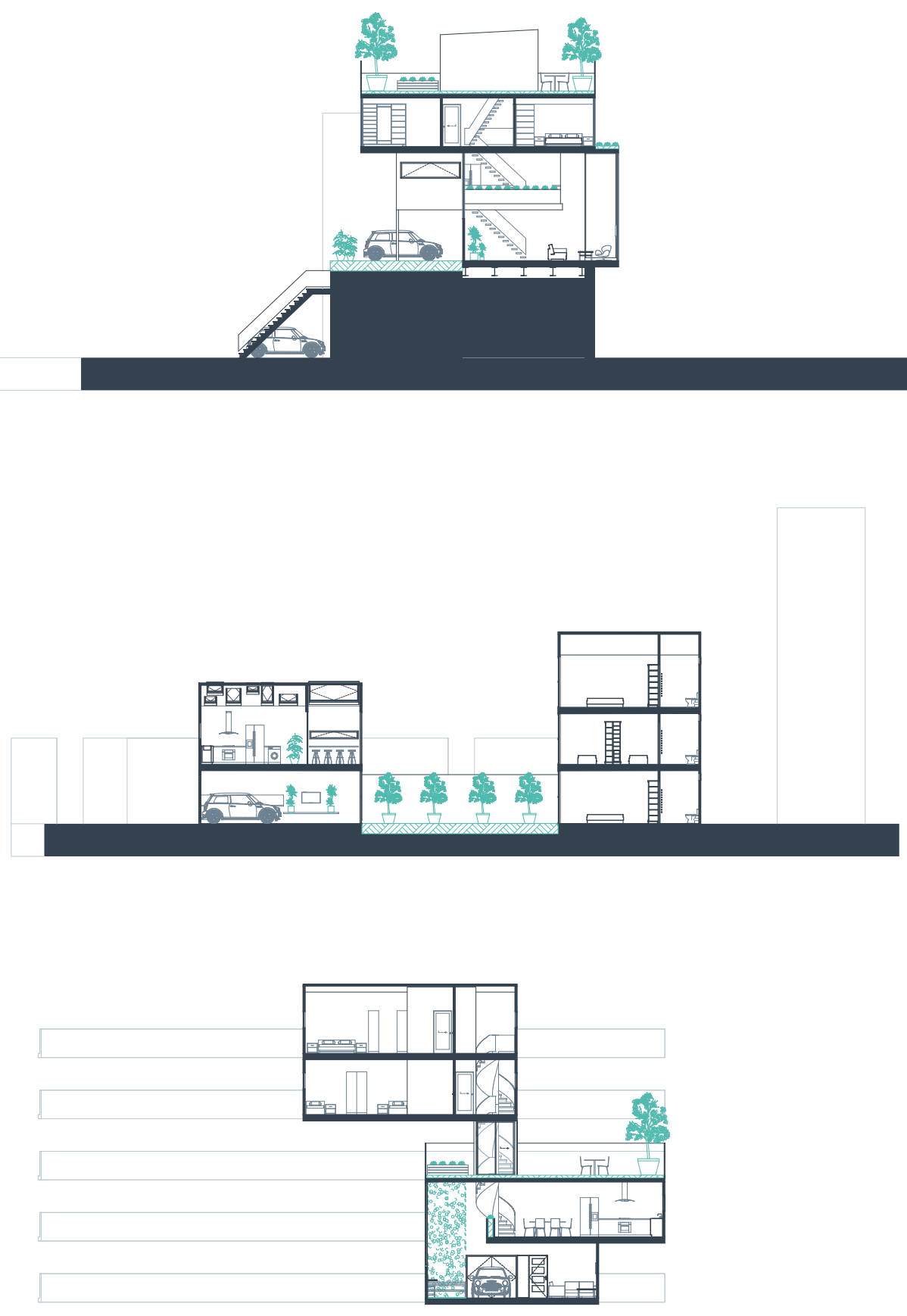


\section{Strategies for Spatial Planning}

- Spatially the house should be arranged with a clear distinction and hierarchy between the public, social spaces and the quiet, private spaces. This will usually be a vertical progression from the most social space up to the most private. However, some sites may be more suited to a horizontal separation in a slightly more suburban approach to spatial planning.

- The outdoor space can, in some cases, provide a distinct spatial separation between the public and private areas of the home. This type of separation can be used to break up the solid mass of the house.

- The social areas of the home should be open plan and flexible to accommodate for varying family requirements and allow for comfortable entertaining on a small or larger scale. The open floorplan will make the space feel larger and more spacious and can be achieved by eliminating interior walls between the kitchen, dining and living areas.
- To make living areas feel more spacious, position the space to connect directly to the outdoor area to allow for an indoor-outdoor flow. This is particularly beneficial for long, narrow sites.

- An open mezzanine level may be considered to provide additional space on a site with a smaller footprint utilising vertical spatial progression. The supplementary volume provided by the resulting double height space can make a room feel much more spacious, lighter and more comfortable.

- For an efficient floorplan in a compact space, eliminate any wasted spaces and avoid unnecessary circulation space. 

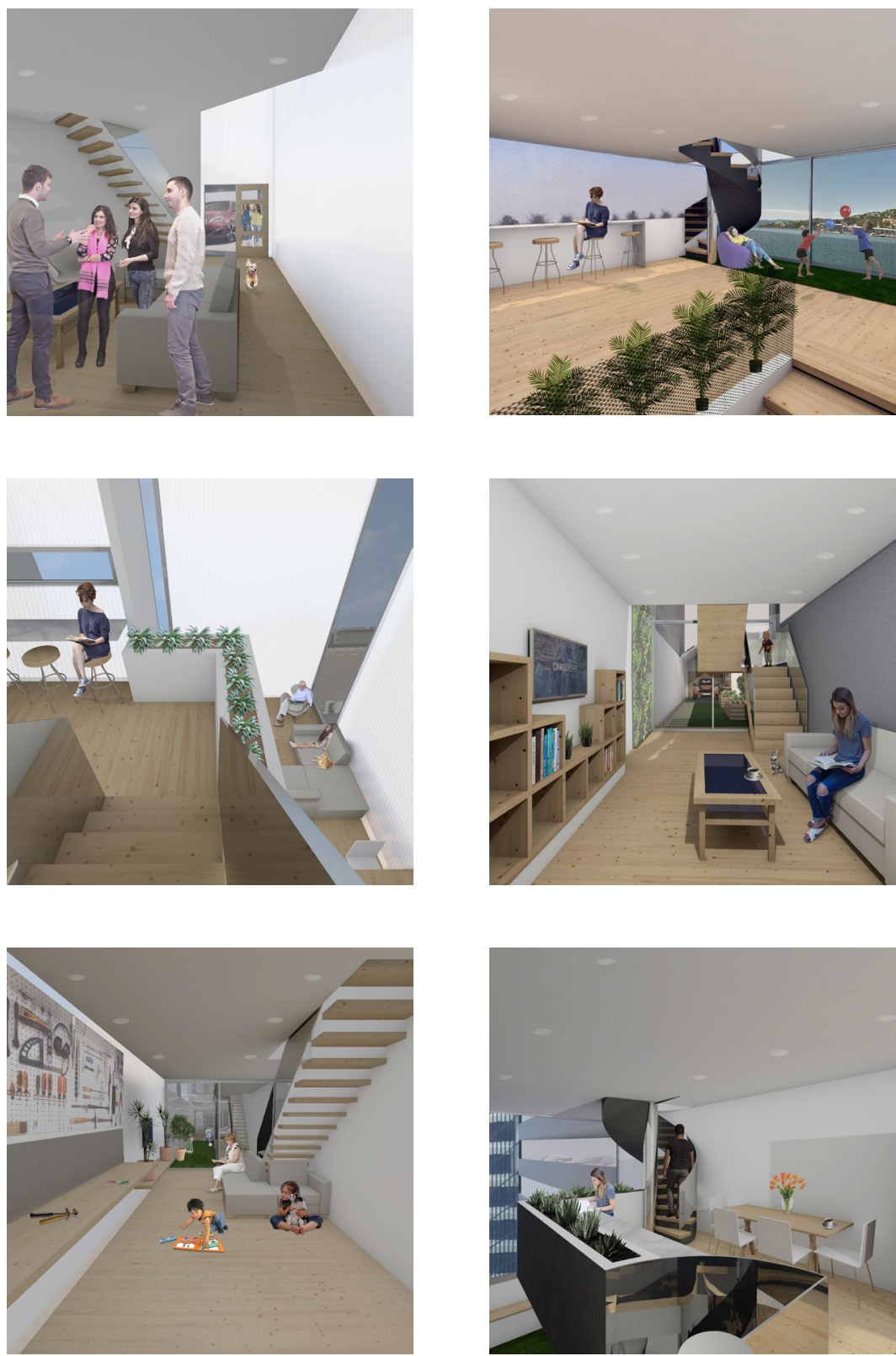


\section{Strategies for Flexible Living}

- Open plan layouts should be used in social areas. An open plan layout is achieved by eliminating interior walls, allowing adjacencies between spaces to become fluid and blurred. This will allow for greater flexibility in space usage both now and in the future.

- In an open plan layout, furniture may function as an adaptable space divider for an alternate method of room separation.

- To efficiently utilise space, the laundry room may be integrated within the kitchen space. Other spaces which may be combined as flexible spaces include the car parking space and the DIY area, as is common in suburban homes, as well as the garage combined with functional outdoor space, and the combination of parking, DIY and living space.

- In order for the house to be adaptable to the requirements of the occupant, several of the rooms in the house should be flexible space rooms.
These rooms are essentially empty spaces with no predefined set function, which the occupant may configure to suit their needs. Separations may be provided by lightweight, temporary walls or with movable freestanding wardrobes providing functional separation. This method allows rooms to serve more than just a singular purpose by blurring the programmatic boundaries that define and constrain the use of the space, allowing the occupant more creativity to adapt the space to their specific needs.

- In some houses, particularly houses on narrow sites, the garage door may also function as the front entrance. In these situations, a side hinged double door is used. This allows the doors to be opened individually, in order to function more like a traditional entry door. 

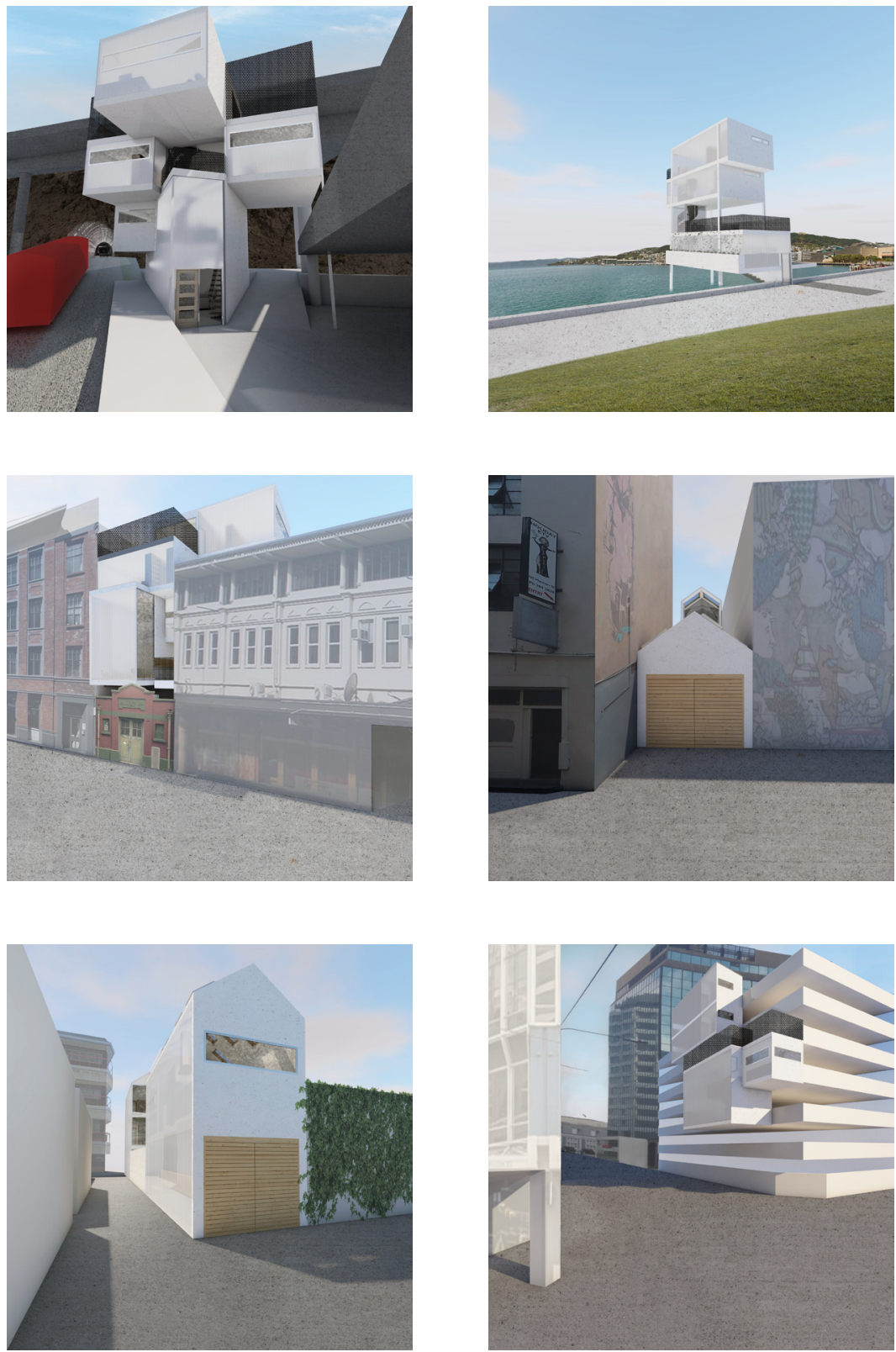


\section{Strategies for Lighting and Privacy}

- Polycarbonate walls can be used in place of large windows to allow a satisfactory amount of diffused natural light to enter a space without compromising on the occupants' privacy.

- Windows should be located with thoughtfulness. The interior function and use of space should dictate window placement rather than exterior appearance, with privacy for the occupant being of upmost importance.

- Windows located at the top of a wall can provide light and views while preventing direct sight lines, providing privacy for the occupants.
- Narrow horizontal windows located at eye level in selected locations, such as over the kitchen sink or above a breakfast bar, offer an exterior outlook in locations where an occupant will be paused to appreciate it, while the height of the window should prevent direct sightlines into the interior.

- Skylights also offer a suitable option to achieve daylight and ventilation without affecting privacy. 

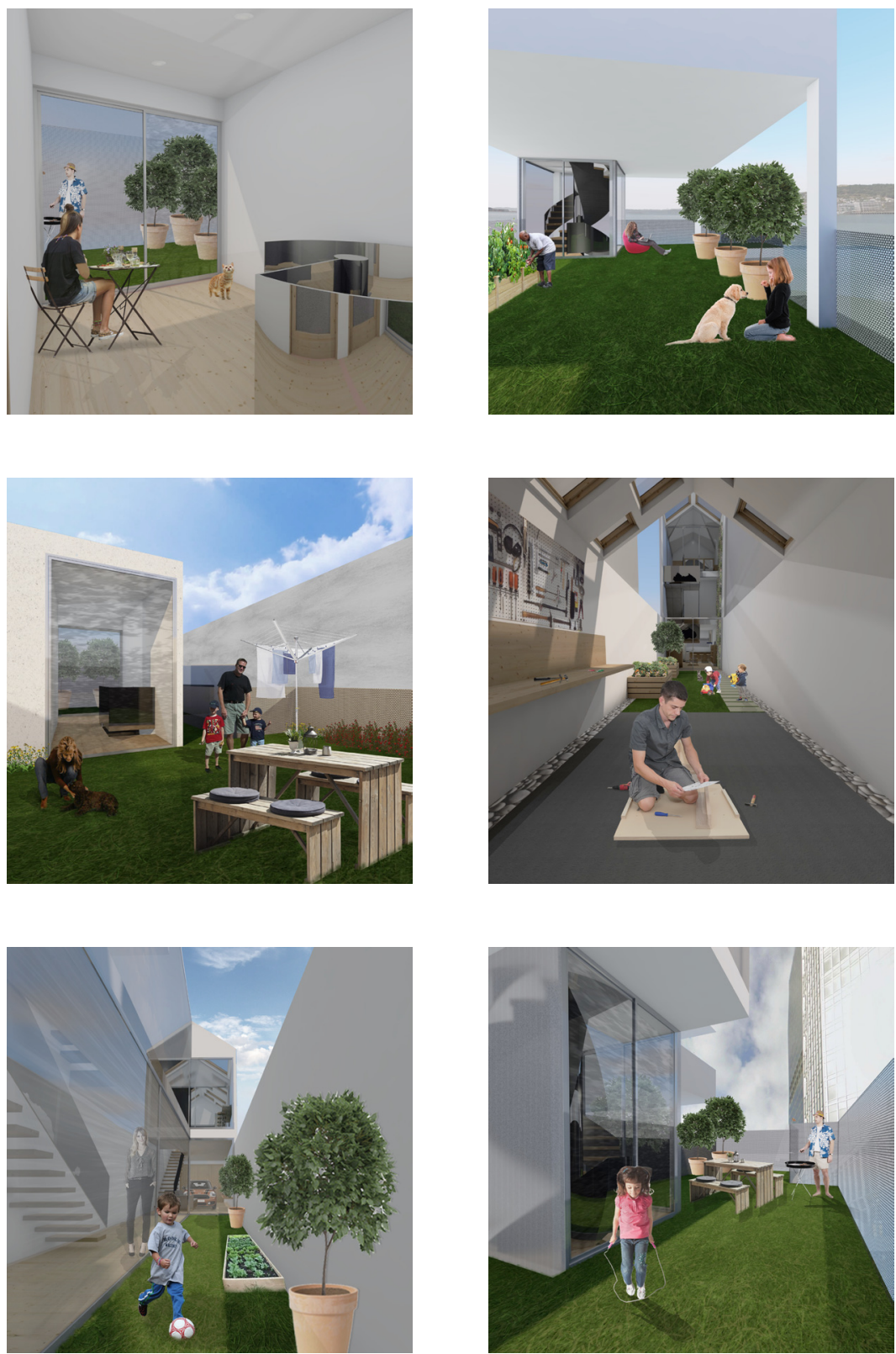


\section{Strategies for Outdoor Connection}

- Each dwelling should accommodate for private outdoor space. This may be in the form of gardens, courtyards or rooftop terraces.

- The outdoor space should be designed to accommodate for a range of activities, similar to a suburban backyard, and be highly flexible to the requirements of the occupant. The space should be suitable for children's play, gardening, an exercise space for pets, outdoor living, space for a clothesline and may also be adapted for DIY purposes.

- The private outdoor areas should be located adjacent to the main living space. This will allow for indooroutdoor flow and will help to make living areas feel more spacious.

- In situations where the main outdoor area cannot be located adjacent to the living space, indoor plating should be incorporated as compensation for the absence of a garden outlook.
- In situations where two outdoor areas are separated by an interior circulation space, this space should be designed to also function as a covered porch, supplementary to the outdoor areas. Connecting the two gardens by creating an indoor-outdoor flow.

- Mesh balustrades or panelling, designed to imitate suburban boundary planting, should be used for safety and to provide privacy around the perimeter of an outdoor space. The height should be selected based on the privacy requirements for each specific location. The mesh allows light to filter through to the garden while also providing privacy for the user.

- For additional privacy, movable planting such as potted trees or hedging, raised vegetable gardens and furniture items can be shifted around the flexible space as necessary, to increase the level of protection as required. 

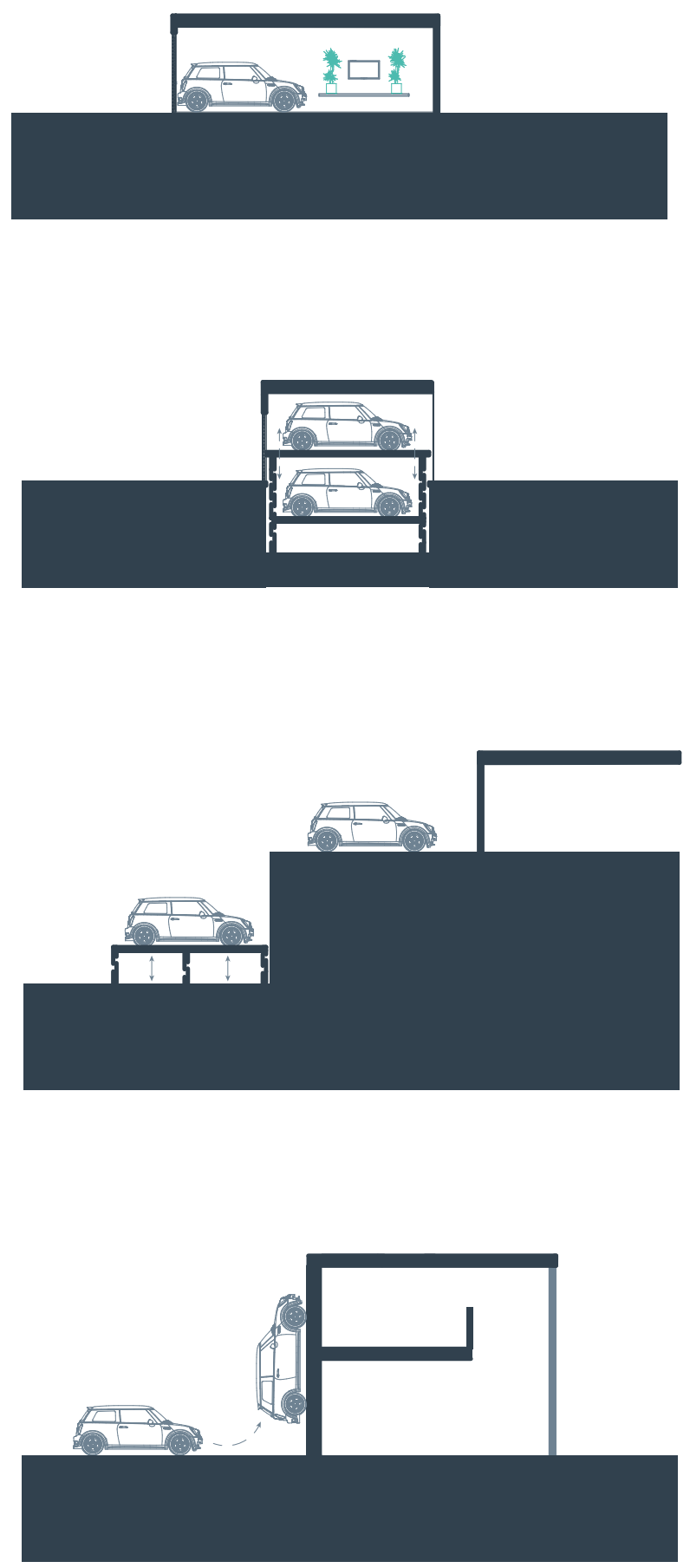


\section{Strategies for Accommodating a Car}

- Innovative, experimental forms of parking should be explored.

- Vehicle lifts can be used to reposition the car vertically. This generates more possibilities and flexibility for parking, and in some cases will allow the car to be more easily accessible from the house.
- Car parking space should be designed to be multifunctional, meaning the space will be valuable whether accommodating for a car or not.

- Solutions should, as much as possible, avoid swapping habitable space for car storage. 


\section{8}

CONCLUSIONS 

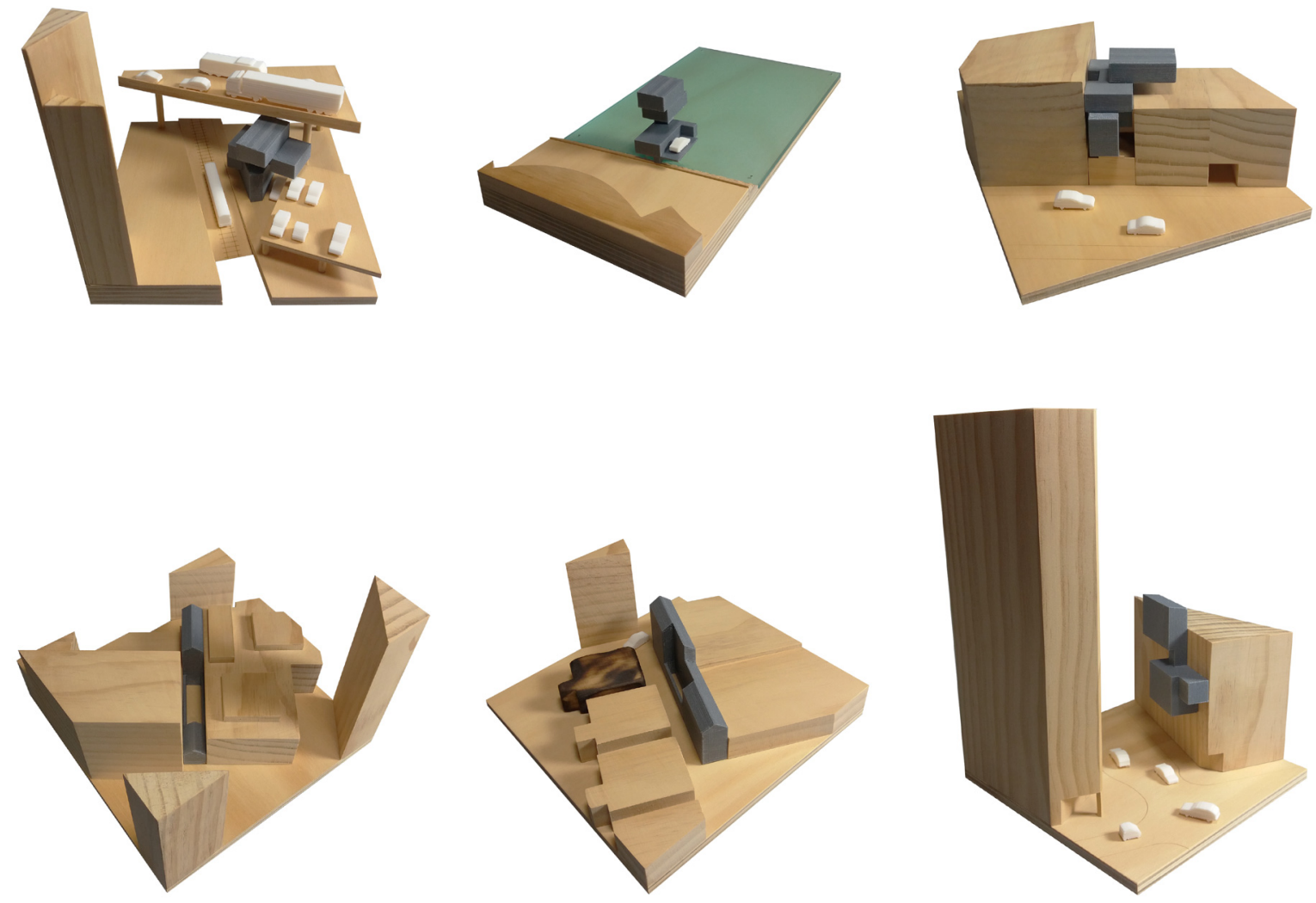


\section{Conclusion}

This research portfolio investigated how residual urban space could support a new housing typology, based on the key qualities and amenities of suburban living.

The research has shown a considerable number of families are beginning to consider moving from the traditional family archetype of the suburban dream to inner city living, in order to make their lives easier by being closer to work and amenities. However, current inner city housing options, which are predominantly apartment blocks, are not designed to accommodate for comfortable family living. Often this means families will eventually end up moving back to the suburbs where the housing is better suited to their needs.

The outcome of this research portfolio proves that it is entirely possible to create urban homes which can provide a lifestyle that achieves and exceeds the expectations of suburban living. Through developing an alternative typology that incorporates the desired suburban qualities, it is possible to change people's preconceptions of inner city living.
By generating a design approach that will draw families back into the city, the amount of demand for suburban homes should begin to reduce, and consequently have a positive impact on decreasing suburban sprawl. By utilising residual urban spaces to provide these family friendly homes, there will be no negative impact on urban sprawl, as these gaps already exist and are viewed as unfeasible for conventional development.

The final designs present six architectural outcomes incorporating the key qualities of suburban living, as defined by the design guidelines, across six different typologies of residual urban space. The development of these architectural outcomes across the six site typologies, ultimately resulted in a conclusive set of strategies, based on the five key areas of focus, which can be adapted and applied to the development of any residual space. A guide created with the aim of encouraging future residential development for families, rethinking the suburban home on residual urban sites. As a way of encouraging families into inner city living and helping to reduce the effects of both suburban and urban sprawl. 


\section{Research Limitations}

For the purposes of this research portfolio, the research and design was limited to catalyst sites in inner city Wellington. It is intended that the strategies and concepts developed through this research could also be applied to other sites in cities throughout New Zealand or around the world.

Residual spaces are, by definition, unique spaces. Therefore, although categorised into typologies, each site will still possess a unique set of challenges. Consequently, it is unreasonable to expect to be able to establish one set design approach that will work across all of these spaces. Instead, this research intends to offer suggestions as to how these sites may be developed by establishing a design solution for a catalyst site from each of the site typologies and discovering which strategies and ideas work best across each of the sites. 


\section{Future Opportunities}

In terms of future opportunities for this housing model, with further research and development, construction of these houses might be considered in terms of modular design. Modularity, as well as prefabrication, would enable cheaper, easier and faster construction within these challenging residual site typologies. Modular design would also allow for an even greater level of flexibility for the occupant, as additional modules can be added to or removed from the house as required. A modular design may also allow the housing to be suitable for other demographics wanting to experience a different type of inner city living, by granting the personal choice of house size, room requirements and configuration. 


\section{BIBLIOGRAPHY \& LIST OF FIGURES}




\section{Bibliography}

Aranguiz, Antonio C. (2005). Small City Homes. Singapore: Page One Publishing

ArchDaily. (2013). House in Tousuien/Suppose Design Office. Retrieved from https://www.archdaily.com/458511/housein-tousuien-suppose-design-office

Bellemo \& Cat. (2017). Polygreen House. Retrieved from http://www.bellemocat.com/residential/polygreen-northcote/

Bonenfant, Norm. (n.d.). Cellular Polycarbonate Glazing. Retrieved from https://greenbuildingsolutions.org/blog/cellularpolycarbonate-glazing/

Bracken, Gregory. (2013). The Shanghai Alleyway House: A Vanishing Urban Vernacular. New York: Routledge.

Breen, Ann, \& Rigby, Dick. (2004). Intown Living: A Different American Dream. Washington: Island Press.

Carroll, Penelope, Witten, Karen, \& Kearns, Robin. (2011). Housing Intensification in Auckland, New Zealand: Implications for Children and Families. Housing Studies, 26(3), 353-367.

Chakrabarti, Vishaan. (2013). A Country of Cities: A Manifesto for an Urban America. New York: Metropolis Books.

Conran, Terence. (2012). How to Live in Small Spaces: Design, Furnishing, Decoration, and Detail for the Smaller Home. London: Conran Octopus.

De Smet, Aurelie. (n.d.) Learning From Tactical Approaches to Urban Voids. Retrieved from http://urbanbeelab.okno.be/ lib/exe/fetch.php?media=ua:urban-voids.pdf

Dovey, Kim, \& Polakit, Kasama. (2007). Urban Slippage: Smooth and Striated Streetscapes in Bangkok. In K. A. Franck \& Q. Stevens (Eds.), Loose Space: Possibility and Diversity in Urban Life (pp. 113-131). New York: Routledge.

Duany, Andres, Plater-Zyberk, Elizabeth, \& Speck, Jeff. (2000). Suburban Nation: The Rise of Sprawl and the Decline of the American Dream. New York: North Point Press.

Egenter, Nold. (n.d.). The Japanese House. Retrieved from http://home.worldcom.ch/negenter/410JapHouseTxE1.html 
Extech. (2017). Is Polycarbonate the Future of Architecture? Retrieved from https://extechinc.com/polycarbonate-futurearchitecture/

Ferguson, Gael. (1994). Building the New Zealand Dream. Palmerston North: The Dunmore Press Limited.

Fincher, Ruth. (2004). Gender and Life Course in the Narratives of Melbourne's High-rise Housing Developers. Australian Geographical Studies, 42(3), 325-338.

Fowler, Michael, \& Van de Voort, Robert. (1983). The New Zealand House. Auckland: Lansdowne.

Franck, Karen A., \& Stevens, Quentin (Eds.). (2007). Tying Down Loose Space. In, Loose Space: Possibility and Diversity in Urban Life (pp. 1-33). New York: Routledge.

Frearson, Amy. (2014). Skinny Houses: It's Amazing How Important One Inch of Space Becomes. Retrieved from https:// www.dezeen.com/2014/08/25/skinny-houses-japan-london-los-angeles-feature/

Friedman, Avi. (2010). Narrow Houses: New Directions in Efficient Design. New York: Princeton Architectural Press.

Gifford, Robert. (2007). The Consequences of Living in High-Rise Buildings. Architectural Science Review, 50(1), 2-17.

Grieco, Lauren. (2011). World Architecture Festival 2011 Best Small House by Domenic Alvaro. Retrieved from https:// www.designboom.com/architecture/waf-2011-best-house-small-house-by-domenic-alvaro/

Griffiths, Alyn. (2014). Formwerkz Architects' Terrace House is Covered with Plants Inside and Out. Retrieved from https://www.dezeen.com/2014/08/18/formwerkz-terrace-house-singapore-concrete-plants/

Harrison, Stuart. (2011). Forty-Six Square Metres of Land Doesn't Normally Become A House: Maximising Living Space Australia and New Zealand. Port Melbourne: Thames \& Hudson.

Harrison, Stuart. (2013). New Suburban: Reinventing the Family Home Australia and New Zealand. Port Melbourne: Thames \& Hudson.

Hope, Alice. (1963). Town Houses. London: Batsford.

Howard, Ebenezer. (1965). Garden Cities of Tomorrow. Cambridge: Massachusetts Institute of Technology Press.

Howden-Chapman, Philippa. (2015, November 2). More Favouring Urban Life Over Quarter-acre Dream [Radio Program]. In S. Ferguson (Host), Morning Report. Wellington: Radio New Zealand.

Ipsos MORI. (2012). The Way We Live Now: What People Need and Expect From Their Homes, A Research Report for the Royal Institute of British Architects. Retrieved from https://www.ipsos.com/sites/default/files/publication/1970-01/sri-ribathe-way-we-live-now-may-2012.pdf

Jamieson, Colin. (2015). The Shrinking of New Zealand's Quarter-acre Paradise. Australian Garden History, 27(2), 16-18. 
Jodidio, Philip. (2006). M2 Minimum Spaces Maximum Living. Mulgrave: Images Publishing Group.

Jodidio, Philip. (2014). Small Architecture Now!. Cologne: Taschen.

Jonas, Marieluise, \& Rahmann, Heike. (2014). Tokyo Void: Possibilities in Absence. Berlin: Jovis.

Marcus, Clare C., \& Sarkissian, Wendy. (1986). Housing as if People Mattered. Berkeley: University of California Press.

Mitre 10. (2015). Back Yards Shrinking but Kiwis Still Love the Quarter-acre Paradise, Research Shows. Retrieved from https://www.mitre10.co.nz/news/backyardsshrinking

Moudon, Anne V. (1983). San Francisco: Historical Patterns of an Urban Architecture. Washington: Urban Design Program, University of Washington.

Nordqvist, Susie. (2011). Kiwi Homes Getting Bigger, Latest Research. Retrieved from http://www.nzherald.co.nz/ business/news/article.cfm?c_id=3\&objectid=10725186

Pollock, Naomi. (2015). Jutaku: Japanese Houses. London: Phaidon.

Pryor, Nicole (Reporter). (2015, January 12). Quarter-acre Pavlova Paradise out of Reach [Radio Program]. In A. Perrottet (Host), Summer Report. Wellington: Radio New Zealand.

Quinton, Ted. (2011). Small House. Retrieved from https://architectureau.com/articles/small-house/

QV. (2011). Average House Size by Age. Retrieved from http://qv.co.nz/n/news-details/phoenix-78?blogld=62

Rivlin, Leanne G. (2007). Found Spaces: Freedom of Choice in Public Life. In K. A. Franck \& Q. Stevens (Eds.), Loose Space: Possibility and Diversity in Urban Life (pp. 38-53). New York: Routledge.

Roberts-Hughes, Rebecca. (n.d.). What People Want and Need From Their Homes Must Be Considered in the Design of Modern Housing. Retrieved from http://eprints.lse.ac.uk/48308/1/blogs.lse.ac.uk-What_people_want_and_need_from_ their_homes_must_be_considered_in_the_design_of_modern_housing.pdf

Schleifer, Simone. (2006). Small City Houses (J. Wintle, Trans.). Spain: Evergreen.

Schwartz, Kenneth. (2014, December). Polycarbonates in Construction. The IAPD Magazine. Retrieved from https://www. iapd.org/Documents/designing-with-plastics/PDF/PC_in_Construction.pdf

Whyte, William. (c1980). The Social Life of Small Urban Spaces. Washington: Conservation Foundation.

Whyte, William. (2014). The Social Life of Small Urban Spaces [Video file]. United States: Kanopy Streaming.

Willis, Carol, \& Genevro, Rosalie (Eds.). (1989). Vacant Lots. New York: Princeton Architectural Press. 
Witten, Karen, \& Carroll, Penelope. (2011). Intensification, Housing Affordability and Families: Learning from the Auckland CBD. In K. Witten, W. Abrahamse, \& K. Stuart (Eds.), Growth Misconduct: Avoiding Sprawl and Improving Urban Intensification in New Zealand (pp. 79-89). Wellington: Steele Roberts Aotearoa.

YR Architecture + Design. (2017). Three Effective Design Strategies for Small Modern Homes. Retrieved from http:// www.yr-architecture.com/3-effective-design-strategies-for-small-modern-homes/ 


\section{List of Figures}

\section{CHAPTER ONE}

1.01 Render of living space

Image by author

1.02 Family working and playing in the garden of a suburban home in the $1950 \mathrm{~s}$

Glennie, Alan. (1950). ZLB Awarua Radio Houses. Retrieved from http://www.qsl.net/zl4pz/zlb/Awarua-05.html

1.03 Intended occupants of the housing proposed in the research Image by author

\section{CHAPTER TWO}

2.01 New Zealand Railway poster encouraging living in the suburbs Archives New Zealand. (1932). Railway Poster, 1930s. Retrieved from http://www.TeAra.govt.nz/en/photograph/25058/ railways-poster-1930s

2.02 Plan of a typical mid twentieth century quarter acre section Salinger, JP, Say, JS, \& Marcussen, KH. (1962). Flower Gardening with the Journal of Agriculture. pp. 17.

2.03 Residual spaces around Wellington, New Zealand Image by author

2.04 Inner city living is beginning to become a desirable option for family living Image by author

2.05 Design guidelines based on what people need and expect from their homes Image by author 
2.06 Printed fibreglass exterior of Polygreen

Bellemo \& Cat. (2017). Polygreen House. Retrieved from http://www.bellemocat.com/residential/polygreen-northcote/

2.07 Flexible open plan layout of A's House Project

ArchDaily. (2016). A's House Project/ Global Architects \& Associates. Retrieved from https://www.archdaily.com/789132/ as-house-project-global-architects-and-associates

2.08 Exterior of Small House with rooftop garden

Grieco, Lauren. (2011). World Architecture Festival 2011 Best Small House by Domenic Alvaro. Retrieved from https:// www.designboom.com/architecture/waf-2011-best-house-small-house-by-domenic-alvaro/

2.09 The Cul-de-Sac House interior featuring courtyard atrium

ArchDaily. (2016). The Cul-de-sac House/ Nguyen Khac Phuoc Architects. Retrieved from http://www.archdaily. com/787629/the-cul-de-sac-house-nguyen-khac-phuoc-architects

\section{CHAPTER THREE}

3.01 Exploration of residual urban spaces in Wellington, New Zealand

Image by author

3.02 Selected sites from each of the six site typologies

Image by author

3.03 Location of the six selected sites in Wellington city

Image by author

3.04 Clifton Terrace Carpark site model showing location of site

Image by author

3.05 Photograph of the site

Image by author

3.06 Island site typology

Image by author

3.07 Map of the site and surrounding amenities

Image by author

3.08 Wellington Waterfront site model showing location of site

Image by author

3.09 Photograph of the site

Image by author 
3.10 In-Between site typology

Image by author

3.11 Map of the site and surrounding amenities

Image by author

3.12 Tory Street site model showing location of site

Image by author

3.13 Photograph of the site

Image by author

3.14 Elevated site typology

Image by author

3.15 Map of the site and surrounding amenities

Image by author

3.16 Lukes Lane site model showing location of site

Image by author

3.17 Photograph of the site

Image by author

3.18 Narrow + Bounded site typology

Image by author

3.19 Map of the site and surrounding amenities

Image by author

3.20 Footscray Avenue site model showing location of site

Image by author

3.21 Photograph of the site

Image by author

3.22 Accessway site typology

Image by author

3.23 Map of the site and surrounding amenities

Image by author

3.24 Victoria and Willeston Street site model showing location of site Image by author 
3.25 Photograph of the site

Image by author

3.26 Elevation site typology

Image by author

3.27 Map of the site and surrounding amenities

Image by author

3.28 Survey of the number of residual space sites on three random Wellington city blocks

Image by author

\section{CHAPTER FOUR}

4.01 Architectural form study across the six site typologies

Image by author

4.02 Clifton Terrace Carpark form study

Image by author

4.03 Wellington Waterfront form study

Image by author

4.04 Tory Street form study

Image by author

4.05 Lukes Lane form study

Image by author

4.06 Footscray Avenue form study

Image by author

4.07 Victoria Street form study

Image by author

\section{CHAPTER FIVE}

5.01 Key areas of focus symbols

Image by author 
5.02 Key areas of focus symbols - Spatial Planning

Image by author

5.03 Required programme icons

Image by author

5.04 Vertical hierarchy of space from social to private

Image by author

5.05 Iterative study of spatial planning

Image by author

5.06 Key areas of focus symbols - Flexible Living

Image by author

5.07 Potential space combinations

Image by author

5.08 Flexible space configurations

Image by author

5.09 Key areas of focus symbols - Lighting and Privacy

Image by author

5.10 The effect of window height on privacy

Image by author

5.11 House in Tousuien interior

Yano, Toshiyuki. (2013). House in Tousuien/ Suppose Design Office. Retrieved from https://www.archdaily.com/458511/ house-in-tousuien-suppose-design-office

$\mathbf{5 . 1 2}$ House in Tousuien exterior day

Yano, Toshiyuki. (2013). House in Tousuien/ Suppose Design Office. Retrieved from https://www.archdaily.com/458511/ house-in-tousuien-suppose-design-office

5.13 House in Tousuien exterior night

Yano, Toshiyuki. (2013). House in Tousuien/ Suppose Design Office. Retrieved from https://www.archdaily.com/458511/ house-in-tousuien-suppose-design-office

5.14 Key areas of focus symbols - Outdoor Connection

Image by author

5.15 Suburban garden locations

Image by author 
5.16 Garden locations in an urban setting in the form of courtyards and rooftop terraces Image by author

5.17 Key areas of focus symbols - Methods for Accommodating a Car Image by author

5.18 Creative and innovative solutions for car storage

Image by author

5.19 Iterative study testing how the car storage solutions might fit with the housing models Image by author

\section{CHAPTER SIX}

6.01 Clifton Terrace site plan Image by author

6.02 Clifton Terrace floorplans

Image by author

6.03 Clifton Terrace section

Image by author

6.04 Exterior render

Image by author

6.05 Living space render

Image by author

6.06 Outdoor connection render

Image by author

6.07 Wellington Waterfront site plan

Image by author

6.08 Wellington Waterfront floorplans

Image by author

6.09 Wellington Waterfront section

Image by author

6.10 Exterior render

Image by author 
6.11 Living space render

Image by author

6.12 Outdoor connection render Image by author

6.13 Tory Street site plan

Image by author

6.14 Tory Street floorplans

Image by author

6.15 Tory Street section

Image by author

6.16 Exterior render

Image by author

6.17 Living space render

Image by author

6.18 Outdoor connection render

Image by author

6.19 Lukes Lane site plan

Image by author

6.20 Lukes lane floorplans

Image by author

6.21 Lukes Lane section

Image by author

6.22 Exterior render

Image by author

6.23 Living space render

Image by author

6.24 Outdoor connection render Image by author

6.25 Footscray Avenue site plan Image by author 
6.26 Footscray Avenue floorplans

Image by author

6.27 Footscray Avenue section

Image by author

6.28 Exterior render

Image by author

6.29 Living space render

Image by author

6.30 Outdoor connection render

Image by author

6.31 Victoria and Willeston Street site plan

Image by author

6.32 Victoria and Willeston Street floorplans

Image by author

6.33 Victoria and Willeston Street section

Image by author

6.34 Exterior render

Image by author

6.35 Living space render

Image by author

6.36 Outdoor connection render

Image by author

\section{CHAPTER SEVEN}

7.01 Final design sections demonstrating spatial planning Image by author

7.02 Open plan living spaces demonstrating flexible living Image by author

7.03 Exteriors to demonstrate window placement and use of polycarbonate for lighting and privacy Image by author 
7.04 Outdoor spaces to demonstrate outdoor connection

Image by author

7.05 Inventive parking ideas to demonstrate accommodation for a car Image by author

\section{CHAPTER EIGHT}

8.01 Final models on site

Image by author 
